\title{
A review of the cleptoparasitic bee genus Epeolus Latreille, 1802 (Hymenoptera: Apidae) in the Caribbean, Central America and Mexico
}

\author{
Thomas M. ONUFERKO \\ Department of Biology, York University, 4700 Keele St., Toronto, ON M3J 1P3, Canada \\ and The Beaty Centre for Species Discovery, Canadian Museum of Nature, \\ Ottawa, ON K1P 6P4, Canada. \\ Email: thomas.onuferko@gmail.com
}

urn:1sid:zoobank.org:author:6E4CC25A-AD82-42D3-9846-C659EDEAF541

\begin{abstract}
The cleptoparasitic bee genus Epeolus Latreille, 1802 is for the first time reviewed for species occurring in the Caribbean, Central America and Mexico, and a single dichotomous identification key to the females and males of species present or likely to be present in these regions is presented. A total of 25 species have been confirmed as present across the region, although another 10 likely occur south of the Mexico-United States border. Three species are newly described-E. hanusiae sp. nov., E. nomadiformis sp. nov. and E. odyneroides sp. nov.- and redescriptions are provided for species occurring exclusively south of the United States of America (species occurring north of Mexico were recently revised elsewhere) except $E$. danieli (Genaro, 2014) comb. nov., which was recently described. One subspecies is elevated to species level (E. obscuripes Cockerell, 1917 stat. nov.). The following five names are newly synonymized under those of four valid species: Trophocleptria schraderi Michener, 1954 syn. nov. under E. boliviensis Friese, 1908, Tro. odontothorax Michener, 1954 syn. nov. under E. claripennis Friese, 1908, E. rugosus Cockerell, 1949 syn. nov. and E. xanthurus Cockerell, 1917 syn. nov. under E. luteipennis Friese, 1916, and E. schmidti Friese, 1925 syn. nov. under E. obscuripes. A diagnosis is provided for the presumably monophyletic and almost entirely Neotropical species group originally regarded as a separate genus, Trophocleptria Holmberg, 1886. Differential diagnoses accompany the descriptions/redescriptions of Neotropical species of Epeolus, and known collection records and information about their ecology are presented.
\end{abstract}

Keywords. DNA barcode, Epeolini, integrative biosystematics, Neotropical, Trophocleptria.

Onuferko T.M. 2019. A review of the cleptoparasitic bee genus Epeolus Latreille, 1802 (Hymenoptera: Apidae) in the Caribbean, Central America and Mexico. European Journal of Taxonomy 563: 1-69. https://doi.org/10.5852/ejt.2019.563

\section{Introduction}

Epeolus Latreille, 1802 (Hymenoptera: Apidae) is a genus of brood parasites specialized on polyester (or cellophane) bees of the genus Colletes Latreille, 1802 (Hymenoptera: Colletidae). It is one of eight genera in the tribe Epeolini (subfamily Nomadinae), and among four (the others being Odyneropsis 
Schrottky, 1902, Thalestria Smith, 1854 and Triepeolus Robertson, 1901) known from Central America. All except the monotypic genus Thalestria (reported from Costa Rica by Friese 1916) include species that were originally described from Central America. Epeolus belongs to the subtribe Epeolina, which includes only the one genus (Rightmyer 2004). In the Americas, Epeolus is most diverse in the United States, but 26 species had been reported south of the Mexico-United States border before the present study (Moure et al. 2007; Onuferko 2018a; Ascher \& Pickering 2019). Although not much is known about the species occurring in Mexico, another 12 previously-described Nearctic species can be expected to occur in the country given the close proximity of some collection localities in the U.S. to the Mexico-United States border: E. ainsliei Crawford, 1932, E. asperatus Cockerell, 1910, E. australis Mitchell, 1962, E. axillaris Onuferko, 2018, E. barberiellus Cockerell, 1907, E. bifasciatus Cresson, 1864 (Mexican records on Discover Life (Ascher \& Pickering 2019) may pertain to a different species that before the present study had not been clearly delineated from E. bifasciatus and was originally considered a subspecies of E. bifasciatus), E. brumleyi Onuferko, 2018, E. canadensis Mitchell, 1962, E. diadematus Onuferko, 2018, E. novomexicanus Cockerell, 1912, E. rufulus Cockerell, 1941 and E. scutellaris Say, 1824 (Onuferko 2018a).

Epeolus was recently revised for species occurring in Canada (Onuferko 2017) and all of North America north of Mexico (Onuferko 2018a). These works include descriptions and the most recent redescriptions of all species known to occur in Canada and the United States, including those whose ranges extend into Mexico and Central America. In the most recent revision, five new species were identified whose ranges are known to extend into Mexico: E. basili Onuferko, 2018, E. chamaesarachae Onuferko, 2018, E. ferrarii Onuferko, 2018, E. splendidus Onuferko, 2018 and E. tessieris Onuferko, 2018. In the Neotropical Region, the number of species known exclusively from south of the United States was 15 before the present study. Most of these belong to a species group that was originally regarded as a separate genus, Trophocleptria Holmberg, 1886. Michener (2000) regarded Trophocleptria as a subgenus of Epeolus, and later (2007) as a monophyletic species group without an official taxonomic rank following Rightmyer (2004), who synonymized Trophocleptria under Epeolus based on a morphological phylogeny published therein, which did not recover the only other named subgroup - subgenus Epeolus (Epeolus) - as monophyletic. Michener (2007) therefore suggested that the term 'Trophocleptria group' be used while the taxon's position relative to the rest of Epeolus remains unclear. Most members of this species group occur in Central America; only Epeolus asperrimus (Moure, 1954), E. carioca (Moure, 1954) and E. variolosus (Holmberg, 1886) are known to be exclusively South American (based on Moure et al. 2007 combined with information presented below). The members of the 'Trophocleptria group' are poorly resolved and in need of revision.

The main objectives of the present study are threefold: 1) to clarify the taxonomy of Epeolus present in the Caribbean, Central America and Mexico, 2) to provide a key for identifying the species that occur or are expected to occur in the region and 3) to present a comprehensive diagnosis for the 'Trophocleptria group' and an updated list of its constituent species. The diagnosis for the genus presented in Onuferko (2018a: 10) works for the present study region and is not repeated here. Rightmyer (2004: 16) provides a diagnosis to separate Epeolina (and thus Epeolus) from other Epeolini. Not much is known about the ecology of the species occurring south of the United States, and herein information about bee and floral hosts are included wherever possible. Common names are also proposed for all species not treated in Onuferko $(2017,2018 \mathrm{a})$.

\section{Material and methods}

For this study, an integrative biosystematics approach was used, as in Gibbs $(2009,2010,2011)$, Pauly et al. (2014), Rocha-Filho \& Packer (2015), Ferrari (2017) and Onuferko (2017, 2018a). Species were delineated on the basis of a discrete morphological feature or set of features, consistently following the typological (or morphological) species concept (see Simpson 1951). To help discriminate cryptic 
taxa, DNA barcodes were obtained from as many vouchers of Epeolus occurring south of the United States as possible. Barcoding involved the removal of genetic material (in one or two legs) from the specimen of interest for DNA extraction, amplification of a $658 \mathrm{bp}$ segment of the mitochondrial cytochrome c oxidase subunit I (COI) gene (Hebert et al. 2003a, b) by PCR and sequencing at the Canadian Centre for DNA Barcoding in Guelph, Ontario, Canada. To validate species designations and to check for contamination errors, a neighbor-joining tree was generated based on Kimura's two parameter distance model for visualization of genetic distances (Kimura 1980). In an automated procedure, high-quality sequences exhibiting considerable divergence from any other were assigned separate barcode index numbers (BINs), which represent operational taxonomic units that closely correspond with actual species (Ratnasingham \& Hebert 2007, 2013). Sequenced specimens were then compared to one another and to non-sequenced (type and non-type) specimens for identification and to help determine the diagnostic morphological feature(s) of a species. Barcode sequences, both partial and BIN-compliant, are published in the 'Neotropical Epeolus' project on the Barcode of Life Data Systems website (http://www.barcodinglife.org/) and are also available through GenBank (https://www.ncbi.nlm.nih.gov/genbank/) (accession numbers are indicated in the 'Material examined' section following the description/redescription of each species and Supplementary File 1).

Terminology follows Onuferko (2017, 2018a), which with the following exceptions follows Michener (2007): the terms frontal area and vertexal area are used instead of frons and vertex, respectively, as on the surface these are not clearly demarcated anatomical features. Terms specific to this study and the focal taxon (Epeolus) (in bold), though adapted in part from Rightmyer (2008) and explained in Onuferko (2017, 2018a), are defined herein for clarity. Length and width specifically refer to measurements made along a bee's longitudinal and lateral axes, respectively. However, the longitudinal extent of a transverse metasomal fascia is described in terms of breadth. In Epeolus, the frontal line is raised and forms a keel that extends into the supraclypeal area. This frontal keel varies in the degree to which it is pronounced among species of Epeolus but is always convex. Although lacking in nearly all species in the 'Trophocleptria group', in most Epeolus spp. the mesoscutum (anteriorly) has a pair of longitudinal lines of pale tomentum, called paramedian bands. Bigibbous is an adjective meaning 'with biconvexities' and describes the medially depressed mesoscutellum in Epeolus. In many species of Epeolus, T1 has basal and apical fasciae that are connected on each side by a longitudinal band of varying width. The enclosed region, which is usually covered in dark brown or black tomentum, is referred to as the discal patch.

\section{Acronyms for terms used herein, which also follow Onuferko $(2017,2018 a)$}

$\begin{array}{ll}\mathrm{AL} & =\text { length of lateral margin of axilla } \\ \mathrm{d} & =\text { diameters of punctures } \\ \mathrm{F} & =\text { flagellomere } \\ \mathrm{i} & =\text { interspaces between punctures } \\ \mathrm{MOD} & =\text { median ocellar diameter } \\ \mathrm{MSCW} & =\text { mesoscutellar width } \\ \mathrm{S} & =\text { sternum } \\ \mathrm{T} & =\text { tergum }\end{array}$

Measurements were taken with the aid of an eyepiece graticule, and anatomical features were measured at their longest and/or widest extents. Scape length does not include the radicle.

Male genitalia were excised and cleared in aqueous $\mathrm{KOH}$ (complete details about the protocol used are given in Onuferko 2018b). Contrary to the standard procedure of fixing insect terminalia in glycerin, each genital capsule was dried and glued to a small card prior to imaging. This ensured that the lateral lobes of the penis were visible for the species that have them; they are difficult to see when immersed 
in glycerin. The male hidden sterna (S7 and S8) were also examined, but not imaged, as they are largely invariant among species of Epeolus (see Onuferko 2017: 54-55, pl. 2 for illustrated examples).

The descriptions provided for each of the treated species follow the format of Onuferko $(2017,2018 \mathrm{a})$. The primary (i.e., name-bearing) types of most Epeolus spp. represented in the region were examined and provided the basis for the species descriptions. Among those that are relevant to the present study, primary types of the following species were unavailable for personal examination with a microscope: E. fumipennis Say, 1837, for which the type most likely has been lost, E. pulchellus Cresson, 1865 and Triepeolus danieli Genaro, 2014. In the case of Tri. danieli, which is known from just two specimens, no representatives were available for detailed study under the microscope. Although I personally was unable to examine the physical holotype specimens of E. pulchellus and Tri. danieli, detailed images of both were made available for study by the institutions where the specimens are housed. Except in the cases of E. fumipennis and E. pulchellus, exact measurements (in $\mathrm{mm}$ ) given in each description are of the primary type. For the two exceptions, the observed size range within each species is given instead. To avoid unnecessary duplication of text, the description of the sex opposite that of the primary type lists only sex-specific differences, except for the usual secondary sexual characters (e.g., number of antennal flagellomeres (10 in females; 11 in males), number of exposed metasomal sterna (five in females because S6 is usually retracted; six in males), number of exposed metasomal terga (six in females; seven in males), and presence/absence of a pseudopygidial area (present on T5 of the female; absent altogether in the male)).

Diagnoses, which include key morphological features that can be used to identify the species in question, are provided, but for species in the 'Trophocleptria group' features specific to the unranked taxon are not included. Instead, a diagnosis for the 'Trophocleptria group' is provided separately, which should be consulted before referring to the diagnoses provided for each of the individual species.

In addition to the diagnoses, a dichotomous identification key was written to differentiate the species treated herein from one another and other species that are known or expected to occur in the region. Epeolus exhibits very little sexual dimorphism, so separate keys for females and males are not provided. Instead, features exhibited by only one sex are explicitly stated as pertaining to either the female or male, and such couplets include at least one other feature to ensure that both sexes can be accurately identified. Since all of the species treated herein occur in countries where Spanish is the (or an) official language, two versions of the same key are presented: one in English and one is Spanish. The Spanish version is presented in Supplementary File 2. The best practices for constructing dichotomous keys according to Walter \& Winterton (2007; see also Packer et al. 2016) were generally followed with the aim of making the key as evenly bifurcated as possible, thereby minimizing the total number of steps required to identify specimens of any species; listing more important and easily diagnosable features first in the couplets and features that are less reliable and/or difficult to assess after; citing an image for every described feature; and including multiple features within a couplet wherever possible in case one should be obscured in the specimen being identified. It should be noted that avoiding monothetic couplets was not always possible. Fortunately, in most such cases features were limited to the mesosoma, the tagma that should be present even in pinned specimens that are badly damaged. All of the referenced features should be visible under a standard dissecting microscope, which should have an eyepiece graticule for precise measurements. The Visionary Digital macro-imaging BK PLUS Lab System was used to take pictures (with a Canon EOS 40D SLR digital camera), which were focus stacked in Helicon Focus and later edited in Adobe Photoshop and PaintShop Pro.

As in Onuferko (2018a), common names are proposed for new and previously-described species. These are generally based on the specific epithet, which in most cases was easy to translate into English and Spanish. 
For species occurring exclusively south of the United States, specimens from 17 entomological institutions were studied. For species occurring on both sides of the border, additional material was obtained from the institutions listed in Onuferko (2018a).

\section{Acronyms for institutions housing studied specimens, with names of contacts (curators and/or collections managers) given in parentheses}

\begin{tabular}{|c|c|c|}
\hline $\mathrm{MNH}$ & & $\begin{array}{l}\text { American Museum of Natural History, New York, NY, USA (J.G. Rozen, Jr. and } \\
\text { C. Smith) }\end{array}$ \\
\hline ANSP & $=$ & $\begin{array}{l}\text { Academy of Natural Sciences of Drexel University, Philadelphia, PA, USA } \\
\text { (J.D. Weintraub) }\end{array}$ \\
\hline BBSL & $=$ & $\begin{array}{l}\text { tah State University, USDA Bee Biology and Systematics Laboratory, Logan, UT, } \\
\text { SA (T.L. Griswold) }\end{array}$ \\
\hline $\mathrm{CNC}$ & & $\begin{array}{l}\text { anadian National Collection of Insects, Arachnids and Nematodes, Ottawa, ON, } \\
\text { anada (S. Cardinal) }\end{array}$ \\
\hline ECOSUR & & $\begin{array}{l}\text { El Colegio de la Frontera Sur, Tapachula, Mexico (all examined material will be } \\
\text { returned to R. Ayala Barajas, Estación de Biología Chamela, Universidad Nacional } \\
\text { Autónoma de México from L. Packer, York University) }\end{array}$ \\
\hline EMEC & $=$ & $\begin{array}{l}\text { University of California, Essig Museum of Entomology, Berkeley, CA, USA } \\
\text { (P. Oboyski) }\end{array}$ \\
\hline $\mathrm{SCA}$ & & Collection of Arthropods, Gainesville, FL, USA (C. Whitehill) \\
\hline & & uba \\
\hline KUNHM & & $\begin{array}{l}\text { Institute and Natural History Museum, Lawrence, } \\
\text { has) }\end{array}$ \\
\hline LACM & $=$ & $\begin{array}{l}\text { tory Museum of Los Angeles County, Los Angeles, CA, USA (B.V. Brown } \\
\text { g) }\end{array}$ \\
\hline MNHNSD & $=$ & $\begin{array}{l}\text { Museo Nacional de Historia Natural "Prof. Eugenio de Jesús Marcano", Santo } \\
\text { Domingo, Dominican Republic (C. Suriel) }\end{array}$ \\
\hline & $=$ & Kingdom (D. Notton) \\
\hline & & \\
\hline & & and M. Buck) \\
\hline UCBME & $=$ & $\begin{array}{l}\text { University of California, Bohart Museum of Entomology, Davis, CA, USA (S. Heydon } \\
\text { and T.J. Zavortink) }\end{array}$ \\
\hline USNM & $=$ & $\begin{array}{l}\text { U.S. National Entomological Collection, National Museum of Natural History, } \\
\text { Washington, DC, USA (S.G. Brady and B. Harris) }\end{array}$ \\
\hline & & Museum für Naturkunde, Berlin, Germany (M. Ohl and V. Richter) \\
\hline
\end{tabular}

For species occurring in the United States, a comprehensive list of examined material is presented in Onuferko (2018a: supplementary material 1, https://doi.org/10.3897/zookeys.755.23939.suppl1). Records of all examined material collected in the Caribbean, Central America, Mexico and South America are presented in Supplementary File 1 of the present study. For species described or redescribed herein, all of the studied material is indicated in the taxonomic treatment section of each species. In lists of studied specimens, bullets separate individual records, any uncertainty surrounding the collection locality or date is indicated with a question mark and GPS coordinates are indicated if on specimen labels. Available institutional identifier numbers are also given for vouchered material.

Species distribution maps were generated in RStudio (ver. 1.1.463) using the packages maptools (Bivand \& Lewin-Koh 2018), to read in shape files of Mexican and U.S. geographic/political boundaries obtained from DIVA-GIS (http://www.diva-gis.org/gdata) and the US Census Bureau (2018), and maps (Becker \& Wilks 2018), for all other national and subnational entities, installed in R (ver. 3.5.2) (R Core Team 2018). Georeferenced occurrence records were taken directly from the labels of examined 
specimens or were estimated from the named locality if GPS coordinates were not indicated on the specimen label (see Supplementary File 1 for the complete list of studied material and specimen details).

\title{
Results
}

\author{
Class Hexapoda Blainville, 1816 \\ Order Hymenoptera Linnaeus, 1758 \\ Superfamily Apoidea Latreille, 1802 \\ Family Apidae Latreille, 1802 \\ Subfamily Nomadinae Latreille, 1802 \\ Tribe Epeolini Robertson, 1903
}

Genus Epeolus Latreille, 1802

\section{Diagnosis for the 'Trophocleptria group' within Epeolus}

Members of the presumably monophyletic 'Trophocleptria group' within Epeolus share the following diagnostic features: 1) the penis lacks the pair of divergent, fleshy lateral lobes present in at least all other New World male Epeolus (Fig. 1) (such lobes are also absent in all other Epeolini genera); 2) in both sexes, the pronotal collar is relatively straight (as opposed to convex) along its anterior margin, and is in most species distinctly elongate (medial length $\sim 1$ MOD) (Fig. 2); 3) the mesoscutellum (except in E. pulchellus) is depressed along its posterior margin beneath a distinct overhanging ridge, which in several species is produced to two posteriorly directed teeth (Fig. 3); and 4) there is a pair of sparsely punctate to impunctate protrusions on the frontal area, each of which is located near the upper mesal margin of the compound eye (Fig. 4A), although these are greatly reduced/inconspicuous in several species (Fig. 4B) (such protrusions are absent in other Epeolus). Furthermore, each mesopleuron (except in E. fumipennis) has a carina delineating its anterior and lateral surfaces, whereas in other New World Epeolus spp. the anterior and lateral surfaces of each mesopleuron are not clearly differentiated from one another (Fig. 5).

Epeolus boliviensis Friese, 1908

Figs 1A, 2A, 6, 7A

Epeolus boliviensis Friese, 1908: 88 (さ).

Trophocleptria schraderi Michener, 1954: 127 (), syn. nov.

\section{Proposed common name}

Bolivian epeolus.

\section{Diagnosis}

Together with the morphological features that are diagnostic for the 'Trophocleptria group', the following in combination can be used to tell E. boliviensis apart from all other Epeolus: the axillae are crenulate along the lateral margin, each with a large tooth near the base (Fig. 6D); the mesoscutellum has a pair of posteriorly directed teeth (Fig. 6D); the fore wings are deeply infuscate apically (Fig. 6AB); T1 has only a bright to pale yellow subapical fascia, which is usually narrower than the T2 apical fascia (Fig. 6B); and the remaining terga lack fasciae, although the apical impressed areas occasionally have sparse, off-white hairs (Fig. 6A-C). In overall appearance, this species is more nomadiform than epeoliform (sensu Michener 2007). Epeolus boliviensis most closely resembles E. fulvopilosus Cameron, 1902 and E. nomadiformis sp. nov., but in E. fulvopilosus T3 and T4 are distinctly fasciate and in both E. fulvopilosus and E. nomadiformis sp. nov. T1 has a broad, medially narrowed or interrupted bright to pale yellow basal fascia, which in E. boliviensis is lacking entirely. 


\section{Material examined}

\section{Primary type material}

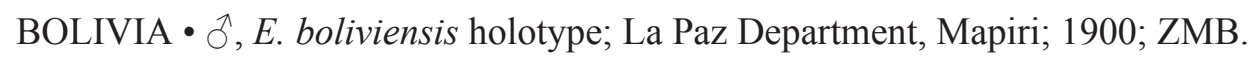

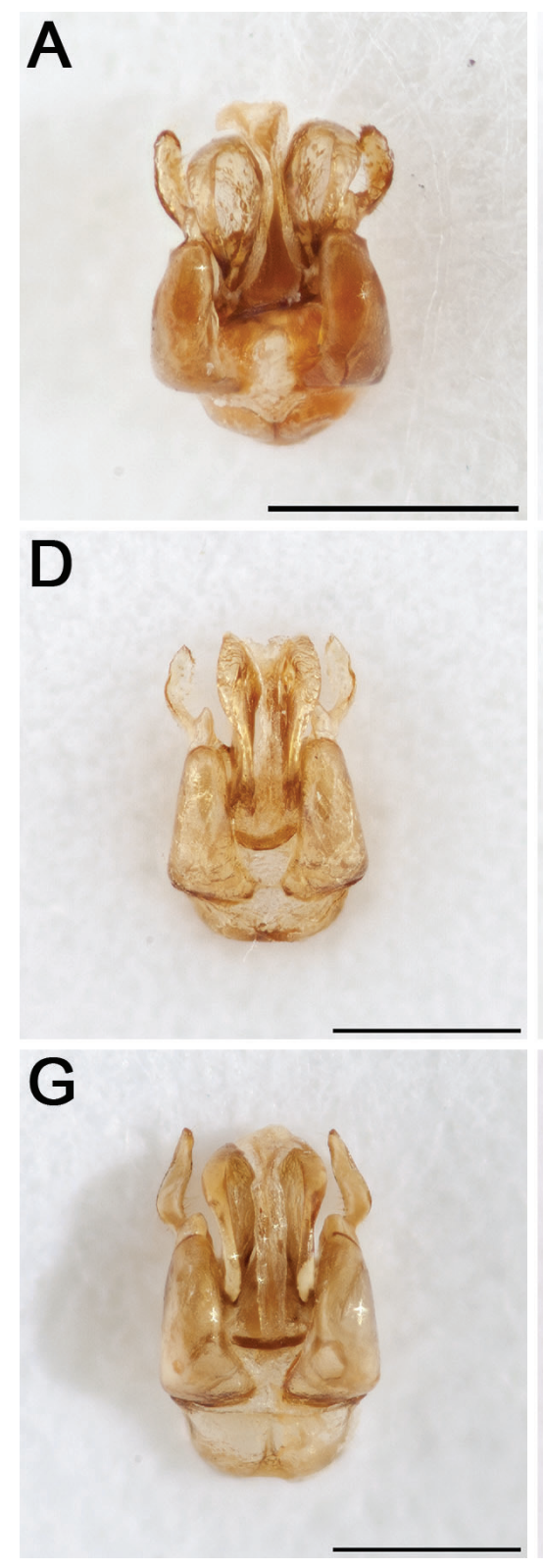

\section{B}

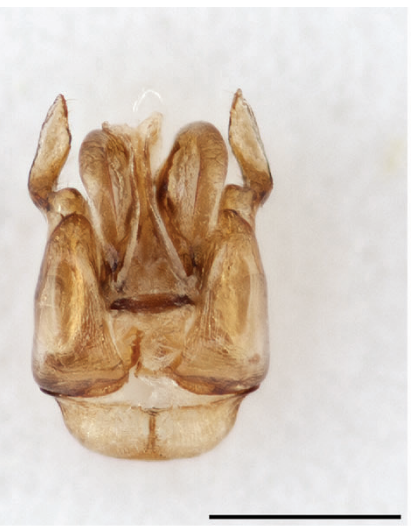

E

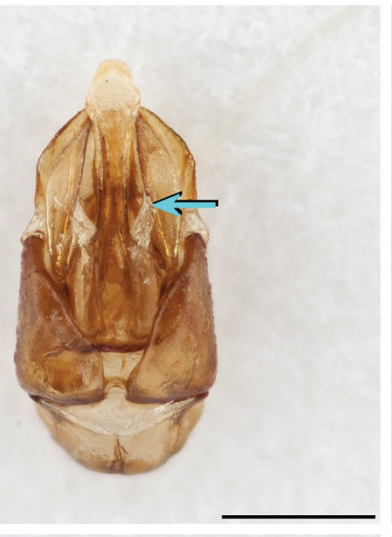

$\mathrm{H}$

Fig. 1. Male genitalia of Epeolus spp. A. E. boliviensis Friese, 1908, in which the penis lacks lobes. B. E. claripennis Friese, 1908, in which the penis lacks lobes. C. E. fulvopilosus Cameron, 1902, in which the penis lacks lobes. D. E. fumipennis Say, 1837, in which the penis lacks lobes. E. E. hanusiae sp. nov., paratype (CNC 754086), showing the penis with a short, fleshy lateral lobe (blue arrow) on each side. F. E. luteipennis Friese, 1916, showing the penis with a long, fleshy lateral lobe (blue arrow) on each side. G. E. niger (Michener, 1954), in which the penis lacks lobes. H. E. obscuripes Cockerell, 1917 stat. nov., in which the penis lacks lobes. I. E. pulchellus Cresson, 1865, in which the penis lacks lobes. Scale bars $=0.5 \mathrm{~mm}$. 
COSTA RICA • , Tro. schraderi holotype; Limón?, Los Diamantes; 26 May 1948; F. Schrader leg.; KUNHM SEMC1461052.

\section{DNA barcoded material with BIN-compliant sequences}

Unavailable.

\section{Non-barcoded material}

ARGENTINA • 1 ð’; Tucumán Province, 12 km N of El Cadillal; 21 Nov. 1989; J.G. Rozen and A. Roig leg.; AMNH AMNH_IZC 00290827.

BOLIVIA • 1 đ̊; Chuquisaca Department, E of Muyupampa; 20 Dec. 1984; L.E. Peña leg.; AMNH AMNH_IZC 00290828 .

BRAZIL • 1 q; Rio de Janeiro, Rio de Janeiro (formerly State of Guanabara), Represa Rio Grande; Jan. 1972; M. Alvarenga leg.; AMNH AMNH_IZC 00290831.

COSTA RICA • 1 q; Alajuela, Peñas Blancas; 7 Jul. 1981; E. Cruz leg.; RAM • 1 q; Cartago, Turrialba (grounds of the Inter-American Institute for Cooperation on Agriculture); 3-5 Jun. 1976; M. Wasbauer leg.; EMEC 1135891 • 1 \%; Heredia, La Selva (4 km SE of Puerto Viejo); 8 May 1980; R. Coville leg.; EMEC 1135892.

ECUADOR • 1 q; El Oro, 10 km NE of Piñas; 7 Jul. 1989; L. Stange and R. Miller leg.; FSCA.

PANAMA • 1 đ̊; Darién, Cana Field Station; $7.7550^{\circ}$ N, $77.6850^{\circ}$ W; 3 Jun. 1996; J. Ashe and R. Brooks leg.; KUNHM SM0039429.

TRINIDAD AND TOBAGO - 1 q; Tunapuna-Piarco, Simla Research Station (8 km N of Arima); 24 Jun.-8. Jul. 1993; S. and J. Peck leg.; CNC 754052.

VENEZUELA • 1 q; Aragua, Cuyagua; 14 May ??94; AMNH AMNH_IZC $00290829 \bullet 1$ ơ; Aragua, El Limon; 26 Mar. 1987; R. Miller and L. Stange leg.; FSCA • 1 q; Aragua, Estación Biológica de Rancho Grande (Portachuelo Pass); 10.3500 ${ }^{\circ}$ N, 67.6833 ${ }^{\circ}$ W; 4 Jun. 1998; J. Ashe, R. Brooks and R. Hanley leg.; BOLD sample ID: CCDB-28315 D02; KUNHM SM0124173 • 1 क; same collection
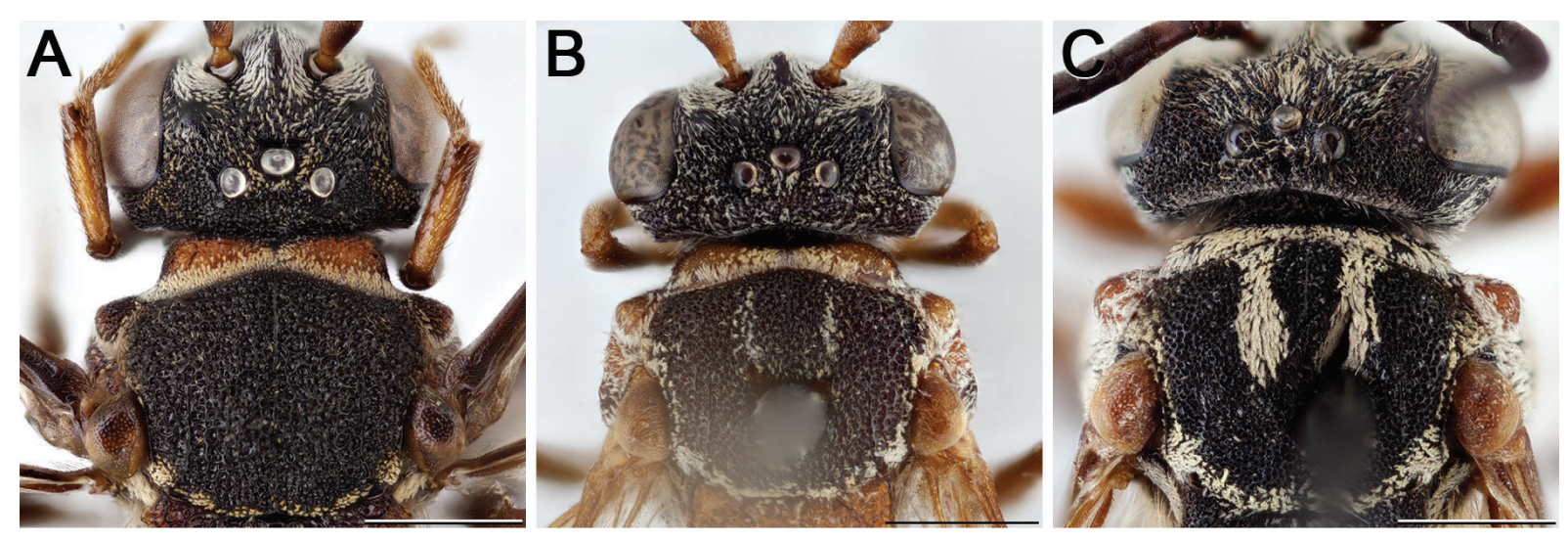

Fig. 2. Pronotal collar of female, dorsal view. A. E. boliviensis Friese, 1908, which is straight along its anterior margin. B. E. fumipennis Say, 1837, which is relatively straight along its anterior margin. C. E. hanusiae sp. nov., paratype (UCBME), which is convex along its anterior margin. Scale bars = $1 \mathrm{~mm}$. 

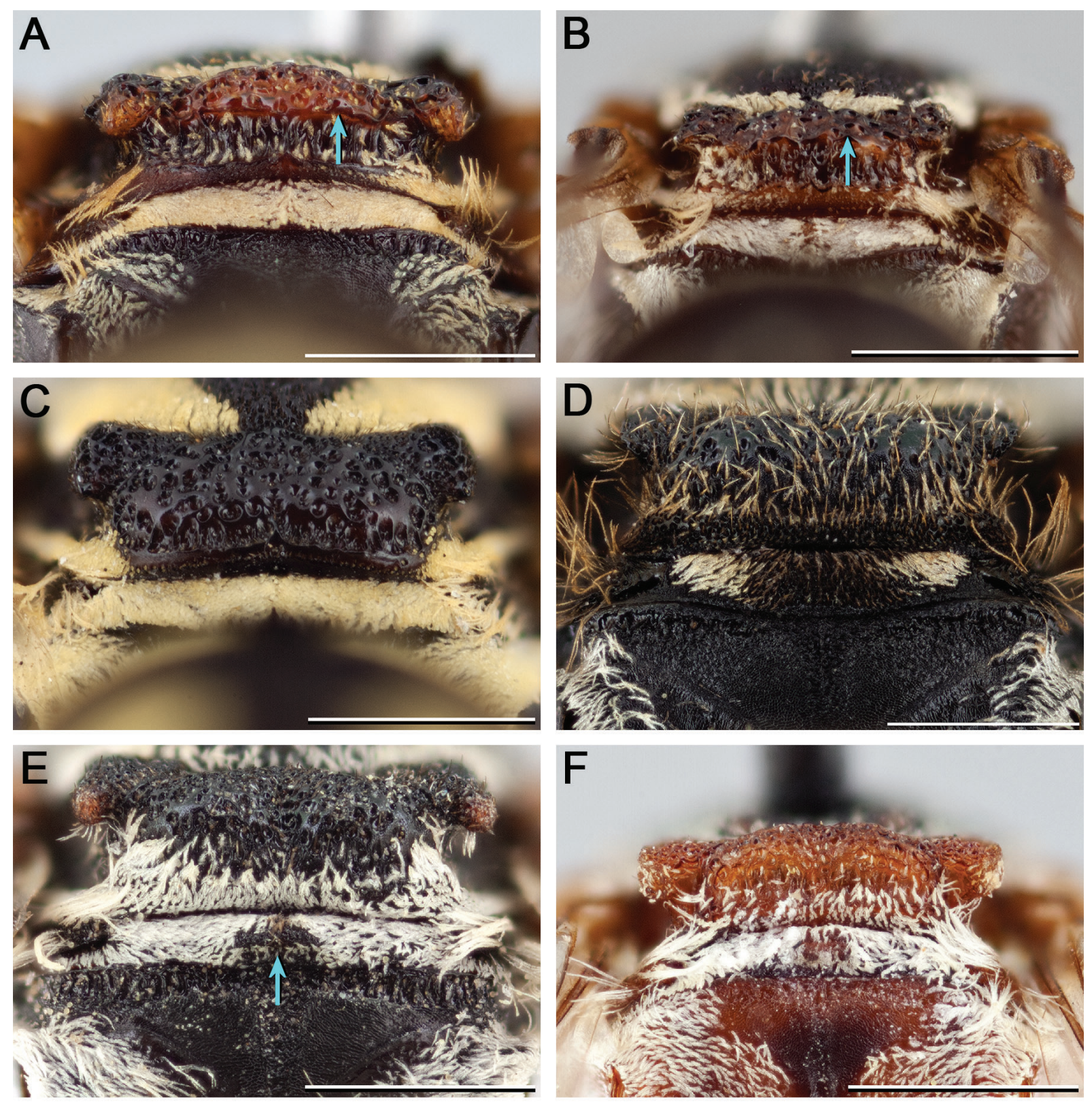

Fig. 3. Mesosoma of female, posterior view. A. E. fulvopilosus Cameron, 1902, showing mesoscutellum with a distinct ridge (blue arrow) overhanging its depressed posterior margin. B. E. fumipennis Say, 1837, showing mesoscutellum with a faint ridge (blue arrow) overhanging its depressed posterior margin. C. E. pulchellus Cresson, 1865, showing mesoscutellum without a distinct ridge delineating its dorsal and posterior portions. D. E. odyneroides sp. nov., paratype (KUNHM SEMC1248301), showing mesoscutellum without a distinct ridge delineating its dorsal and posterior portions. E. E. axillaris Onuferko, 2018, paratype, showing metanotum with a distinct posteromedial depression (blue arrow). F. E. rufulus Cockerell, 1941, holotype, showing flat metanotum. Scale bars $=1 \mathrm{~mm}$. 


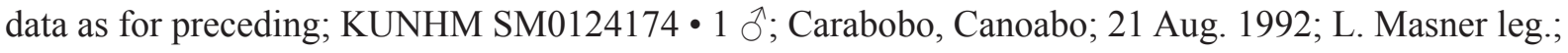
CNC 754053 - 2 qo+; Táchira, Pregonero (Campamento Siberia hospital); 10-31 Jul. 1989; S. and J. Peck leg.; CNC 754054, 754055.

\section{Redescription}

\section{Male}

MeAsurements. Length $6.2 \mathrm{~mm}$; head length $1.6 \mathrm{~mm}$; head width $1.9 \mathrm{~mm}$; fore wing length $5.5 \mathrm{~mm}$.

INTEGUMENT COLORATION. Black in part, at least partially ferruginous on mandible, labrum, clypeus, supraclypeal area, frontal area, antenna, pronotal collar, pronotal lobe, tegula, axilla, mesoscutum, mesoscutellum, metanotum, mesopleuron, metapleuron, propodeum, legs, T1, pygidial plate and metasomal sterna. Mandible with apex darker than rest of mandible; preapical tooth lighter than mandibular apex (difficult to see in holotype because mandibles closed; described from non-type specimens). Antenna brown except scape, pedicel and F1 extensively orange. F2 with orange spot basally. Pronotal collar, pronotal lobe and tegula pale ferruginous to amber. Wing membrane dusky subhyaline, slightly darker at apex. Legs more extensively reddish orange than brown or black.
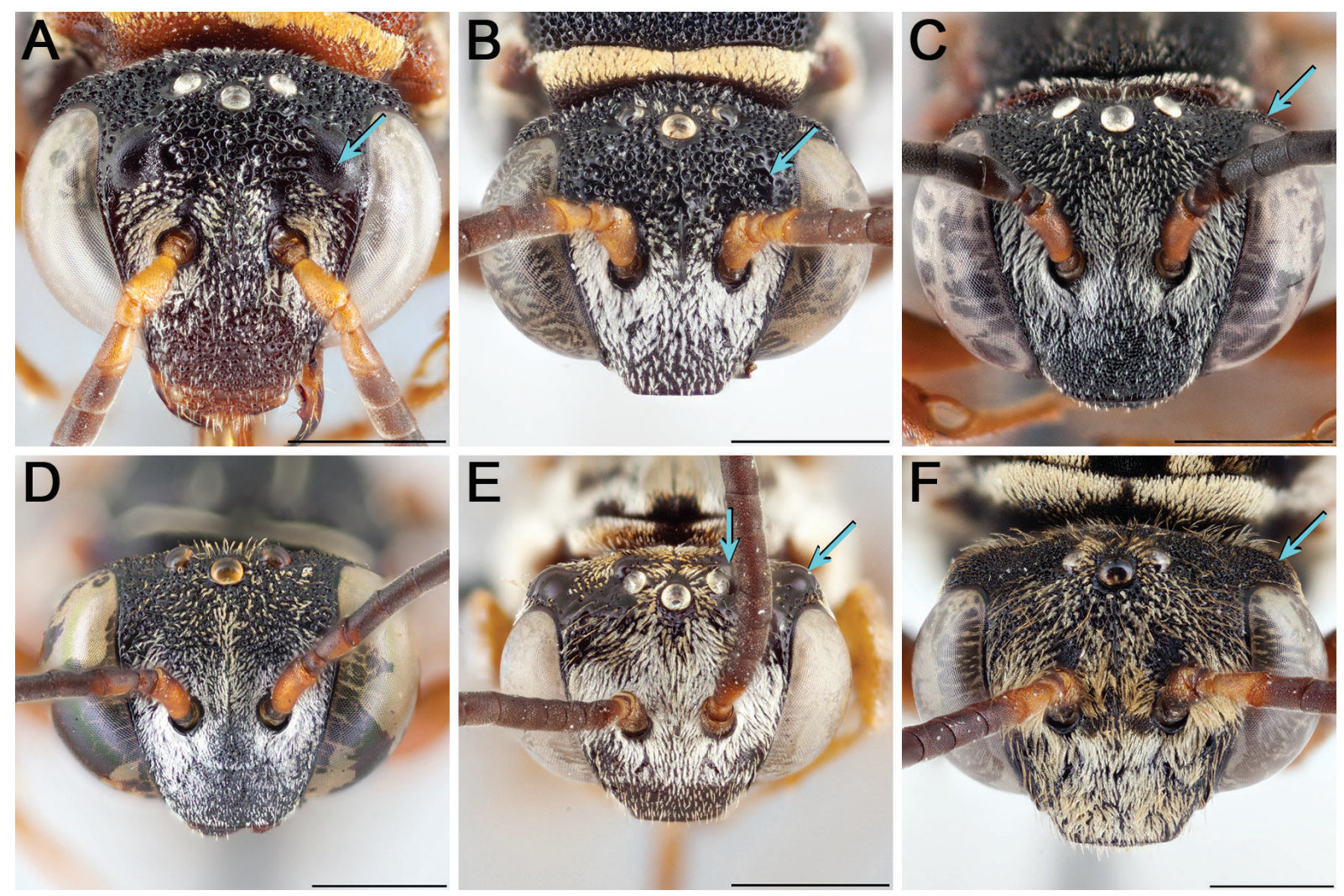

Fig. 4. Head of female. A. E. bifasciatus Cresson, 1864 showing frontal area with impunctate, granulose protrusion (blue arrow) on each side. B. E. obscuripes Cockerell, 1917 stat. nov. showing frontal area with very weak/inconspicuous protrusion (blue arrow) on each side. C. E. scutellaris Say, 1824 showing dorsal protrusion (blue arrow) on each side where upper genal area meets vertexal area. D. E. pusillus Cresson, 1864 showing frontal and vertexal areas without protrusions. E. E. chamaesarachae Onuferko, 2018, paratype, showing vertexal area with two shiny, impunctate protrusions (blue arrows) on each side. F. E. flavofasciatus Smith, 1879 showing single (closely punctate) dorsal protrusion (blue arrow) on each side where upper genal area meets vertexal area. Scale bars $=1 \mathrm{~mm}$. 
Pubescence. Face with tomentum densest around antennal socket. Tomentum slightly sparser on clypeus; upper paraocular and frontal areas and vertexal area mostly exposed. Pronotal collar mostly bare in holotype, but with narrow band of pale yellow short, appressed setae along posterior margin in nontype specimens. Mesoscutum without pale tomentum. Mesopleuron nearly bare, except along margins. Metanotum with tomentum uninterrupted, uniformly off-white. T1 with narrow, pale yellow subapical fascia. T2 with broader, complete pale yellow apical fascia without anterolateral extensions. Metasoma otherwise without fasciae, although T3-T6 basally with inconspicuous bands of sparse pale gray-brown
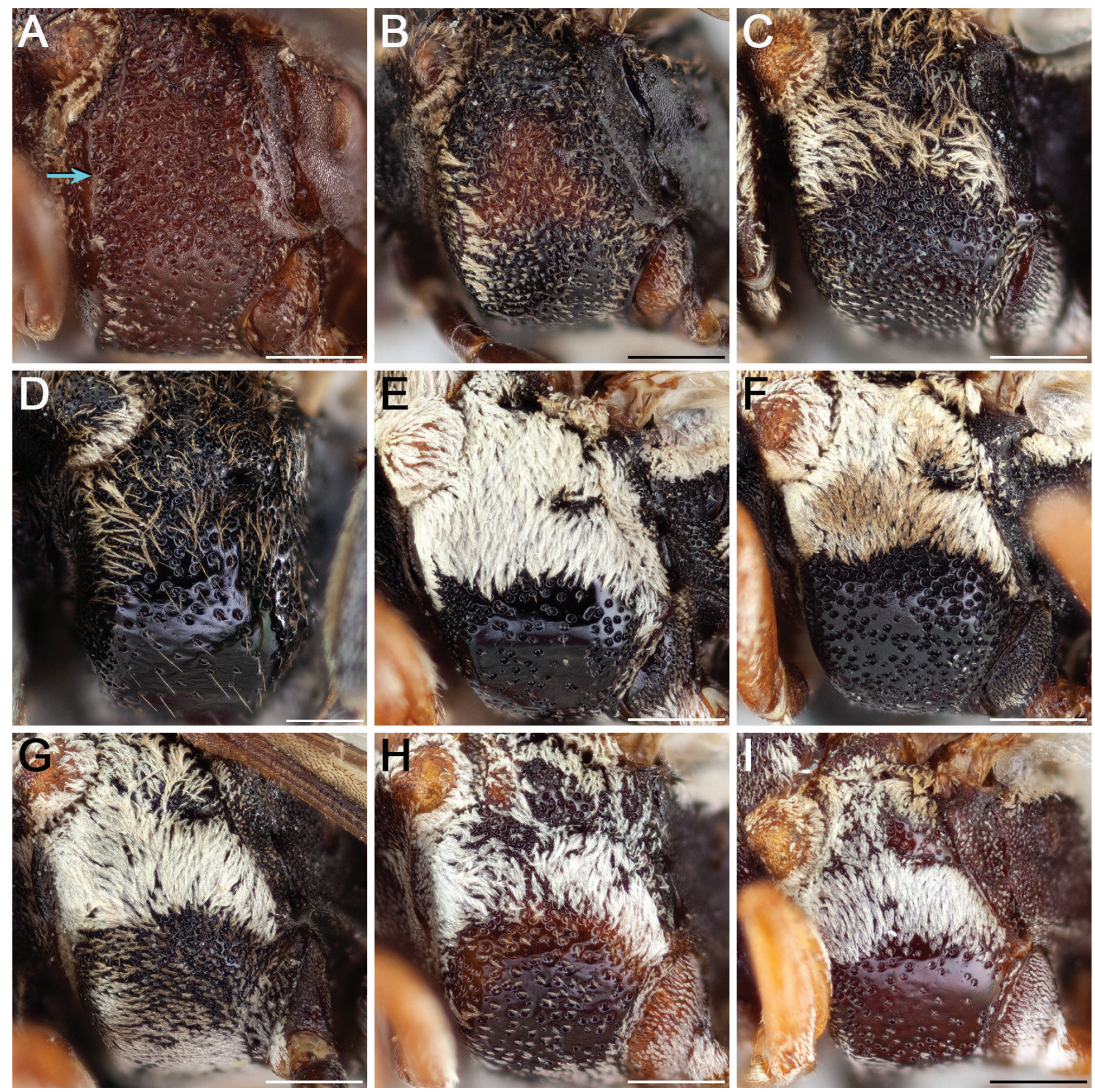

Fig. 5. Mesopleuron of female, lateral view. A. E. claripennis Friese, 1908, holotype (ZMB), blue arrow indicates carina delineating the anterior and lateral surfaces of the mesopleuron. B. E. niger (Michener, 1954). C. E. luteipennis Friese, 1916. D. E. odyneroides sp. nov., paratype (KUNHM SEMC1248301). E. E. chamaesarachae Onuferko, 2018, paratype. F. E. diadematus Onuferko, 2018, paratype. G. E. hanusiae sp. nov., paratype (UCBME). H. E. interruptus Robertson, 1900. I. E. tessieris Onuferko, 2018, paratype. Scale bars $=0.5 \mathrm{~mm}$. 
hairs. S4 and S5 with long (>1 MOD), curved coppery to silvery subapical hairs, which are often darker apically.

SURFACE SCULPTURE. Punctures dense, but those of head and mesosoma sparser in some areas, larger, deeper and more distinct. Labrum and clypeus with punctures equally dense (most $i \leq 1 d)$. Small impunctate shiny spot lateral to lateral ocellus. Mesoscutum, mesoscutellum and axilla very coarsely and densely rugose-punctate. Tegula densely punctate mesally $(\mathrm{i}=1-2 \mathrm{~d})$, sparsely punctate $(\mathrm{i}>2 \mathrm{~d})$ to impunctate along margins. Mesopleuron with larger and denser $(i \leq 1 \mathrm{~d})$ punctures in upper half than ventrolateral half $(\mathrm{i} \leq 2 \mathrm{~d}$ ), interspaces shining (somewhat dull due to tessellate surface microsculpture in multiple non-type specimens). Metasomal terga with punctures very fine, dense ( $\mathrm{i} \approx 1 \mathrm{~d}$ ), evenly distributed on disc. Pygidial plate with large deep punctures more or less evenly spaced throughout, with interspaces shining.

Structure. Preapical tooth acute. Labral apex with pair of small denticles (separated by shallow concavity), each preceded by longitudinal carina. Frontal keel strongly raised. Frontal area with pair of discrete sparsely punctate protrusions, interspaces shining; each located near upper mesal margin of compound eye. Head dorsally with pair of protrusions, each located where upper genal area meets vertexal area. Vertexal area strongly convex in frontal view. Scape with greatest length $1.5 \times$ greatest width. F2 noticeably longer than wide $(\mathrm{L} / \mathrm{W}$ ratio $=1.2)$. Preoccipital ridge separated from hypostomal carina by about 1.5-2 MOD. Pronotal collar elongate (medial length $\sim 1$ MOD), expanded laterally to about $2 \times$ medial length in dorsal view and somewhat concave along anterior margin. Mesoscutellum weakly bigibbous, depressed along posterior margin beneath distinct overhanging ridge produced to pair
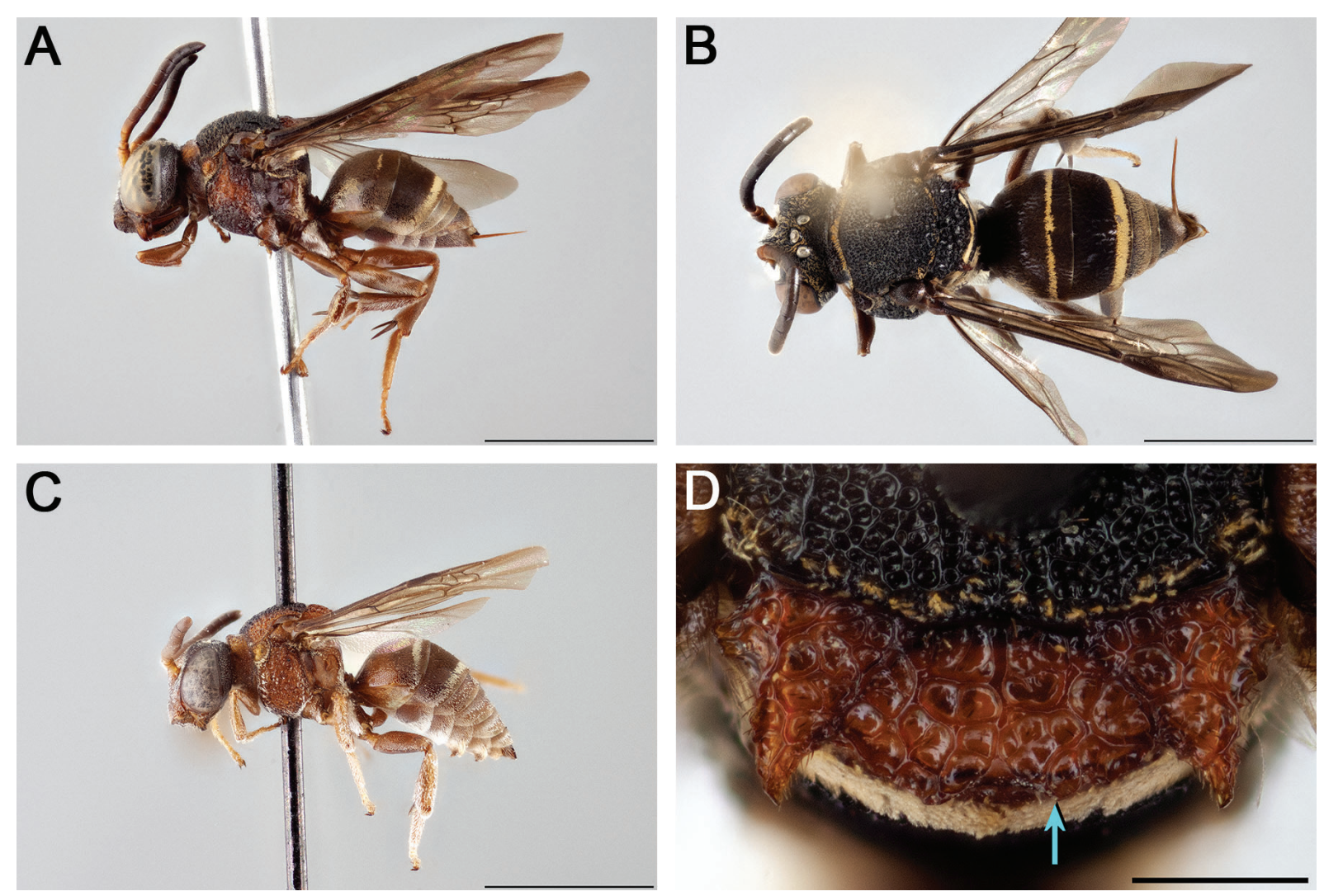

Fig. 6. Epeolus boliviensis Friese, 1908. A. Female, habitus, lateral view. B. Female, habitus, dorsal view. C. Male holotype, habitus, lateral view, ZMB. D. Female axillae and mesoscutellum, dorsal view (blue arrow indicates one of two posteriorly directed tooth-like projections of mesoscutellum). Scale bars: $\mathrm{A}-\mathrm{C}=3 \mathrm{~mm} ; \mathrm{D}=0.5 \mathrm{~mm}$. 
of posteriorly directed teeth. Axilla large, its lateral margin more than half as long as mesoscutellar width $(\mathrm{AL} / \mathrm{MSCW}$ ratio $=0.7)$ and tip extending beyond apex of horizontal dorsal portion of mesoscutellum; axilla with tip distinctly pointed, but unattached to mesoscutellum for less than $2 / 5$ (though more than $1 / 3$ ) the medial length of axilla (with free portion $2 / 5$ its medial length or longer in multiple non-type specimens); axilla with lateral margin crenulate, with large tooth near base, and carinate but relatively straight. Mesopleuron with carina delineating its anterior and lateral surfaces. Fore wing with three submarginal cells. Pygidial plate apically truncate.

\section{Female}

Description as for male except for usual secondary sexual characters and as follows: F2 even longer than wide $(\mathrm{L} / \mathrm{W}$ ratio $=1.4)$; T5 laterally with long, erect simple setae; T5 with pseudopygidial area lunate, its apex less than twice as wide as medial length, indicated by silvery setae on impressed disc of apicomedial region elevated from rest of tergum; pygidial plate with much smaller punctures; S4 and S5 with straight and much shorter hairs (S5 with apical fimbria of coppery to silvery hairs extending beyond apex of sternum by $\sim 1 / 2 \mathrm{MOD})$.

\section{Distribution}

Central America and tropical South America + Trinidad in the Lesser Antilles (Fig. 7A). Based on known records, E. boliviensis appears to be the most widely distributed species of Epeolus in the Neotropics.

\section{Ecology}

\section{Host records}

Michener (1974) reported that females of E. boliviensis (as Tro. schraderi) were observed frequently flying about the nests of Ancyloscelis Latreille, 1829 (Hymenoptera: Apidae: Eucerinae) and Melitoma Lepeletier \& Serville, 1828 (Hymenoptera: Apidae: Eucerinae), which they entered, and the earth wall where they were located. It remains to be seen whether either or both of these associations is/are true, but, given the strong association of Epeolus with Colletes, these alternative associations are unexpected to say the least. One member of the 'Trophocleptria group', Epeolus bifasciatus, has been observed on separate occasions (personally and by T. Roulston, personal communication, 2016) in the presence of a single species of Colletes, C. latitarsis Robertson, 1891, so one would expect similar species of Epeolus to be associated with Colletes as well.

\section{Floral records}

The label of one examined voucher specimen indicates a floral association with Coffea L. (Rubiaceae).

\section{Remarks}

The examined primary type specimen of E. boliviensis bears a label that simply says "Type", which is presumed to be Heinrich Friese's original type label. Below it is a label that says "LECTOTYPUS" and "A. Roig Alsina, 1989". The lectotype designation cannot be traced to any publication, nor does it seem warranted since Friese's (1908) original description of the species gives no indication that it was described from more than one (male) specimen. Moure et al. (2007) refer to this specimen as the holotype, not the lectotype, and in the present study it is also recognized as such.

Fig. 7 (opposite page). Occurrence records (yellow circles except where indicated otherwise) of: A. Epeolus boliviensis Friese, 1908. B. E. claripennis Friese, 1908. C. E. danieli (Genaro, 2014) comb. nov. (orange square) and E. luteipennis Friese, 1916. D. E. fulvopilosus Cameron, 1902. E. E. fumipennis Say, 1837. F. E. hanusiae sp. nov. G. E. niger (Michener, 1954). H. E. nomadiformis sp. nov. I. E. obscuripes Cockerell, 1917 stat. nov. J. E. odyneroides sp. nov. K. E. pulchellus Cresson, 1865. 


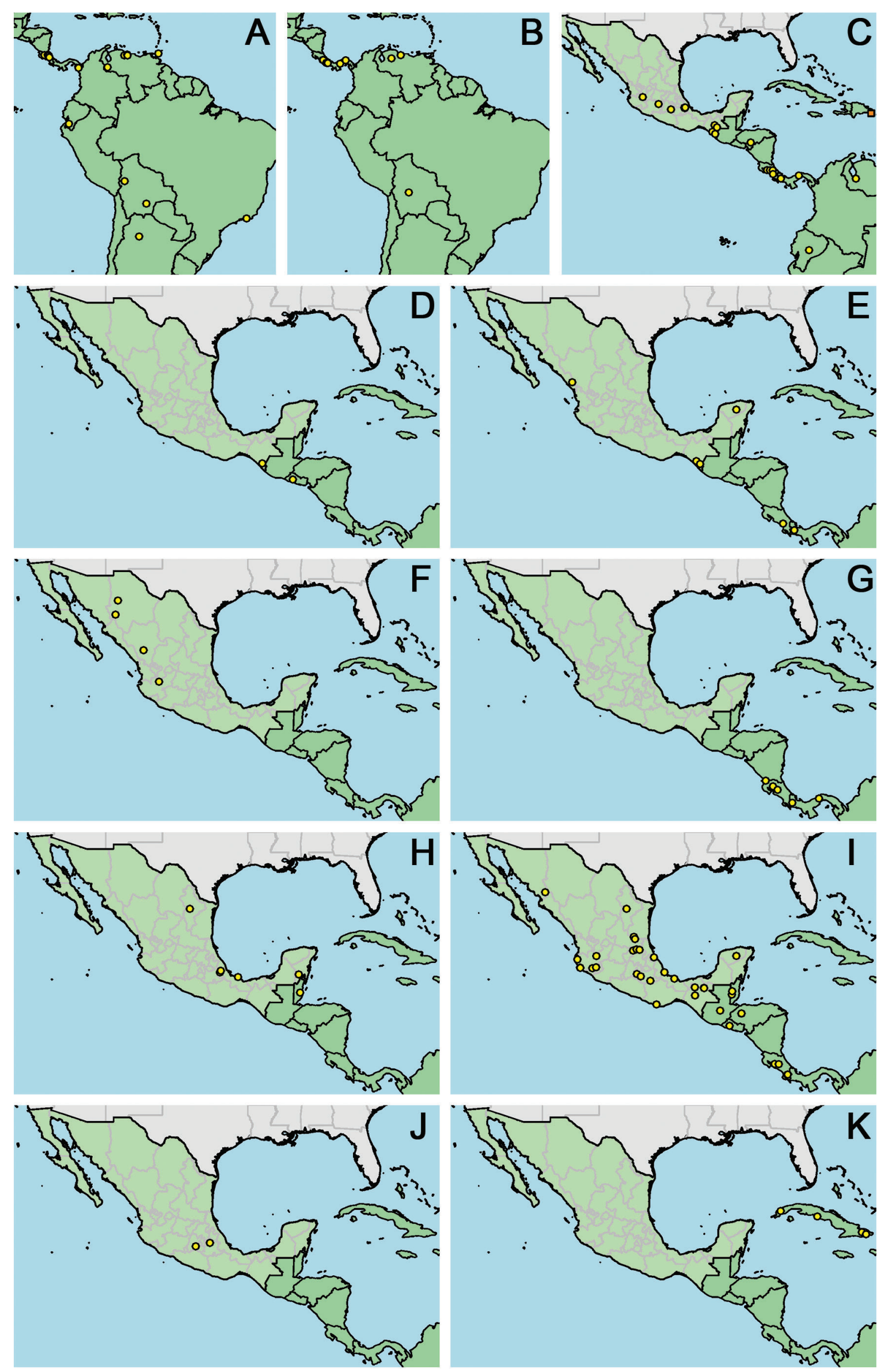


This species exhibits notable variability in integument coloration, with the following features varying from black to partially or entirely ferruginous among examined specimens: pronotal collar, pronotal lobe, axilla, mesoscutum, mesoscutellum, metanotum, mesopleuron, metapleuron and propodeum. In some examined specimens of this species, the $\mathrm{T} 1$ subapical fascia has a pair of anterolateral extensions (longitudinal bands). Michener (1974) indicates that Tro. schraderi (herein synonymized under E. boliviensis) is probably only a geographic variant of E. variolosus (Holmberg, 1886) (as Tro. variolosa). This seems unlikely given that in E. variolosus the mesoscutum is consistently red laterally and black medially, the mesopleura are more densely and finely punctate, and T1 has a single broad apical fascia (the remaining terga lack fasciae), whereas in the Tro. schraderi holotype the mesoscutum is entirely black, the mesopleura are more sparsely and coarsely punctate, $\mathrm{T} 1$ has a narrow bright to pale yellow subapical fascia and $\mathrm{T} 2$ has a single broad apical fascia (the remaining terga also lack fasciae). Although the male holotype of Tro. variolosa was not examined (according to Moure et al. 2007 it is probably lost), two male syntypes (one at the AMNH and one at the ZMB, the latter bears a label that says "Lectotypus" and "A. Roig Alsina, 1989", but the lectotype designation cannot be traced to any publication) of E. unifasciatus Friese, 1908, a name which Schrottky (1910) established as a junior synonym of $E$. variolosus, were examined, along with many non-type specimens from Argentina, Bolivia and Brazil (Supplementary File 1). In the holotype of E. boliviensis the mesoscutum is red laterally and black medially, as it is in E. variolosus, but the specimen much more closely resembles the holotype of Tro. schraderi and specimens from the Caribbean, Central America and northern South America in its much smaller size, more slender appearance, more sparsely and coarsely punctate mesopleuron, and presence of an apical fascia on $\mathrm{T} 2$.

Although BIN-compliant sequences are presently not available for E. boliviensis, a partial sequence $293 \mathrm{bp}$ in length is available for a female specimen from Venezuela that closely resembles the Tro. schraderi holotype, which does not cluster closely with the only two BIN-compliant sequences available for what is herein considered to be $E$. variolosus (sequenced female specimens from Argentina resembling the syntypes of $E$. unifasciatus) in a $\mathrm{NJ}$ tree of sequences $>200 \mathrm{bp}$ in length (minimum distance $=2.8 \%$, Supplementary File 3). Moreover, the morphological differences between the specimens from the Caribbean, Central America and tropical South America understood to be E. boliviensis and those from in and around the Southern Cone that are understood to be E. variolosus are consistent, and therefore the two forms are herein considered to be heterospecific.

Epeolus claripennis Friese, 1908

Figs 1B, 5A, 7B, 8

Epeolus claripennis Friese, 1908: 88 (†).

Trophocleptria odontothorax Michener, 1954: 126 (†), syn. nov.

\section{Proposed common name}

Clear-winged epeolus.

\section{Diagnosis}

Together with the morphological features that are diagnostic for the 'Trophocleptria group', the following in combination can be used to tell E. claripennis apart from all other Epeolus: the axillae are crenulate along the lateral margin, each with a large tooth near the base (Fig. 8D); the mesoscutellum has a pair of posteriorly directed teeth (Fig. 8D); the mesopleura are coarsely punctate, each with sparser punctures ventrolaterally (many $\mathrm{i} \geq 2 \mathrm{~d}$ ) than in the upper half, with interspaces dull due to tessellate surface microsculpture (Fig. 5A); the fore wings are deeply infuscate basally and (unusually for Epeolus) clear apically (Fig. 8A-B); and the metasomal terga lack pale pubescence (Fig. 8A-C). Epeolus claripennis most closely resembles E. niger (Michener, 1954) in that both species are almost entirely black and at 
least the fore wings of females are deeply infuscate basally and clear apically, but in E. niger there is no large tooth laterally near the base of each axilla, the mesoscutellum does not have a pair of posteriorly directed teeth and the mesopleura are more finely punctate, each with punctures more or less equally dense throughout (few $\mathrm{i} \geq 2 \mathrm{~d}$ ).

\section{Material examined}

Primary type material

BOLIVIA • + , E. claripennis holotype; Cochabamba Department, Tarata; 1900; ZMB.

PANAMA • +, Tro. odontothorax holotype; Chiriquí, El Volcán Chiriquí; 27 Feb. 1936; F.E. Lutz leg.; AMNH AMNH_IZC 00324262.

\section{Secondary type material}

PANAMA • 1 Oे, Tro. odontothorax allotype; Coclé, El Valle de Antón; 1 Apr. 1945; C.D. Michener leg.; AMNH AMNH_IZC 00324263.

DNA barcoded material with BIN-compliant sequences

Available. BOLD:ADB1637. Specimens examined and sequenced:

COSTA RICA • 1 ð’; San José, Montecarlo (MORA ref. site); $9.3419^{\circ}$ N, $83.6041^{\circ}$ W; 14 Feb. 2005; H.T. Ngo leg.; BOLD sample ID: CCDB-28315 F06; PCYU.

\section{Non-barcoded material}

COSTA RICA - 1 क; Puntarenas, F. Las Cruces (6 km S of San Vito); 21 or 25 Aug. 1976; E.M. Fisher leg.; LACM LACM ENT 363332 • 1 §’; San José, Montecarlo (MORA ref. site); $9.3420^{\circ} \mathrm{N}, 83.6039^{\circ} \mathrm{W}$; 7 May 2005; H.T. Ngo leg.; PCYU • 1 q; same collection data as for preceding; 13 May 2005; H.T. Ngo leg.; PCYU • 1 §’; same collection data as for preceding; 13 Jul. 2005; H.T. Ngo leg.; PCYU • 1 q; same collection data as for preceding; 2 Sep. 2005; H.T. Ngo leg.; PCYU • 1 क; same collection data as for preceding; 9 Jan. 2006; H.T. Ngo leg.; PCYU • 1 q; San José, Quizarra (Sr. Rojas' farm); 12 May 2005; H.T. Ngo leg.; PCYU • 2 o $O$; San José, San Isidro de El General; Feb. 1993; F.D. Parker leg.; BBSL.

PANAMA - 1 đ̊; Panamá, 15 km N of El Llano (Camino Cartí); 10 May 1981; R.W. Brooks leg.; KUNHM SM0738700 • 1 ; ; same collection data as for preceding; KUNHM SM0738701.

VENEZUELA • 1 q; Aragua, Estación Biológica de Rancho Grande (Portachuelo Pass); $10.3500^{\circ}$ N,

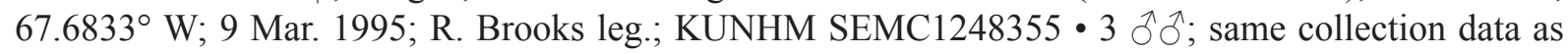
for preceding; 4 Jun. 1998; J. Ashe, R. Brooks and R. Hanley leg.; KUNHM SM0124175, SM0124178, SM0124179 • 2 ㅇ; same collection data as for preceding; 4 Jun. 1998; J. Ashe, R. Brooks and R. Hanley leg.; KUNHM SM0124176, SM0124177 • 1 §’; Carabobo, Henri Pittier National Park (Portachuelo Pass); $10.3475^{\circ}$ N, $67.6878^{\circ}$ W; 15 Sep. 2008; J. Skevington leg.; PCYU • 1 đ; Lara, Parque Nacional Yacambú (16.1 km SE of Sanare); $9.7000^{\circ} \mathrm{N}, 69.5850^{\circ} \mathrm{W} ; 2$ Jun. 1998; J. Ashe, R. Brooks and R. Hanley leg.; KUNHM SM0122036.

\section{Redescription}

\section{Female}

MEAsurements. Length $8.5 \mathrm{~mm}$; head length $2.0 \mathrm{~mm}$; head width $2.4 \mathrm{~mm}$; fore wing length $7.5 \mathrm{~mm}$.

INTEGUMENT COLORATION. Mostly dark brown to black; notable exceptions as follows: at least partially ferruginous on mandible, antenna, tegula and legs. Mandible with apex darker than rest of mandible; preapical tooth lighter than mandibular apex (difficult to see in E. claripennis holotype because mandibles closed; described from non-type specimens). Flagellum, except left F1 and F2, missing in E. claripennis 
holotype, but brown and (except F1) slightly lighter than partially dark brown (otherwise orange) scape, pedicel and F1, primarily due to extensive pilosity on flagellum, in Tro. odontothorax holotype and multiple non-type specimens. Wing membrane subhyaline, basally dusky. Legs with brown or black more extensive than reddish orange.

Pubescence. Face with tomentum densest around antennal socket. Tomentum slightly sparser on clypeus; upper paraocular and frontal areas and vertexal area mostly exposed. Pronotal collar with narrow band of ferruginous short, appressed setae along posterior margin. Mesoscutum without pale tomentum in E. claripennis holotype, but with some ferruginous short, appressed setae along posterior margin in multiple non-type specimens. Mesopleuron nearly bare, except along margins. Metanotum with tomentum discolored or rubbed off in E. claripennis holotype, but sparser medially and uniformly light brown/pale ferruginous in Tro. odontothorax holotype and multiple non-type specimens. Dorsum of metasoma without bands of pale tomentum. T5 laterally with long, erect simple setae. T5 with pseudopygidial area lunate, its apex twice as wide as medial length, with basal impressed triangular portion covered in gray-brown short, appressed setae differentiated from transverse band of coppery to silvery short, appressed setae along posterior-facing apical margin. S5 with apical fimbria of coppery to silvery hairs extending beyond apex of sternum by $\sim 1 / 2$ MOD.

Surface sculpture. Punctures dense, but those of head and mesosoma sparser in some areas, larger, deeper and more distinct. Labrum with larger and sparser punctures (most $i>1 d)$ than clypeus $(i \leq 1 d)$. Impunctate spot lateral to lateral ocellus absent in E. claripennis holotype, but shiny spot present in
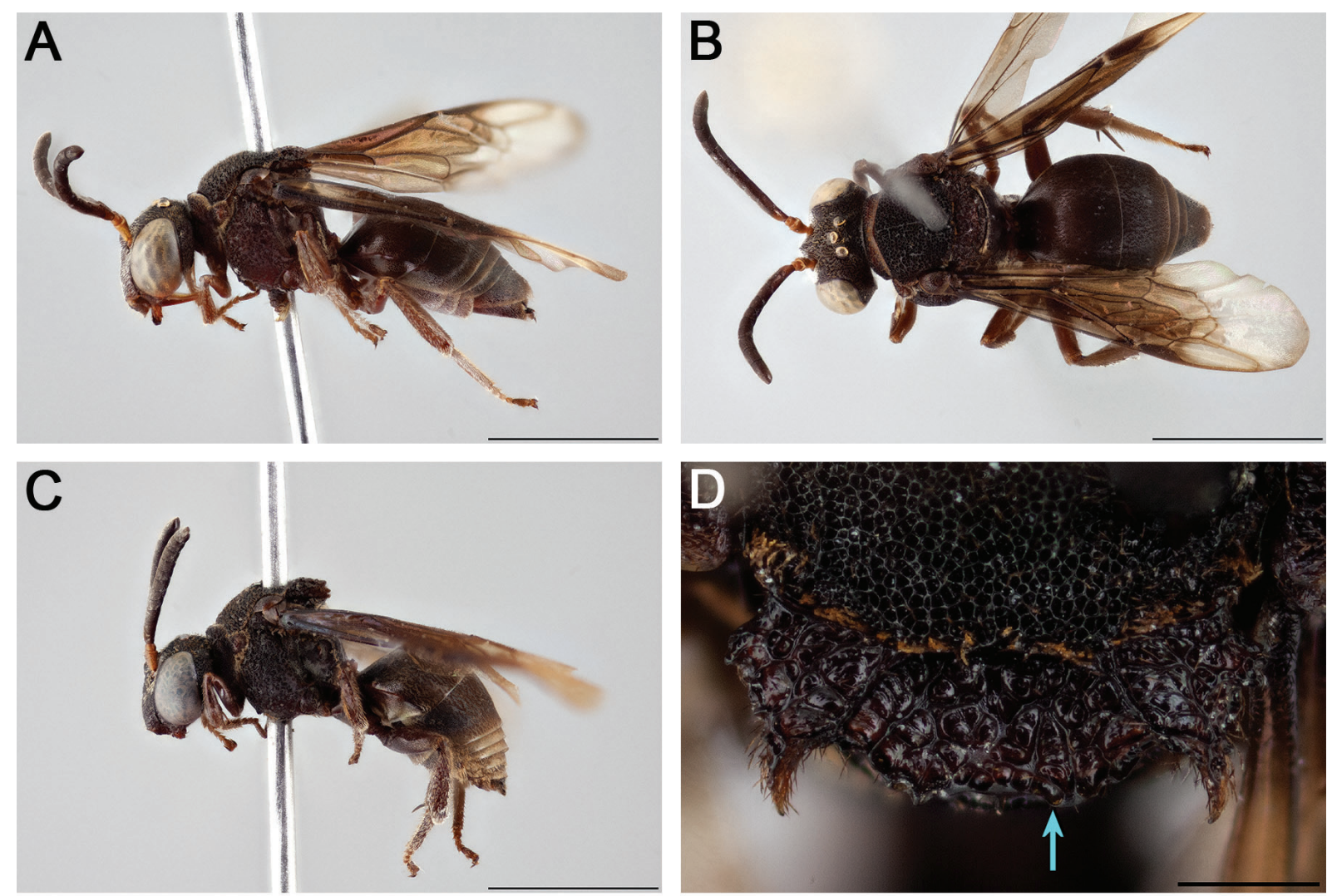

Fig. 8. Epeolus claripennis Friese, 1908. A. Female, habitus, lateral view. B. Female, habitus, dorsal view. C. Male, habitus, lateral view. D. Female axillae and mesoscutellum, dorsal view (blue arrow indicates one of two posteriorly directed tooth-like projections of mesoscutellum). Scale bars: A-C = $3 \mathrm{~mm} ; \mathrm{D}=0.5 \mathrm{~mm}$. 
multiple non-type specimens. Mesoscutum, mesoscutellum and axilla very coarsely and densely rugosepunctate. Tegula densely punctate mesally $(\mathrm{i}=1-2 \mathrm{~d})$, sparsely punctate $(\mathrm{i}>2 \mathrm{~d})$ to impunctate along margins. Mesopleuron with denser $(i<1 d)$ punctures in upper half than ventrolateral half (many $i \geq 1 d$ ), interspaces dull due to tessellate surface microsculpture; mesopleuron with punctures similar in size throughout. Metasomal terga with punctures very fine, dense (i $\approx 1 \mathrm{~d})$, evenly distributed on disc.

Structure. Preapical tooth acute. Labral apex with pair of small denticles (separated by shallow concavity), each preceded by longitudinal carina. Frontal keel strongly raised. Frontal area with pair of discrete, sparsely punctate granulose protrusions, each located near upper mesal margin of compound eye. Head dorsally with pair of protrusions, each located where upper genal area meets vertexal area. Vertexal area strongly convex in frontal view. Scape with greatest length $1.5 \times$ greatest width. F2 noticeably longer than wide $(\mathrm{L} / \mathrm{W}$ ratio $=1.5)$. Preoccipital ridge separated from hypostomal carina by about 1.5-2 MOD. Pronotal collar elongate (medial length $\sim 1$ MOD), expanded laterally to about $2 \times$ medial length in dorsal view and relatively straight along anterior margin. Mesoscutellum weakly bigibbous, depressed along posterior margin beneath distinct overhanging ridge produced to pair of posteriorly directed teeth. Axilla large, its lateral margin more than half as long as mesoscutellar width $(\mathrm{AL} / \mathrm{MSCW}$ ratio $=0.7)$ and tip extending beyond apex of horizontal dorsal portion of mesoscutellum; axilla with tip conspicuously diverging from side of mesoscutellum, distinctly hooked, and axilla with free portion approximately half its medial length; axilla with lateral margin crenulate, with large tooth near base, and carinate but relatively straight. Mesopleuron with carina delineating its anterior and lateral surfaces. Fore wing with three submarginal cells. Pygidial plate apically truncate.

\section{Male}

Description as for female except for usual secondary sexual characters and as follows: F2 shorter, but still longer than wide $(\mathrm{L} / \mathrm{W}$ ratio $=1.2)$; pygidial plate apically rounded, with larger and deeper punctures, closely punctate throughout; S3-S5 with much longer (>1 MOD) coppery to silvery subapical hairs, those of S4 and S5 curved.

\section{Distribution}

Central America and northwestern to western-central South America (Fig. 7B).

\section{Ecology}

\section{Host records}

Unknown.

\section{Floral records}

Labels of examined voucher specimens indicate floral associations with Coffea and Psychotria L. (Rubiaceae).

\section{Remarks}

The examined primary type specimen of E. claripennis bears a label that simply says "Type", which is presumed to be Heinrich Friese's original type label. Below it is a label that says "LECTOTYPUS" and "A. Roig Alsina, 1989". The lectotype designation cannot be traced to any publication, nor does it seem warranted since Friese's (1908) original description of the species gives no indication that it was described from more than one (female) specimen. Moure et al. (2007) refer to this specimen as the holotype, not the lectotype, and in the present study it is also recognized as such.

Although the holotypes of E. claripennis and Tro. odontothorax are from widely separated localities, in Bolivia and Panama, respectively, there are no apparent differences between the two specimens that fall outside the range of variation observed among conspecifics that were, by contrast, collected at the same 
place and time. Although only a single BIN-compliant sequence is available for a specimen identified as E. claripennis, a partial sequence $297 \mathrm{bp}$ in length obtained from a visibly different bee (see Figs 8,16 ), herein considered to be a separate species (E. nomadiformis sp. nov.), has been matched to it with $99.7 \%$ similarity. Thus, it seems unlikely that additional barcodes from specimens exhibiting the diagnostic features of E. claripennis should uncover any cryptic species. Epeolus claripennis exhibits very little intraspecific morphological variation and appears to be one of the more widespread and commonly collected species in the 'Trophocleptria group'.

The extensive black coloration and apically clear fore wings of this species (presumably the latter is what inspired the epithet 'claripennis') and E. niger give both the distinctive appearance of Parachartergus R. von Ihering, 1904 (Hymenoptera: Vespidae: Polistinae). These features are also shared with various tropical stingless bees (e.g., Trigona Jurine, 1807 spp.), some of which are known to be in mimetic complexes that include a diversity of aculeates, including other bees (Smith-Pardo 2005), and even nonhymenopterous insects such as flower flies (Diptera: Syrphidae) (Reemer 2013).

\section{Epeolus danieli (Genaro, 2014) comb. nov.}

Figs $7 \mathrm{C}, 9$

Triepeolus danieli Genaro, 2014: 23 (ㅇ).

\section{Proposed common name}

Daniel's epeolus.

\section{Diagnosis}

The following morphological features in combination can be used to tell E. danieli apart from all other New World Epeolus: the axillae are large, each with the tip extending as far back as the apex of the horizontal dorsal portion of the mesoscutellum, distinctly hooked, each with the tip unattached to the mesoscutellum for more than $1 / 3$ of the entire medial length of the axilla, and like the mesoscutellum ferruginous (Fig. 9C); T1 has a distinct, although medially interrupted, basal fascia, which on each side is connected to the apical fascia by a longitudinal band (Fig. 9B); the T1-T4 apical fasciae are broadened submedially and separated into rounded lobes medially (Fig. 9B); and the metasomal fasciae are uniformly yellow (Fig. 9B).

\section{Material examined}

\section{Primary type material}

DOMINICAN REPUBLIC • + , Tri. danieli holotype (studied from images); La Altagracia Province, Cueva del Puente (Guaraguao, Parque Nacional Del Este); 9 May 1992; B. Hierro leg.; MNHNSD 18.107 .

\section{DNA barcoded material with BIN-compliant sequences}

Unavailable.

\section{Description}

This species was recently described (Genaro 2014).

\section{Distribution}

This species is presently known from a single location in the Dominican Republic and is the only species of Epeolus known to occur on the island of Hispaniola (Fig. 7C). 


\section{Ecology}

\section{Host records}

Unknown. Only members of the genus Colletes have been confirmed as hosts of Epeolus, but there are no records of Colletes from Hispaniola on either Moure's Bee Catalogue (Moure et al. 2007) or Discover Life (Ascher \& Pickering 2019).

\section{Floral records}

Unknown.

\section{Remarks}

Although originally described as a species of Triepeolus, images of the holotype of Tri. danieli (fig. 5 in Genaro 2014 and additional images kindly provided by Gabriel de los Santos, MNHNSD, which are presented in Fig. 9 of the present study) show features that are diagnostic for Epeolus (sensu Rightmyer 2004; see also Onuferko 2017). Specifically, the apical lateral processes of S6 are convergent, spatulate, and bear setae modified into minute, pointed denticles, which are directed laterally (Fig. 9D). By contrast, in Triepeolus and all other Epeolini the processes are parallel or slightly divergent, rod-like and bear coarse, spine-like setae, which are directed medioventrally to ventrally (Rightmyer 2004). Additionally, as in most Epeolus spp., the pseudopygidial area in the Tri. danieli holotype is lunate and wider than long (the apex $>2 \times$ the medial length) (Fig. 9D). In Triepeolus, the pseudopygidial area varies greatly among species but very rarely forms a wide silvery lunule on the apical margin (Rightmyer 2004).
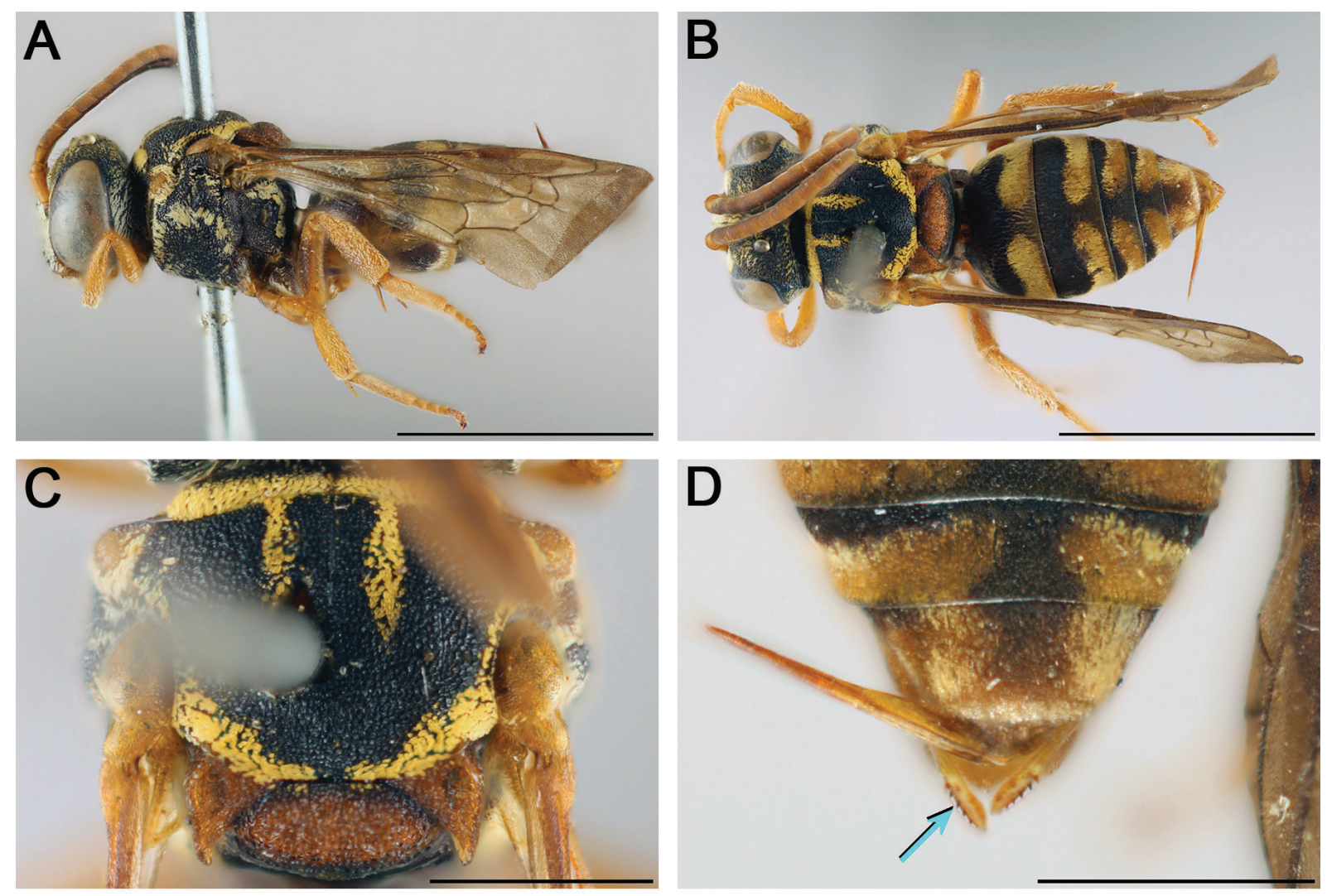

Fig. 9. Epeolus danieli (Genaro, 2014) comb. nov., holotype, $q$ (MNHNSD 18.107). A. Habitus, lateral view. B. Habitus, dorsal view. C. Mesosoma, dorsal view. D. Posterior part of metasoma, dorsal view (blue arrow indicates process of S6). Images courtesy of G. de los Santos, MNHNSD. Scale bars: A-B = $3 \mathrm{~mm} ; \mathrm{C}-\mathrm{D}=1 \mathrm{~mm}$. 
The only (female) paratype (fig. 8 in Genaro 2014) is meant to have been deposited in the USNM but does not appear to be there (B. Harris and S. Droege, personal communication, 2019). Genaro (2014) reports that the collection data for the paratype is the same as for the holotype. The male of E. danieli is still unknown, and no additional representatives of this species appear to have been found since its original description.

Although recognizable as an Epeolus, within the genus the species is incertae sedis. It is difficult to confirm the species' placement within or outside of the 'Trophocleptria group' from images of the holotype and published description alone. Since no representatives of this species were available for more detailed examination, the species is not redescribed herein. However, despite having been described as a species of Triepeolus, Genaro's (2014) original description is sufficiently detailed to tell E. danieli apart from all other New World Epeolus occurring south of the United States. Epeolus danieli is the only species in the genus known to occur in Hispaniola, where it appears to be endemic, and apart from the diagnostic generic features can be distinguished from the other two known Hispaniolan species of Epeolini (Tri. nisibonensis Genaro, 2001 and Tri. victori Genaro, 1998) using the illustrated key presented in Genaro (2014: 23).

Epeolus fulvopilosus Cameron, 1902

Figs $1 \mathrm{C}, 3 \mathrm{~A}, 7 \mathrm{D}, 10$

Epeolus fulvo-pilosus Cameron, 1902: 377 (§ [sic, actually + ]).

\section{Proposed common name}

Yellow-haired epeolus.

\section{Diagnosis}

Together with the morphological features that are diagnostic for the 'Trophocleptria group', the following in combination can be used to tell E. fulvopilosus apart from all other Epeolus: the axillae are crenulate along the lateral margin, each with a large tooth near the base (Fig. 10D); the mesoscutellum has a pair of posteriorly directed teeth (Fig. 10D); the mesopleura are coarsely punctate, each with sparser punctures ventrolaterally (many $\mathrm{i} \geq 2 \mathrm{~d}$ ) than in the upper half, with interspaces shining; the fore wings are deeply infuscate apically (Fig. 10B); T1 has a broad, medially narrowed or interrupted, bright to pale yellow basal fascia (Fig. 10B); and T2-T4 have complete bright to pale yellow apical fasciae (Fig. 10A-C). Epeolus fulvopilosus most closely resembles E. boliviensis and E. nomadiformis sp. nov. in terms of integument coloration, surface sculpture and structure. Whereas in E. fulvopilosus T3 and T4 are distinctly fasciate, in E. boliviensis and E. nomadiformis sp. nov. T3 and T4 lack fasciae, although the apical impressed areas occasionally have sparse, off-white hairs. Epeolus boliviensis also lacks a basal fascia, which is present in E. fulvopilosus and E. nomadiformis sp. nov. In terms of the patterns of pubescence on the mesosoma and metasoma, E. fulvopilosus is more similar to E. fumipennis. However, in E. fumipennis the mesoscutum has a pair of well-defined paramedian bands, which are absent in E. fulvopilosus, although in the latter the mesoscutum of the female anteriorly has faint lines of bright yellow tomentum along the midline and between the midline and parapsidal lines; there is no large tooth laterally near the base of each axilla; the mesoscutellum does not have a pair of posteriorly directed teeth; the anterior and lateral surfaces of each mesopleuron are not clearly differentiated from one another; the mesopleura are more finely punctate, each with punctures more or less equally dense throughout (few $\mathrm{i} \geq 2 \mathrm{~d}$ ); and $\mathrm{T} 1$ has a broad, medially narrowed bright to pale yellow submedial fascia.

\section{Material examined}

Primary type material

MEXICO • +, holotype; west coast; G.F. Mathew leg.; NHMUK NHMUK010812213. 
DNA barcoded material with BIN-compliant sequences

Unavailable.

\section{Non-barcoded material}

EL SALVADOR • 1 đ; La Libertad, Mount San Salvador; 8 Jul. 1963; M.E. Irwin and D.Q. Cavagnaro leg.; EMEC 1135878.

MEXICO・ 1 q; Chiapas, 20-25 mi N of Huixtla; 4 Jun. 1969; H.J. Teskey leg.; CNC 754058.

\section{Redescription}

\section{Female}

Measurements. Length $8.5 \mathrm{~mm}$; head length $2.2 \mathrm{~mm}$; head width $2.6 \mathrm{~mm}$; fore wing length $7.2 \mathrm{~mm}$.

INTEGUMENT COLORATION. Mostly black; notable exceptions as follows: at least partially ferruginous on mandible, labrum, antenna, pronotal collar, pronotal lobe, tegula, axilla, mesoscutellum, metanotum, mesopleuron, legs and pygidial plate. Mandible with apex darker than all but extreme base; preapical tooth lighter than mandibular apex (difficult to see in holotype because mandibles closed; described from non-type specimen). Antenna brown except scape, pedicel and F1 extensively orange (antennae, except left scape, missing in holotype; described from non-type specimen). F2 with orange spot basally. Pronotal collar, pronotal lobe and tegula pale ferruginous to amber. Wing membrane dusky subhyaline, slightly darker at apex. Legs more extensively reddish orange than brown or black.
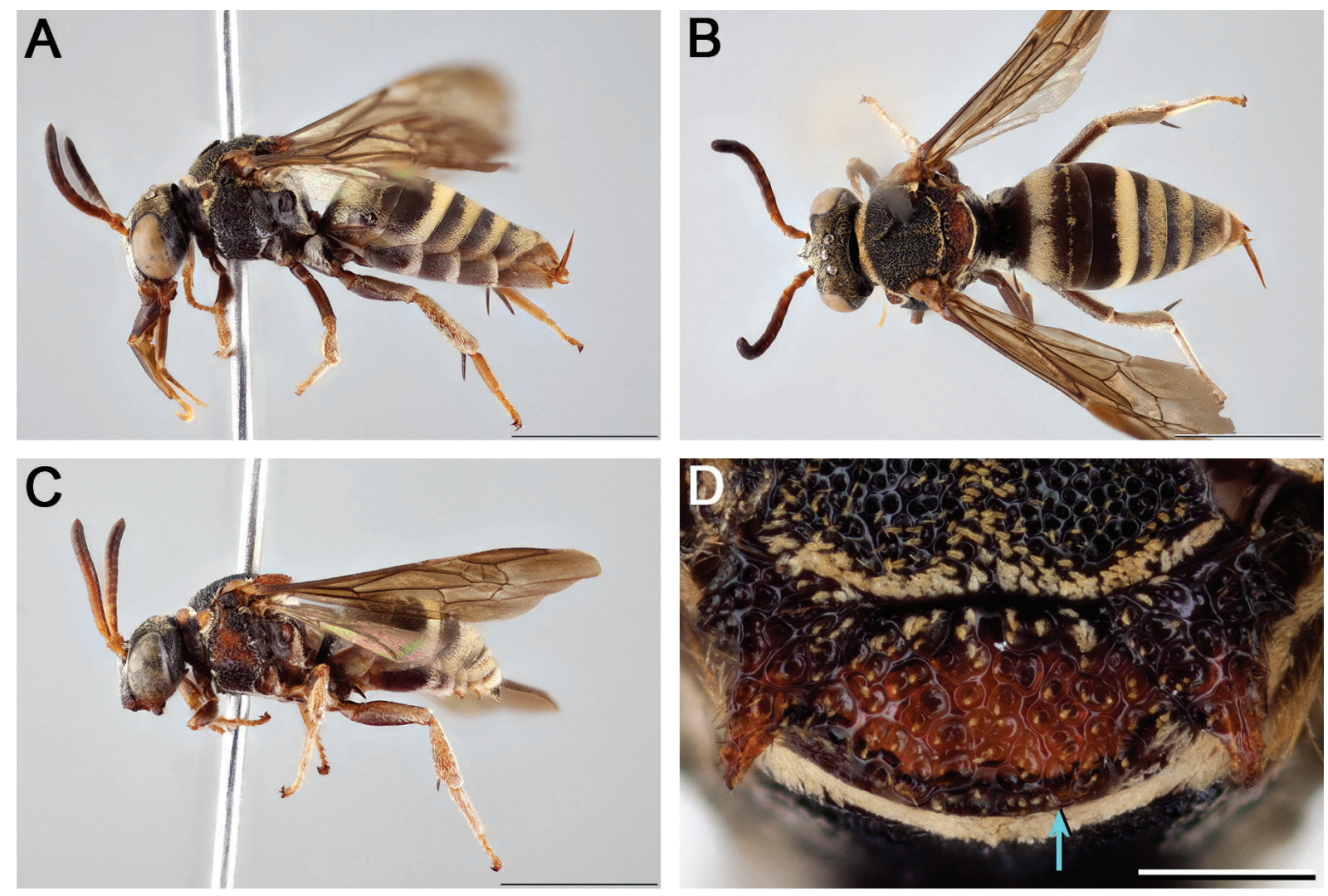

Fig. 10. Epeolus fulvopilosus Cameron, 1902. A. Female, habitus, lateral view. B. Female, habitus, dorsal view. C. Male, habitus, lateral view. D. Female axillae and mesoscutellum, dorsal view (blue arrow indicates one of two posteriorly directed tooth-like projections of mesoscutellum). Scale bars: $\mathrm{A}-\mathrm{C}=3 \mathrm{~mm} ; \mathrm{D}=0.5 \mathrm{~mm}$. 
Pubescence. Face with tomentum densest around antennal socket, slightly sparser on clypeus, upper paraocular and frontal areas, and vertexal area. Dorsum of mesosoma and metasoma with bands of bright to pale yellow short, appressed setae. Pronotal collar with tomentum uniformly bright yellow. Mesoscutum anteriorly with faint lines of bright yellow tomentum along midline and between midline and parapsidal line. Mesopleuron nearly bare, except along margins. Metanotum with tomentum uninterrupted, uniformly pale yellow. T1 with pale tomentum mostly rubbed off in holotype, but with broad, medially interrupted bright yellow basal fascia and very narrow, bright yellow subapical fascia in non-type specimen. T2 with complete bright yellow apical fascia, broadest medially and without anterolateral extensions. T3 and T4 with complete, bright yellow apical fasciae of slightly sparser tomentum. T5 with large, continuous patch of bright yellow tomentum bordering and contacting pseudopygidial area, laterally with long, erect simple setae. T5 with pseudopygidial area lunate, its apex more than twice as wide as medial length, indicated by silvery setae on impressed disc of apicomedial region elevated from rest of tergum. S5 with apical fimbria of coppery to silvery hairs not extending beyond apex of sternum by much more than $1 / 4$ MOD.

Surface SCUlPture. Punctures dense, but those of head and mesosoma sparser in some areas, larger, deeper, and more distinct. Labrum with larger and sparser punctures $(i=1-2 d)$ than clypeus $(i<1 d)$. Small impunctate dull/textured spot lateral to lateral ocellus. Mesoscutum, mesoscutellum, and axilla very coarsely and densely rugose-punctate. Tegula densely punctate anteriorly and mesally (i<1d), sparsely punctate $(i>2 d)$ to impunctate posteriorly and along margins. Mesopleuron with denser $(i<1 \mathrm{~d})$ punctures in upper half than ventrolateral half $(i \leq 2 d)$, interspaces shining though with some coriarious surface miscrosculpture; mesopleuron with punctures similar in size throughout. Metasomal terga with punctures very fine, dense ( $\mathrm{i} \approx 1 \mathrm{~d})$, evenly distributed on disc.

Structure. Preapical tooth acute. Labral apex with pair of small denticles, each preceded by small discrete longitudinal ridge. Frontal keel strongly raised. Frontal area with pair of discrete, sparsely punctate protrusions, interspaces shining; each located near upper mesal margin of compound eye. Head dorsally with pair of protrusions, each located where upper genal area meets vertexal area. Vertexal area strongly convex in frontal view. Scape with greatest length $1.5 \times$ greatest width. F2 noticeably longer than wide $(\mathrm{L} / \mathrm{W}$ ratio $=1.5)$ (antennae, except left scape, missing in holotype; described from non-type specimen). Preoccipital ridge separated from hypostomal carina by no less than 1 MOD (difficult to see in holotype; described from non-type specimen). Pronotal collar elongate (medial length $\sim 1$ MOD), expanded laterally to about $2 \times$ medial length in dorsal view and relatively straight along anterior margin. Mesoscutellum weakly bigibbous, depressed along posterior margin beneath distinct overhanging ridge produced to pair of posteriorly directed teeth. Axilla large, its lateral margin more than half as long as mesoscutellar width $(\mathrm{AL} / \mathrm{MSCW}$ ratio $=0.7)$ and tip extending as far back as apex of horizontal dorsal portion of mesoscutellum; axilla with tip conspicuously diverging from side of mesoscutellum, distinctly hooked and axilla with free portion $2 / 5$ its medial length; axilla with lateral margin crenulate, with large tooth near base and carinate but relatively straight. Mesopleuron with carina delineating its anterior and lateral surfaces. Fore wing with three submarginal cells. Pygidial plate apically truncate.

\section{Male}

Description as for female except for usual secondary sexual characters and as follows: face more sparsely hairy; F2 shorter, but still longer than wide $(\mathrm{L} / \mathrm{W}$ ratio $=1.2)$; mesoscutum without lines of bright or pale yellow tomentum; T1 with basal fascia absent or rubbed off in only available male specimen (only small patch of pale yellow hairs present anterolaterally (left side only)); pygidial plate apically rounded, with larger and deeper punctures, closely punctate throughout; S3-S5 with much longer (>1 MOD) coppery to silvery subapical hairs, those of S4 and S5 curved. 


\title{
Distribution
}

Presently only known from a few sites along the Pacific coast in Central America and Mexico (Fig. 7D).

\section{Ecology}

\section{Host records}

\author{
Unknown.
}

\section{Floral records}

Cockerell (1933) indicated floral associations with Melampodium divaricatum (Rich. ex Rich.) DC. (Asteraceae) and Synedrella nodiflora (L.) Gaertn. (Asteraceae), although the identification of the specimens with which these records are associated could not be confirmed in the present study.

\section{Remarks}

The specimen upon which Cameron's (1902) description is based is female, not male as is indicated in the original publication. Herein, the male is described from a specimen that more closely resembles the primary type of E. fulvopilosus than that of any other species. Cockerell (1933) claims to have examined 17 specimens of this species, including both sexes, although their whereabouts are unknown and his identification of them could not be confirmed in the present study. DNA barcode sequences are presently not available for E. fulvopilosus, but a unique combination of physical attributes supports its status as a separate species as outlined in the diagnosis.

Epeolus fumipennis Say, 1837

Figs 1D, 2B, 3B, 7E, 11, 12A

Epeolus fumipénnis Say, 1837: 403 (sex not stated).

\section{Proposed common name}

Dusky-winged epeolus.

\section{Diagnosis}

Together with most of the morphological features that are diagnostic for the 'Trophocleptria group' (see exception below), the following in combination can be used to tell E. fumipennis apart from all other Epeolus: the mesoscutum has a pair of well-defined paramedian bands (Figs 2B, 11B); there is no large tooth laterally near the base of each axilla (Fig. 11D); the mesoscutellum does not have a pair of posteriorly directed teeth (Fig. 11D); the mesopleura are finely punctate, each with punctures more or less equally dense throughout (few $\mathrm{i} \geq 2 \mathrm{~d}$ ); the fore wings are deeply infuscate apically (Fig. 11A-B); $\mathrm{T} 1$ has a broad, medially narrowed, bright to pale yellow submedial fascia (Fig. 11B); and T2-T4 have complete bright to pale yellow apical fasciae (Fig. 11B). Whereas in other species in the 'Trophocleptria group' each mesopleuron has a carina delineating its anterior and lateral surfaces, in E. fumipennis the anterior and lateral surfaces of each mesopleuron are not clearly differentiated from one another. Epeolus fumipennis is similar to E. fulvopilosus in terms of the patterns of pubescence on the mesosoma and metasoma. However, in E. fulvopilosus the mesoscutum lacks paramedian bands, although the mesoscutum of the female anteriorly has faint lines of bright yellow tomentum along the midline and between the midline and parapsidal lines; there is a large tooth laterally near the base of each axilla; the mesoscutellum has a pair of posteriorly directed teeth; each mesopleuron has a carina delineating its anterior and lateral surfaces; the mesopleura are more coarsely punctate, each with sparser punctures ventrolaterally (many $i \geq 2 d$ ) than in the upper half, with interspaces shining; and T1 has a broad, medially narrowed or interrupted bright to pale yellow basal fascia. Additionally, females may be separated on the basis of the pseudopygidial area, which uniquely in E. fumipennis consists of a basal impressed triangular 
portion covered in silvery short, appressed setae differentiated from a transverse band of coppery short, appressed setae along the posterior-facing apical margin of T5 (Fig. 12A). Epeolus fumipennis is also similar to E. obscuripes Cockerell, 1917 stat. nov. in that in males of both species T1-T6 are typically fasciate. However, in E. obscuripes the mesoscutum lacks paramedian bands, the axillae are shorter, not extending as far back as the ridge overhanging the depressed posterior margin of the mesoscutellum, and $\mathrm{T} 1$ has a broad, medially narrowed or interrupted, bright to pale yellow basal fascia.

\section{Material examined}

Primary type material

MEXICO • (not examined, presumably destroyed).

\section{DNA barcoded material with BIN-compliant sequences}

Available. BOLD:ACZ0714. Specimens examined and sequenced:

PANAMA 1 đ; Chiriquí, $8 \mathrm{~km} \mathrm{~S}$ of Boquete; $8.6986^{\circ} \mathrm{N}, 82.4505^{\circ} \mathrm{W}$; $14-20$ Jan. 2012; F.D. Parker and T.D. McIntyre leg.; BOLD sample ID: CCDB-28239 H01; BBSL FDP119767 • 1 \%; same collection data as for preceding; 21-31 Jan. 2012; F.D. Parker and T.D. McIntyre leg.; BOLD sample ID: CCDB28239 G12; BBSL FDP120261.
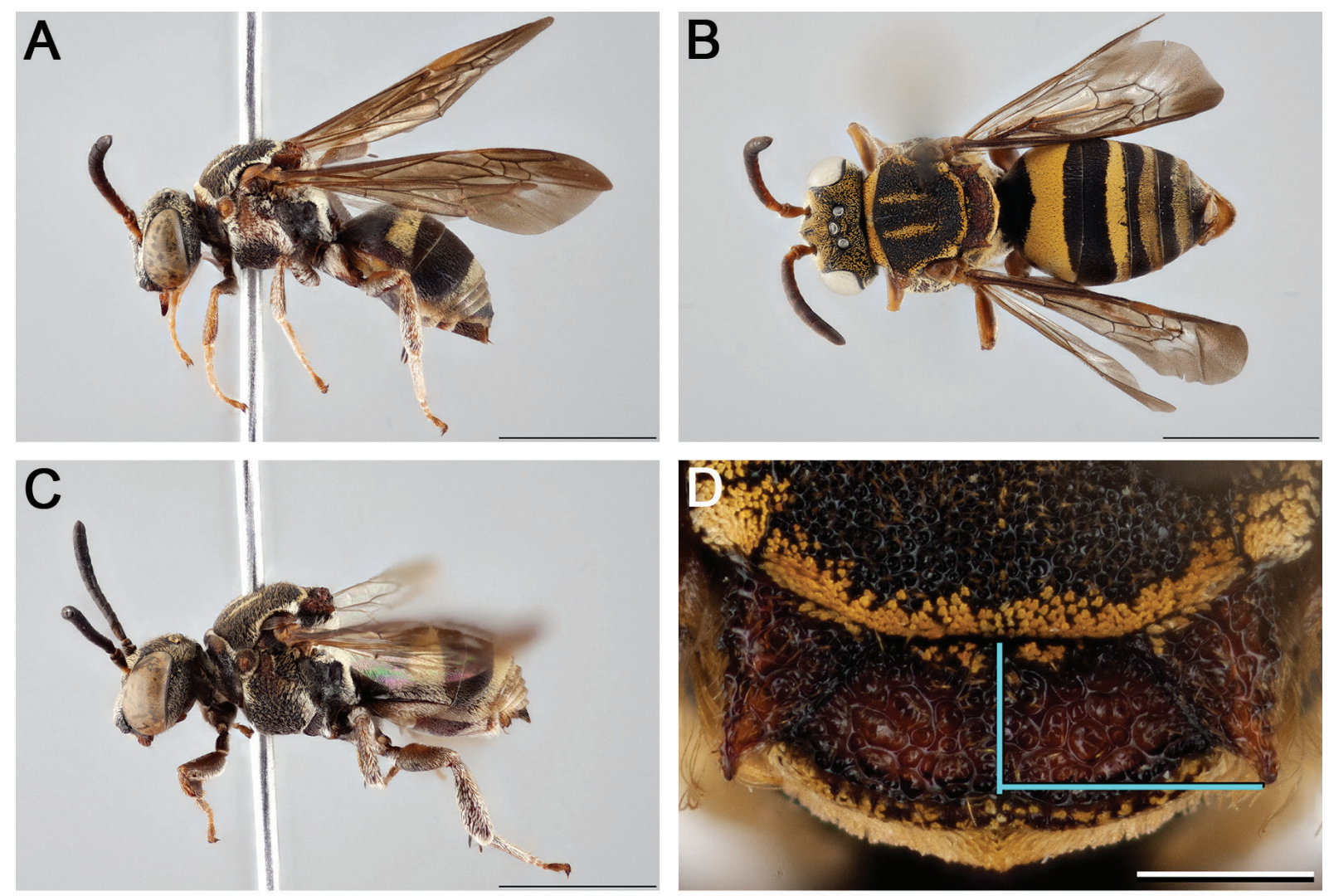

Fig. 11. Epeolus fumipennis Say, 1837. A. Female, habitus, lateral view. B. Female, habitus, dorsal view. C. Male, habitus, lateral view. D. Female axillae and mesoscutellum, dorsal view (blue lines indicate the posterior extent of the axilla relative to the length of the horizontal dorsal portion of the mesoscutellum). Scale bars: $\mathrm{A}-\mathrm{C}=3 \mathrm{~mm}$; $\mathrm{D}=0.5 \mathrm{~mm}$. 
Non-barcoded material

COSTA RICA • 1 đ̇; San José, Pérez Zeledón (San Isidro vicinity); 1 Feb.-12 Apr. 2001; T.H. Ricketts leg.; KUNHM SEMC1248326.

MEXICO • 2 q,+ 1 đ; ANSP • 1 o; Chiapas, Ei. La Palma (Acacoyagua); $15.5665^{\circ}$ N, $92.7902^{\circ} \mathrm{W}$; 17 Dec. 2004; M. Rincón, R. Ayala, M. Guzmán, J. Esponda and C. Balboa leg.; ECOSUR ECOTAE-42220 • 1 §’; Chiapas, Ei. Rosario Zacatonal (Acacoyagua); $15.2783^{\circ} \mathrm{N}, 92.3983^{\circ} \mathrm{W} ; 17$ Nov. 2006; C. Balboa, J. Mérida, M. Guzmán, M. Cigarroa and J. Toto leg.; ECOSUR ECO-TAE-50698 • 1 + ; same collection data as for preceding; 29 Nov. 2006; C. Balboa, J. Mérida, M. Guzmán, M. Cigarroa and J. Toto leg.; ECOSUR ECO-TAE-51519 • 1 P; Sinaloa, 9 mi E of Chupaderos; 19 Mar. 1962; F.D. Parker leg.; BBSL • 1 q; Yucatán, Chichén Itzá; 18 Apr.; 1962; F.D. Parker and L.A. Stange leg.; UCBME.

PANAMA 1 \%; Chiriquí, $8 \mathrm{~km} \mathrm{~S}$ of Boquete; $8.6986^{\circ} \mathrm{N}, 82.4505^{\circ} \mathrm{W}$; $15-29$ Feb. 2012; F.D. Parker and T.D. McIntyre leg.; BBSL FDP126465.

\section{Redescription}

\section{Female}

MeAsurements. Length 6.8-9.2 mm; head length $1.7-2.2 \mathrm{~mm}$; head width $2.2-2.8 \mathrm{~mm}$; fore wing length $5.9-7.2 \mathrm{~mm}$.

INTEGUMENT COLORATION. Mostly black; notable exceptions as follows: at least partially ferruginous on mandible, labrum, antenna, pronotal collar, pronotal lobe, tegula, axilla, mesoscutellum, metanotum, mesopleuron and legs. Mandible with apex darker than all but extreme base; preapical tooth slightly lighter than mandibular apex. Antenna brown and orange in part. Pronotal collar, pronotal lobe and tegula pale ferruginous to amber. Wing membrane dusky subhyaline, slightly darker at apex. Legs more extensively reddish orange than brown or black.

PuBESCENCE. Face with tomentum densest around antennal socket, slightly sparser on clypeus, upper paraocular and frontal areas, and vertexal area. Dorsum of mesosoma and metasoma with bands of
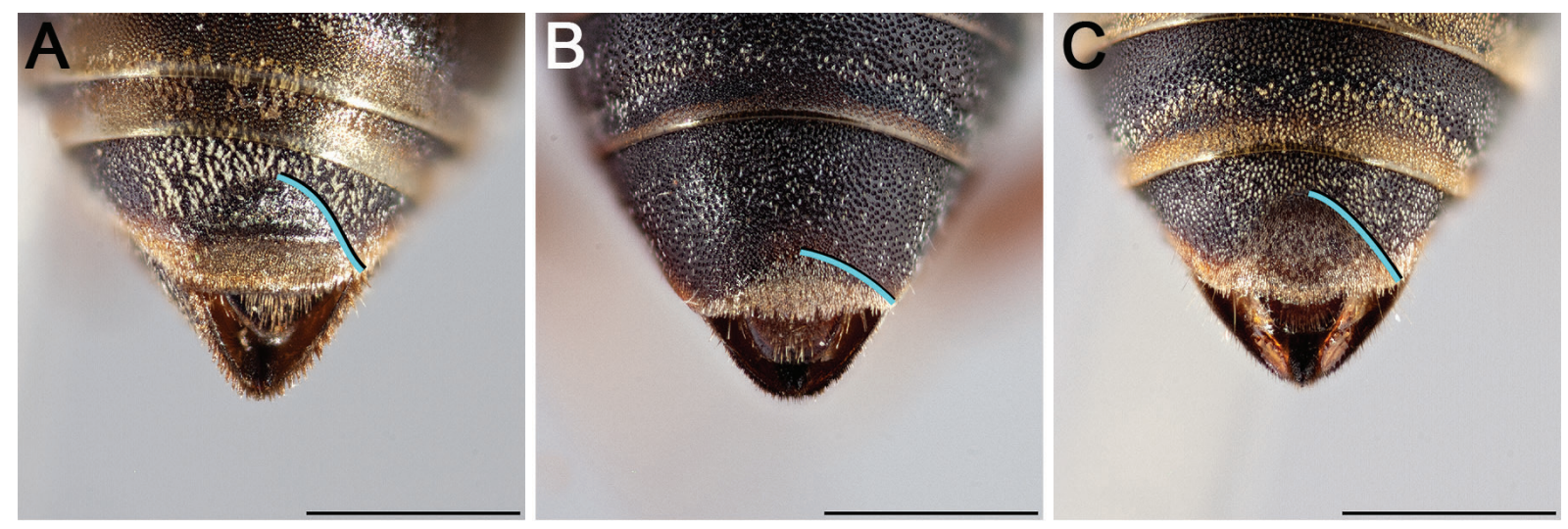

Fig. 12. Pseudopygidial area of female, dorsal view. A. E. fumipennis Say, 1837, which consists of a basal impressed triangular or semicircular portion covered in silvery short, appressed setae differentiated from a transverse band of coppery short, appressed setae along the posterior-facing apical margin of T5. B. E. bifasciatus Cresson, 1864, which is more than twice as wide as long. C. E. obscuripes Cockerell, 1917 stat. nov., which is not more than twice as wide as long. The pseudopygidial area is the apical portion of T5 that changes slope from the rest of the tergum and is covered in short, coppery or silvery hairs uniform in length (posteromesad the light blue lines). Scale bars $=1 \mathrm{~mm}$. 
bright to pale yellow short, appressed setae. Pronotal collar with tomentum uniformly pale yellow. Mesoscutum with paramedian band. Mesopleuron sparsely hairy, but tomentum dense ventrally as well as between two sparsely hairy patches (one beneath base of fore wing (hypoepimeral area), a larger circular patch occupying much of ventrolateral half of mesopleuron). Metanotum with tomentum uninterrupted, uniformly off-white. T1 with broad, medially narrowed bright yellow submedial fascia. T2 with complete bright yellow apical fascia, broadest medially and without anterolateral extensions. T3 and T4 with complete, pale yellow apical fasciae of slightly sparser tomentum. T5 with large, continuous patch of pale yellow tomentum bordering and contacting pseudopygidial area. T5 with pseudopygidial area lunate, its apex less than twice as wide as medial length, with basal impressed triangular portion covered in silvery short, appressed setae differentiated from transverse band of coppery short, appressed setae along posterior-facing apical margin. S5 with apical fimbria of coppery to silvery hairs extending beyond apex of sternum by $\sim 1 / 3$ MOD.

SuRfaCe SCULPTURE. Punctures dense. Labrum and clypeus with punctures equally dense (i<1d). Small impunctate shiny spot lateral to lateral ocellus. Mesoscutum, mesoscutellum and axilla very coarsely and densely rugose-punctate. Tegula densely punctate anteriorly and mesally $(i \leq 1 \mathrm{~d})$, sparsely punctate (i $>2$ d) to impunctate posteriorly and along margins. Mesopleuron with ventrolateral half densely punctate $(i \leq 1 \mathrm{~d})$, interspaces shining; mesopleuron with punctures more or less equally dense throughout. Metasomal terga with punctures very fine, dense (i $\approx 1 \mathrm{~d})$, evenly distributed on disc.

StRUCTURE. Preapical tooth forming right-angled triangle. Labral apex with three small denticles, lateral two each preceded by small discrete longitudinal ridge. Frontal keel strongly raised. Frontal area with pair of very discrete densely punctate protrusions, each located near upper mesal margin of compound eye. Head dorsally with pair of protrusions, each located where upper genal area meets vertexal area. Vertexal area strongly convex in frontal view. Scape with greatest length $1.5 \times$ greatest width. F2 noticeably longer than wide $(\mathrm{L} / \mathrm{W}$ ratio $=1.4-1.5)$. Preoccipital ridge separated from hypostomal carina by no less than 1 MOD. Pronotal collar rather short (medial length $\sim^{2 / 3}$ MOD), expanded laterally to about $2 \times$ medial length in dorsal view, and relatively straight along anterior margin. Mesoscutellum moderately bigibbous, depressed along posterior margin beneath overhanging ridge. Axilla large, its lateral margin more than half as long as mesoscutellar width $(\mathrm{AL} / \mathrm{MSCW}$ ratio $=0.6)$ and tip extending as far back as apex of horizontal dorsal portion of mesoscutellum; axilla with tip conspicuously diverging from side of mesoscutellum, distinctly hooked, and axilla with free portion $2 / 5$ its medial length; axilla with lateral margin relatively straight and carinate. Fore wing with three submarginal cells. Pygidial plate apically truncate.

\section{Male}

Description as for female except for usual secondary sexual characters and as follows: F2 shorter, not noticeably longer than wide $(\mathrm{L} / \mathrm{W}$ ratio $=1.1)$; pygidial plate apically rounded, with larger and deeper punctures, closely punctate basomedially and sparsely punctate apically and laterally, with interspaces shining; S3-S5 with much longer (>1 MOD), coppery to silvery subapical hairs, those of S4 and S5 curved.

\section{Distribution}

Central America and Mexico (Fig. 7E).

\section{Ecology}

Host records

Unknown. 


\section{Floral records \\ Unknown.}

\section{Remarks}

The specimen upon which Say's (1837) description is based was probably destroyed, along with most of Thomas Say's insect collection (LeConte 1859: v-vi, xix (footnote)). Mawdsley (1993) lists only four Hymenoptera specimens from Say's collection that are presently housed in the Harvard University Museum of Comparative Zoology in Cambridge, MA, USA, and all are ichneumonids. Personal searches through the collections of most $(20 / 28)$ of the entomological institutions listed in the Materials and Methods of Onuferko (2018a) did not turn up any specimens authoritatively identified as E. fumipennis. Nevertheless, the original description suggests a species of Epeolus in the 'Trophocleptria group' in which the mesoscutum has paramedian bands of pale tomentum, and among the examined Neotropical Epeolus specimens are several fitting such a description, and all appear to be conspecific. Morphological features suggesting a species within the 'Trophocleptria group' are as follows, quoted verbatim: "collar with a ferruginous disk, contracted in the middle", "tergum, first and second segments with a yellow band, the first broader and widely interrupted; remaining segments with a whitish band" and "the last segment with the addition of an obscure rufous terminal margin" (Say 1837). The last of these appears to describe the apical portion of the female pseudopygidial area, which is covered in coppery (rather than silvery) setae in the examined specimens that appear to be representatives of this species (Fig. 12A). According to Brumley (1965), who considered E. fumipennis to be within the 'Trophocleptria group', specimens at the Academy of Natural Sciences of Drexel University in Philadelphia, PA, USA and KUNHM that were collected from the Midwestern and Southeastern United States and identified as E. fumipennis are actually E. bifasciatus. Given that the taxonomic understanding of this species has been problematic, a re-description is warranted, and is based on all available representatives of this species. Although the sex upon which Say's (1837) original description is based was not stated, the description of the last metasomal segment suggests a female. Therefore, in the present redescription of the species (vide supra) a detailed description of the female is given, whereas the description of the male lists only key differences between the sexes.

Epeolus hanusiae sp. nov. urn:lsid:zoobank.org:act:D3322A0B-3133-4BA9-A752-F5009E03B1ED

Figs 1E, 2C, 5G, 7F, 13

\section{Proposed common name}

Anna's epeolus.

\section{Diagnosis}

The following morphological features in combination can be used to tell E. hanusiae sp. nov. apart from all other New World Epeolus except E. interruptus Robertson, 1900: the metanotum has a blunt median process (Fig. 13D) and T1 has a wide triangular discal patch with concave anterolateral sides (Fig. 13B). Whereas in E. interruptus each mesopleuron has sparser punctures ventrolaterally (many i $>1 d)$ than in the upper half and the axillae and mesoscutellum are usually entirely ferruginous, in E. hanusiae sp. nov. each mesopleuron is densely punctate throughout (most $\mathrm{i} \leq 1 \mathrm{~d}$ ) (Fig. 5G) and the axillae and mesoscutellum are entirely black. Epeolus hanusiae sp. nov. is also similar to E. tessieris in that in both species the mesoscutum has short paramedian bands, the axillae do not attain the midlength of the mesoscutellum and T1-T4 have medially interrupted apical fasciae. However, in E. tessieris the axillae and mesoscutellum are entirely ferruginous, the metanotum is flat, each mesopleuron has sparser punctures ventrolaterally (many $\mathrm{i}>1 \mathrm{~d}$ ) than in the upper half and $\mathrm{T} 1$ has a trapezoidal to nearly semicircular discal patch. 


\section{Etymology}

The specific epithet honors the author's sister, Hanusia (Anna) Onuferko, in gratitude for her support throughout this project. The noun is feminine and declined in the genitive case.

\section{Material examined}

\section{Primary type material}

MEXICO • , holotype; Jalisco, El Tigre; 18 Jul. 1954; J.W. MacSwain leg.; EMEC 1135889.

\section{Secondary type material}

MEXICO • 1 \%, paratype; Chihuahua, Cuiteco; 25 Jul. 1969; T.A. Sears, R.C. Gardner and C.S. Glaser leg.; UCBME • 1 § , paratype; Chihuahua, Matachic; 7 Jul. 1947; D. Rockefeller Exp., Michener leg.; AMNH • 1 क , paratype; Durango, Navíos (26 mi E of El Salto); Aug. 1964; L.A. Kelton leg.; CNC $754077 \cdot 1$ 1 , paratype; same collection data as for preceding; 2 Aug. 1964; L.A. Kelton leg.; CNC $754086 \bullet 1$ o , allotype; same collection data as for holotype; EMEC 1135885.

\section{DNA barcoded material with BIN-compliant sequences} Unavailable.
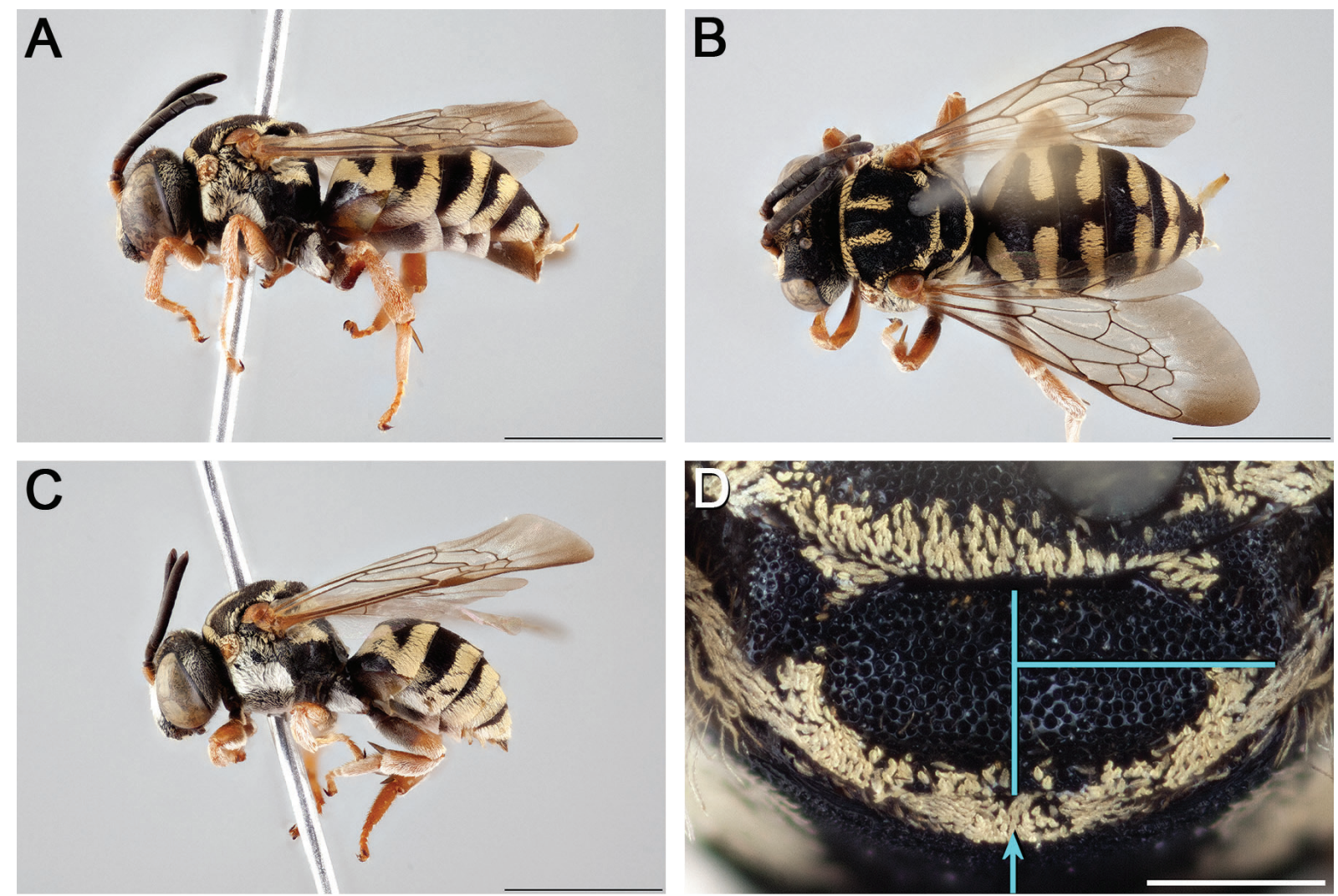

Fig. 13. Epeolus hanusiae sp. nov. A-B, D. Holotype, q (EMEC 1135889). C. Allotype, đ̊ (EMEC 1135885). A. Habitus, lateral view. B. Habitus, dorsal view. C. Habitus, lateral view. D. Axillae and mesoscutellum, dorsal view (blue arrow indicates blunt median process of metanotum; blue lines indicate the posterior extent of the axilla relative to the length of the mesoscutellum). Scale bars: $\mathrm{A}-\mathrm{C}=$ $3 \mathrm{~mm} ; \mathrm{D}=0.5 \mathrm{~mm}$. 


\section{Description}

\section{Female}

Measurements. Length $8.4 \mathrm{~mm}$; head length $2.1 \mathrm{~mm}$; head width $3.0 \mathrm{~mm}$; fore wing length $7.0 \mathrm{~mm}$.

INTEGUMENT COLORATION. Mostly black; notable exceptions as follows: partially to entirely ferruginous on mandible, labrum, antenna, pronotal lobe, tegula, legs and pygidial plate. Mandible with apex darker than all but extreme base; preapical tooth lighter than mandibular apex. Antenna brown except scape and F1 extensively orange. Pronotal lobe and tegula pale ferruginous to amber. Wing membrane subhyaline, apically dusky. Legs more extensively reddish orange than brown or black.

Pubescence. Face with tomentum densest around antennal socket. Tomentum slightly sparser on clypeus; upper paraocular and frontal areas and vertexal area mostly exposed. Dorsum of mesosoma and metasoma with bands of off-white and yellow short, appressed setae. Pronotal collar with tomentum uniformly yellow. Mesoscutum with paramedian band. Mesopleuron densely hairy, except for three sparsely hairy, circular patches (one below pronotal lobe, one behind pronotal lobe and a larger one occupying much of ventrolateral half of mesopleuron). Metanotum with tomentum uninterrupted, black laterally and pale yellow medially (uniformly pale yellow in allotype and multiple paratypes). T1 with discal patch very wide, basal and apical fasciae only narrowly joined laterally and in shape of rounded triangle with anterolateral sides concave. T1 with basal fascia interrupted medially, T1-T3 with apical fasciae interrupted medially and narrowed before becoming somewhat broader laterally, $\mathrm{T} 2$ fascia with anterolateral extensions of sparser tomentum. T4 with fascia narrowed medially. T5 with two large patches of pale tomentum lateral to and separate from pseudopygidial area, laterally with long, erect simple setae. T5 with pseudopygidial area lunate, its apex more than twice as wide as medial length, indicated by silvery setae on impressed disc of apicomedial region elevated from rest of tergum. S5 with apical fimbria of coppery to silvery hairs not extending beyond apex of sternum by much more than $1 / 4$ MOD.

SuRfaCe SCUlPtURE. Punctures dense. Labrum with larger punctures than clypeus, but punctures of both equally dense (i $\leq 1 \mathrm{~d})$. Small impunctate matte spot lateral to lateral ocellus. Mesoscutum, mesoscutellum and axilla coarsely and densely rugose-punctate. Tegula densely punctate mesally ( $i \leq 1 \mathrm{~d})$, less so laterally $(i=1-2 d)$. Mesopleuron with ventrolateral half densely punctate $(i \leq 1 d)$, interspaces shining; mesopleuron with punctures similar in size and more or less equally dense throughout. Metasomal terga with punctures very fine, dense ( $\mathrm{i} \approx 1 \mathrm{~d})$, evenly distributed on disc.

STRUCTURE. Preapical tooth forming right-angled triangle. Labrum with pair of small subapical denticles, each preceded by small discrete longitudinal ridge. Frontal keel not strongly raised. Head dorsally with pair of weak protrusions, each located where upper genal area meets vertexal area. Vertexal area weakly convex in frontal view. Scape with greatest length $1.8 \times$ greatest width. F2 noticeably longer than wide $(\mathrm{L} / \mathrm{W}$ ratio $=1.4)$. Preoccipital ridge separated from hypostomal carina by about 1.5-2 MOD (difficult to see in holotype; described from paratype). Pronotal collar short (medial length $\sim 1 / 2$ MOD) and convex along anterior margin. Mesoscutellum moderately bigibbous. Axilla small to intermediate in size, its lateral margin less than half as long as mesoscutellar width $(\mathrm{AL} / \mathrm{MSCW}$ ratio $=0.4)$ and tip not extending beyond midlength of mesoscutellum; axilla with tip distinctly pointed, but unattached to mesoscutellum for less than $2 / 5$ medial length of axilla; axilla with lateral margin relatively straight and without carina. Metanotum with blunt median process obscured by tomentum. Fore wing with three submarginal cells. Pygidial plate apically truncate. 


\section{Male}

Description as for female except for usual secondary sexual characters and as follows: F2 shorter, as long as wide $(\mathrm{L} / \mathrm{W}$ ratio $=1.0)$; pygidial plate apically rounded, with larger and deeper punctures, closely punctate throughout; S4 and S5 with much longer (>1 MOD), curved, coppery to silvery subapical hairs.

\section{Distribution}

Presently only known from western Mexico (Fig. 7F).

\section{Ecology}

\section{Host records}

Unknown.

\section{Floral records}

\section{Unknown.}

\section{Remarks}

Epeolus hanusiae sp. nov. and the very similar E. interruptus exhibit marked differences in mesosomal puncture density (see diagnosis). DNA barcode sequences are presently not available for E. hanusiae sp. nov., but the morphological difference is consistent, and the two forms are herein recognized as heterospecific. The ranges of the two species may overlap to some extent, but that of E. interruptus is much more extensive and includes most of the United States as well as southern Canada (Onuferko 2018a: fig. 62), whereas E. hanusiae sp. nov. is currently only known from a few sites in western Mexico along the Sierra Madre Occidental (Fig. 7F). In males of both species, the penis has a pair of short, fleshy lateral lobes, which are absent altogether in species within the 'Trophocleptria group' but more elongate in other New World Epeolus spp.

Epeolus luteipennis Friese, 1916

Figs 1F, 5C, 7C, 14, 27A

Epeolus luteipennis Friese, 1916: 335 (ㅇ, Љึ), new lectotype designation.

Epeolus xanthurus Cockerell, 1917: 298 (ठ઼), syn. nov.

Epeolus rugosus Cockerell, 1949: 459 (ㅇ), syn. nov.

\section{Proposed common name}

Yellow-winged epeolus.

\section{Diagnosis}

The following morphological features in combination can be used to tell E. luteipennis apart from all other Epeolus: the axillae are small to intermediate in size, not extending much beyond the midlength of the mesoscutellum (extending to $<2 / 3$ its length) but the free portion of each axilla is more than $1 / 4$ as long as its entire medial length, and the axillae (except sometimes their tips) and mesoscutellum are black (Fig. 14D); the mesoscutellum does not have a distinct ridge delineating its dorsal and posterior portions; T1 has only a complete or medially interrupted off-white to pale yellow basal fascia (Fig. 14A-B); and T2-T4 have complete bright to pale yellow apical fasciae (Fig. 14A-C). Epeolus luteipennis most closely resembles E. odyneroides sp. nov. and E. splendidus in terms of integument coloration, pubescence and structure. However, in E. odyneroides sp. nov. T1 lacks fasciae altogether, whereas in E. splendidus T1 has a complete bright yellow apical fascia as well as a complete white basal fascia, with little space in between. Also, in E. odyneroides sp. nov. each mesopleuron has sparser punctures ventrolaterally (many i $>1$ d) than in the upper half, whereas in E. luteipennis each mesopleuron is densely punctate throughout 
(most $\mathrm{i}<1 \mathrm{~d}$ ) (Fig. 5C). This species is also very similar in overall appearance to Triepeolus bilineatus Cockerell, 1949, Tri. cameroni (Meade-Waldo, 1913) and Tri. mexicanus (Cresson, 1878), but both sexes of E. luteipennis can easily be told apart from any similar-looking Triepeolus by the presence of a preapical tooth on each mandible; in all Triepeolus spp., the mandibles are simple (Rightmyer 2004).

\section{Material examined}

Primary type material

COSTA RICA • đ̂, E. luteipennis lectotype; San José, San José; 1903; Schmidt leg.; ZMB.

ECUADOR • ふै, E. xanthurus holotype; “Collection CF Baker”; USNM 534608.

HONDURAS • +, E. rugosus holotype; Francisco Morazán, Zamorano; 14 Jul. ????; Vidales leg.; USNM 534050.

\section{Secondary type material}

COSTA RICA $1 \hat{\jmath}$, E. luteipennis paralectotype; Alajuela, San Mateo; AMNH 25582.

DNA barcoded material with BIN-compliant sequences

Unavailable.

\section{Non-barcoded material}

COSTA RICA • 1 क; Cartago, Turrialba; 9 Jun. 1948; F. Schrader leg.; KUNHM SEMC1248314 • 1 ; ; same collection data as for preceding; 21 Jun. 1948; F. Schrader leg.; KUNHM SEMC1248315 • 1 đ̃; San José, Pérez Zeledón (San Isidro vicinity); 1 Feb.-12 Apr. 2001; T.H. Ricketts leg.; KUNHM SEMC1248325.

MEXICO • 1 क; ANSP • 1 q; Chiapas, Comitán; 20 Jul. 1969; L.A. Kelton leg.; CNC 754065・1 đ̊;

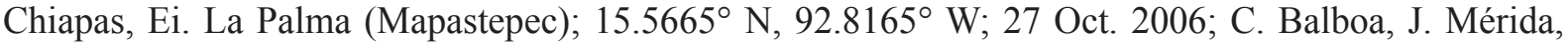
M. Guzmán, M. Cigarroa and J. Toto leg.; ECOSUR ECO-TAE-49935 1 +; Chiapas, Ei. Las Golondrinas (Acacoyagua); $15.2562^{\circ}$ N, $92.3880^{\circ}$ W; 29 Nov. 2004; M. Guzmán, M. Rincón, J. Esponda, C. Balboa

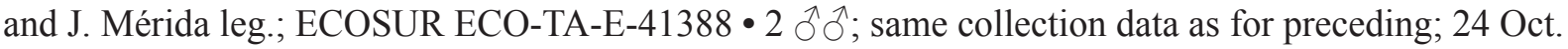
2006; C. Balboa, J. Mérida, M. Guzmán, M. Cigarroa and J. Toto leg.; ECOSUR ECO-TAE-49452, ECO-TAE-49453 • 1 ơ; Chiapas, Teopisca; 31 Jul. 1969; L.A. Kelton leg.; CNC 754066 • 2 우; Jalisco, Guadalajara; "8.10.??”; McClendon leg.; ANSP • 1 ô; Michoacán, Morelia; 25 Jun. 1957; J.A. Chemsak and B.J. Rannells leg.; EMEC 1135854 - 2 우; Morelos, 2 mi SW of Yautepec; 2 Jul. 1961; C.D. Michener leg.; KUNHM SEMC1247913, SEMC1247914 • 1 ơ; Veracruz, $10 \mathrm{~km} \mathrm{~N}$ of

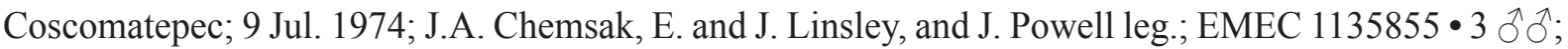
Veracruz, 7.1 km E of Huatusco; 16 Jul. 1990; R.L. Minckley leg.; KUNHM SM0735386, SM0735387, SM0735388 • 1 đ̄; Veracruz, S of Ixhuatlán (SE Huatusco); 17-18 Jul. 1990; I. Yarom leg.; BOLD sample ID: CCDB-28315 D04; KUNHM SEMC1248289.

PANAMA • 1 क; Panama Canal Zone Summit; Jan. 1947; N.L.H. Kraus leg.; EMEC 1135853 • 1 ð’; Chiriquí, $8 \mathrm{~km} \mathrm{~S}$ of Boquete; $8.6986^{\circ} \mathrm{N}, 82.4505^{\circ} \mathrm{W}$; 5-13 Jan. 2012; F.D. Parker and T.D. McIntyre leg.; BBSL FDP118503.

VENEZUELA • 1 क; Mérida, Valle de Culata; 23 Jul. 1988; C. Porter and L. Stange leg.; FSCA.

\section{Redescription}

Male

MEAsuREMENTs. Length $6.3 \mathrm{~mm}$; head length $1.7 \mathrm{~mm}$; head width $2.2 \mathrm{~mm}$; fore wing length $5.5 \mathrm{~mm}$. 
INTEGUMENT COLORATION. Mostly black; notable exceptions as follows: partially to entirely ferruginous on mandible, antenna, pronotal lobe, tegula, legs, metasomal terga (including pygidial plate) and metasomal sterna. Mandible with apex and preapical tooth darker than all but basal quarter (preapical tooth difficult to see in E. luteipennis lectotype because mandibles closed; described from non-type specimens). Antenna brown except F1 extensively orange. Pronotal lobe and tegula pale ferruginous to amber. Wing membrane subhyaline, apically dusky on anterior margin. Legs with brown or black more extensive than reddish orange.

Pubescence. Face with tomentum densest on clypeus and around antennal socket, sparser on upper paraocular area and vertexal area. Dorsum of mesosoma and metasoma with bands of off-white and bright yellow short, appressed setae. Pronotal collar with tomentum uniformly bright yellow. Mesoscutum with large anteromedial patch of bright yellow tomentum. Mesopleuron with upper half densely hairy, except beneath base of fore wing (hypoepimeral area); ventrolateral half sparsely hairy. Metanotum with tomentum uninterrupted, pale yellow laterally and black medially. T1 with broad, medially narrowed pale yellow basal fascia (medially interrupted in multiple non-type specimens). T2-T4 each with complete bright yellow apical fascia, T2 fascia without anterolateral extensions. S4 and S5 with long ( $>1$ MOD), curved, coppery to silvery subapical hairs, which are often darker apically.

SuRfaCe SCUlPtURE. Punctures dense. Labrum with larger and sparser punctures $(\mathrm{i}=1-2 \mathrm{~d})$ than clypeus $(\mathrm{i}<1 \mathrm{~d})$. Small impunctate shiny spot lateral to lateral ocellus. Mesoscutum, mesoscutellum and axilla coarsely and densely rugose-punctate. Tegula very densely punctate mesally $(i<1 d)$, less so laterally
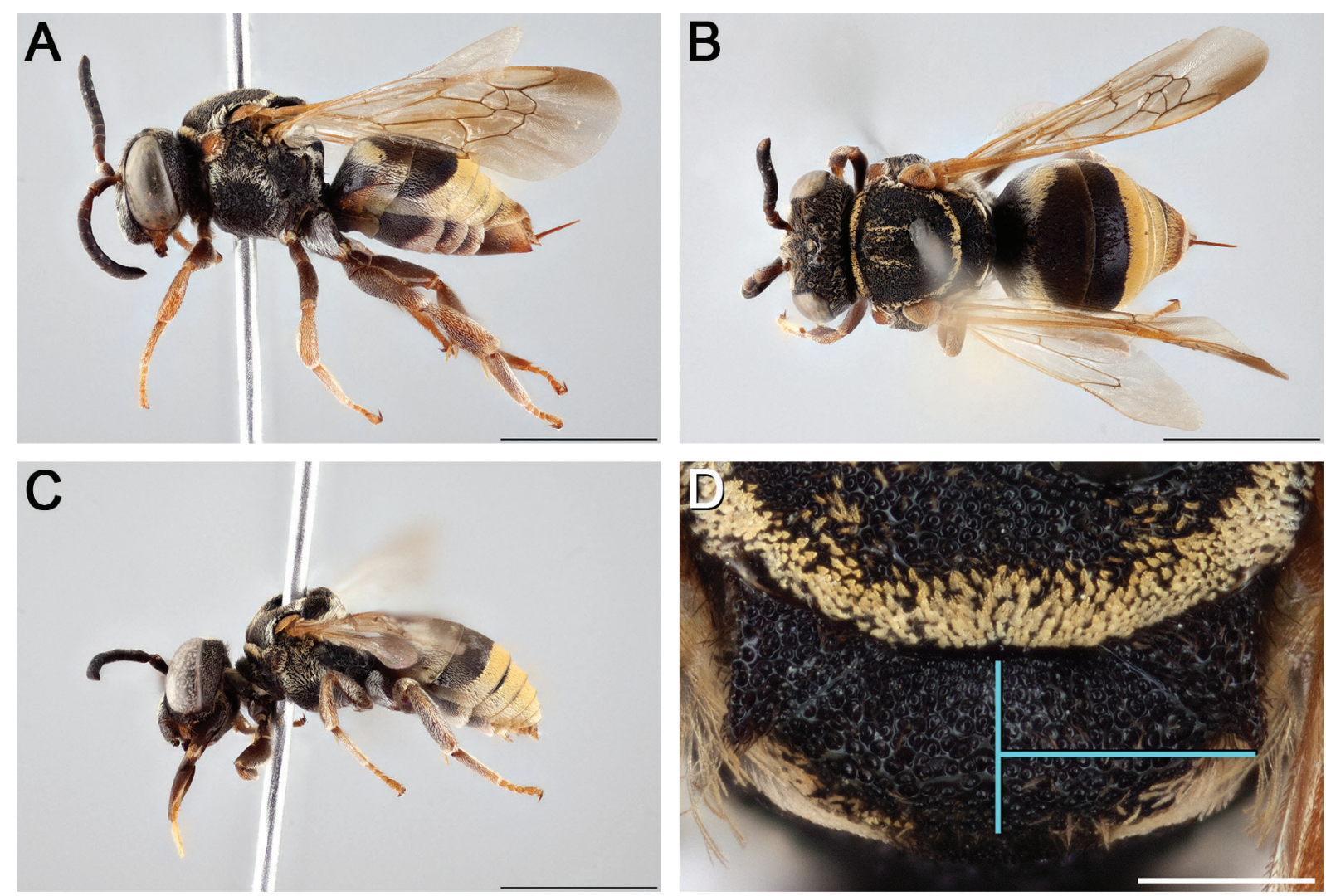

Fig. 14. Epeolus luteipennis Friese, 1916. A. Female, habitus, lateral view. B. Female, habitus, dorsal view. C. Male, habitus, lateral view. D. Female axillae and mesoscutellum, dorsal view (blue lines indicate the posterior extent of the axilla relative to the length of the mesoscutellum). Scale bars: $\mathrm{A}-\mathrm{C}=$ $3 \mathrm{~mm} ; \mathrm{D}=0.5 \mathrm{~mm}$. 
$(\mathrm{i}=1-2 \mathrm{~d})$. Mesopleuron with ventrolateral half coarsely and densely punctate (most $\mathrm{i}<1 \mathrm{~d}$ ) to rugose; mesopleuron with punctures similar in size and more or less equally dense throughout. Metasomal terga with punctures very fine, dense ( $\mathrm{i} \approx 1 \mathrm{~d})$, evenly distributed on disc. Pygidial plate with large, deep punctures more or less evenly spaced throughout, with interspaces shining.

STRUCTURE. Preapical tooth acute. Labrum with pair of small subapical denticles not preceded by carinae. Frontal keel not strongly raised. Vertexal area weakly convex in frontal view. Scape with greatest length $1.8 \times$ greatest width. F2 as long as wide $(\mathrm{L} / \mathrm{W}$ ratio $=1.0)$. Preoccipital ridge separated from hypostomal carina by about 1.5 MOD. Pronotal collar short (medial length $\sim 1 / 2 \mathrm{MOD}$ ) and convex along anterior margin. Mesoscutellum moderately bigibbous. Axilla small to intermediate in size, its lateral margin less than half as long as mesoscutellar width $(\mathrm{AL} / \mathrm{MSCW}$ ratio $=0.4)$ and tip not extending beyond midlength of mesoscutellum; axilla with tip distinctly pointed, but unattached to mesoscutellum for less than $2 / 5$ medial length of axilla; axilla with lateral margin relatively straight and without carina. Fore wing with three submarginal cells. Pygidial plate apically rounded.

\section{Female}

Description as for male except for usual secondary sexual characters and as follows: F2 slightly but not noticeably longer than wide $(\mathrm{L} / \mathrm{W}$ ratio $=1.1)$; T5 with large, continuous patch of bright yellow tomentum bordering and separate from pseudopygidial area present only in female; T5 with pseudopygidial area lunate, its apex more than twice as wide as medial length, indicated by silvery setae on impressed disc of apicomedial region elevated from rest of tergum; pygidial plate apically truncate, with smaller, denser punctures; S4 and S5 with straight and much shorter hairs (S5 with apical fimbria of coppery to silvery hairs extending beyond apex of sternum by $\sim 1 / 3 \mathrm{MOD}$ ).

\section{Distribution}

Central America, Mexico and northwestern South America (Fig. 7C). This is the only species of Epeolus outside of the 'Trophocleptria group' that has been recorded from South America.

\section{Ecology}

\section{Host records}

Unknown.

\section{Floral records}

Unknown.

\section{Remarks}

Friese (1916) described E. luteipennis from both sexes but provided a more complete description of the male. For this reason, and since only male syntypes were examined in the present study, a male is herein designated as the lectotype, and is the specimen upon which the redescription of the male of this species is based. Below what is presumed to be Heinrich Friese's original type label for this specimen, which simply says "Type", is a label that says "LECTOTYPE" and "desig. Melo, 2016". Since Melo's (2016) lectotype designations of Friese's Neotropical Epeolus types cannot be traced to any publication, the designation for E. luteipennis is made herein instead. Ferrari (2017) cites personal communication with G. Melo regarding the addition of the latter's lectotype label to another of Friese's syntype specimens (in this case Colletes nigritulus Friese, 1910), with 2015 given as the year of the designation, indicating that the designation (at that time) remained to be published.

Moure et al. (2007) list E. xanthurus as a possible synonym of Triepeolus buchwaldi (Friese, 1908), an outwardly very different species. I have examined the holotype of E. xanthurus, a male, which except for its larger size (length $7.9 \mathrm{~mm}$ ) agrees with the present redescription based on the lectotype 
of E. luteipennis. Moure et al. (2007) also list E. rugosus as the original name under which Triepeolus rugosus (Cockerell, 1949) was published, but the name Tri. rugosus refers to a different species from Eastern North America, described by Mitchell (1962). The holotype of E. rugosus, a female, exhibits the following features typical of its genus, Epeolus: the pseudopygidial area is lunate, its apex is more than twice as wide as its medial length and covered in short, silvery hairs, and the apices of the processes of S6 are convergent, spatulate and bear setae modified into pointed denticles. The holotype of E. rugosus too is larger (length $8.3 \mathrm{~mm}$ ) than the lectotype of E. luteipennis, but otherwise there are very few morphological differences among the three primary type specimens, which are understood herein to be conspecific.

Although BIN-compliant sequences are presently not available for E. luteipennis, a partial sequence $421 \mathrm{bp}$ in length is available for a male specimen from the Mexican state of Veracruz, which does not cluster closely with any sequences from other Epeolus species in a NJ tree of sequences $>200 \mathrm{bp}$ in length (minimum distance $=4.2 \%$, Supplementary File 3 ).

Epeolus niger (Michener, 1954)

Figs $1 \mathrm{G}, 5 \mathrm{~B}, 7 \mathrm{G}, 15$

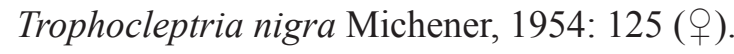

\section{Proposed common name}

Black epeolus.

\section{Diagnosis}

Together with the morphological features that are diagnostic for the 'Trophocleptria group', the following in combination can be used to tell E. niger apart from all other Epeolus: there is no large tooth laterally near the base of each axilla (Fig. 15D); the mesoscutellum does not have a pair of posteriorly directed teeth (Fig. 15D); the mesopleura are finely punctate, each with punctures more or less equally dense throughout (few $\mathrm{i} \geq 2 \mathrm{~d}$ ) (Fig. 5B); and the metasomal terga lack pale pubescence (Fig. 15A-C). Epeolus niger most closely resembles E. claripennis in that both species are almost entirely black and at least the fore wings of females are deeply infuscate basally and (unusually for Epeolus) clear apically, but in E. claripennis there is a large tooth laterally near the base of each axilla, the mesoscutellum has a pair of posteriorly directed teeth and the mesopleura are more coarsely punctate, each with sparser punctures ventrolaterally (many $\mathrm{i} \geq 2 \mathrm{~d}$ ) than in the upper half, with interspaces dull due to tessellate surface microsculpture.

\section{Material examined}

Primary type material

PANAMA • + , Tro. nigra holotype; Chiriquí, El Volcán Chiriquí; 29 Feb. 1936; F.E. Lutz leg.; AMNH AMNH_IZC 00324260 .

\section{Secondary type material}

PANAMA • 1 §, Tro. nigra allotype; Chiriquí, El Volcán Chiriquí; 23 Feb. 1936; F.E. Lutz leg.; AMNH AMNH_IZC 00324261.

DNA barcoded material with BIN-compliant sequences

Unavailable. 


\section{Non-barcoded material}

COSTA RICA • 1 q; Alajuela, Alajuela? (Eladio's, river trail); 19 May 1989; J. Ashe, R. Leschen and R. Brooks leg.; KUNHM SEMC1248345 • 3 우; Alajuela, Peñas Blancas; Apr. 1987; E. Cruz leg.; RAM 1 ô; Guanacaste, Volcan Cacao Station (Guanacaste National Park); 13 Feb. 1995; L.S. Kimsey leg.; UCBME.

\section{Redescription}

\section{Female}

MeAsurements. Length $8.0 \mathrm{~mm}$; head length $2.1 \mathrm{~mm}$; head width $2.7 \mathrm{~mm}$; fore wing length $8.1 \mathrm{~mm}$.

INTEGUMENT COLORATION. Mostly dark brown to black; notable exceptions as follows: at least partially ferruginous on mandible, antenna, pronotal collar, tegula, mesopleuron and legs. Mandible with apex darker than rest of mandible; preapical tooth lighter than mandibular apex (difficult to see in holotype because mandibles closed; described from non-type specimen). Antenna brown except scape, pedicel and F1 extensively orange. Wing membrane subhyaline, basally dusky. Legs with brown or black more extensive than reddish orange.

PubesCENCE. Face with tomentum densest around antennal socket. Clypeus, upper paraocular and frontal areas, and vertexal area mostly exposed. Pronotal collar with narrow band of ferruginous short, appressed setae along posterior margin. Mesoscutum with some ferruginous short, appressed setae along posterior margin. Mesopleuron nearly bare, except along margins. Metanotum with tomentum sparser medially, uniformly light brown/pale ferruginous. Dorsum of metasoma without bands of pale tomentum. T5
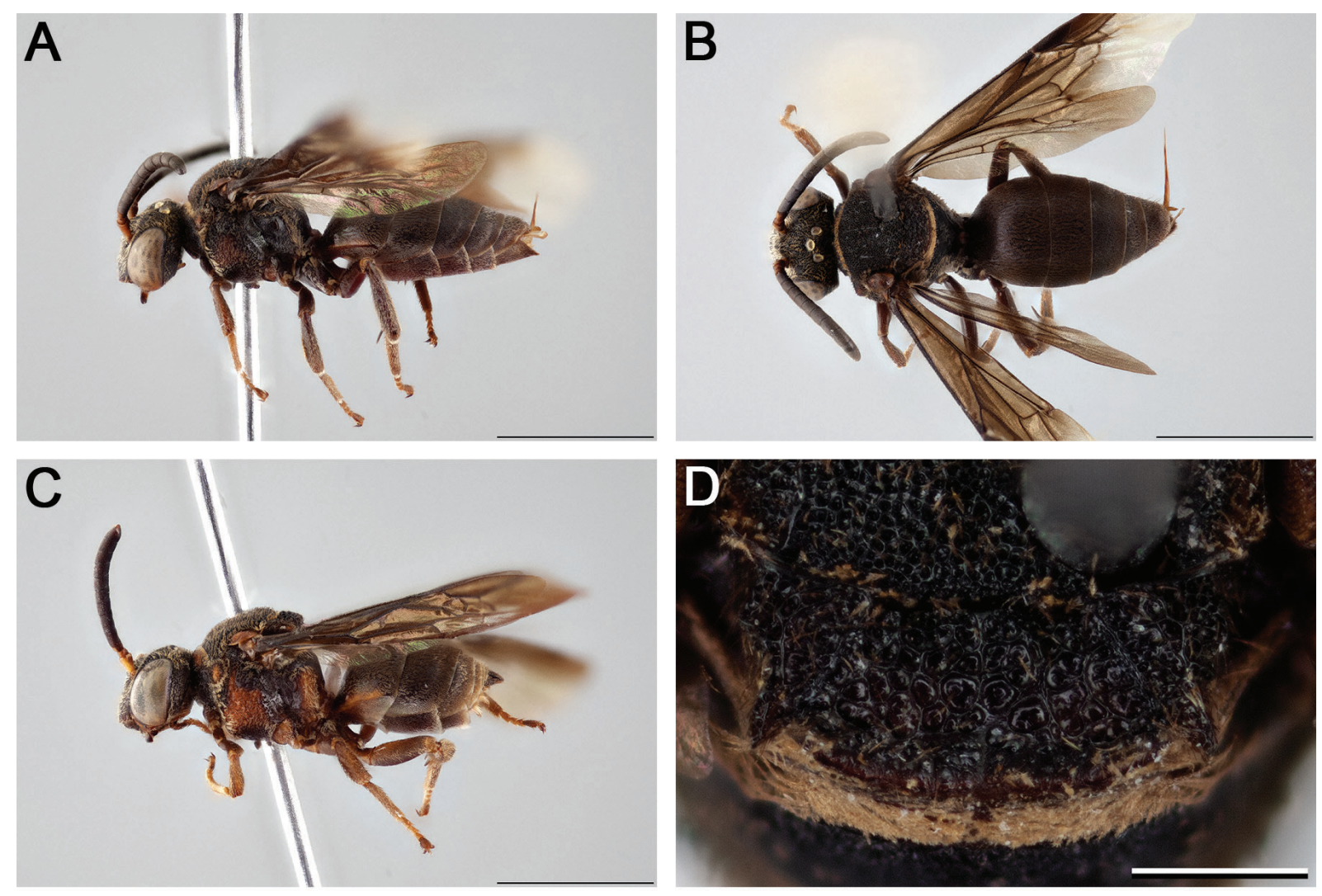

Fig. 15. Epeolus niger (Michener, 1954). A. Female, habitus, lateral view. B. Female, habitus, dorsal view. C. Male, habitus, lateral view. D. Female axillae and mesoscutellum, dorsal view. Scale bars: $\mathrm{A}-\mathrm{C}=3 \mathrm{~mm} ; \mathrm{D}=0.5 \mathrm{~mm}$. 
laterally with long, erect simple setae. T5 with pseudopygidial area lunate, its apex more than twice as wide as medial length, indicated by silvery setae on disc of apicomedial region elevated from rest of tergum. S5 with apical fimbria of coppery to silvery hairs extending beyond apex of sternum by $\sim 1 / 2$ MOD.

SURFACE SCULPTURE. Punctures dense. Labrum with larger and sparser punctures (many $i \geq 1 \mathrm{~d}$ ) than clypeus $(\mathrm{i}<1 \mathrm{~d})$. Small impunctate dull/textured spot lateral to lateral ocellus. Mesoscutum, mesoscutellum and axilla very coarsely and densely rugose-punctate. Tegula densely punctate anteriorly and mesally $(i \leq 1 d)$, sparsely punctate (i>2d) to impunctate posteriorly and along margins. Mesopleuron with ventrolateral half densely punctate $(i \leq 1 d)$, interspaces dull due to tessellate surface microsculpture; mesopleuron with punctures more or less equally dense throughout. Metasomal terga with punctures very fine, dense ( $\approx \approx 1 d$ ), evenly distributed on disc.

Structure. Preapical tooth acute. Labral apex with pair of small denticles (separated by shallow concavity), each preceded by small, discrete longitudinal ridge. Frontal keel strongly raised. Frontal area with pair of discrete, sparsely punctate, granulose protrusions, each located near upper mesal margin of compound eye. Head dorsally with pair of protrusions, each located where upper genal area meets vertexal area. Vertexal area strongly convex in frontal view. Scape with greatest length $1.4 \times$ greatest width. F2 noticeably longer than wide $(\mathrm{L} / \mathrm{W}$ ratio $=1.4)$. Preoccipital ridge separated from hypostomal carina by no less than 1 MOD. Pronotal collar rather short (medial length $\sim 2 / 3 \mathrm{MOD}$ ), expanded laterally to about $2 \times$ medial length in dorsal view, and relatively straight along anterior margin. Mesoscutellum moderately bigibbous, depressed along posterior margin beneath overhanging ridge. Axilla large, its lateral margin more than half as long as mesoscutellar width $(\mathrm{AL} / \mathrm{MSCW}$ ratio $=0.6)$ and tip extending as far back as apex of horizontal dorsal portion of mesoscutellum; axilla with tip conspicuously diverging from side of mesoscutellum, distinctly hooked, and axilla with free portion between $1 / 3$ and $2 / 5$ its medial length; axilla with lateral margin relatively straight and carinate. Mesopleuron with weak carina delineating its anterior and lateral surfaces. Fore wing with three submarginal cells. Pygidial plate apically rounded.

\section{Male}

Description as for female except for usual secondary sexual characters and as follows: F2 shorter, not noticeably longer than wide $(\mathrm{L} / \mathrm{W}$ ratio $=1.1)$; wing membrane dusky throughout; pygidial plate with larger and deeper punctures, closely punctate throughout; S4 and S5 with much longer ( $>1$ MOD), curved coppery to silvery subapical hairs.

\section{Distribution}

Previously known only from Panama, herein newly reported from Costa Rica (Fig. 7G).

\section{Ecology}

Host records

Unknown.

\section{Floral records}

Unknown.

\section{Remarks}

Epeolus niger exhibits unusual sexual dimorphism in that in females the fore wings are only deeply infuscate basally, whereas in males the wings are infuscate throughout. The extensive black coloration and apically clear fore wings of this species and E. claripennis give both the distinctive appearance of Parachartergus. These features are also shared with various tropical stingless bees (e.g., Trigona spp.), 
some of which are known to be in mimetic complexes that include a diversity of aculeates, including other bees (Smith-Pardo 2005), and even non-hymenopterous insects such as flower flies (Diptera: Syrphidae) (Reemer 2013).

In addition to the examined material, this species is known from another four specimens from Panama (Michener 1954). Thus, E. niger appears to be uncommon, or at least uncommonly collected, compared to the similar-looking but much more widely distributed species E. claripennis. Based on known records, adults of E. niger are active between February and May.

Epeolus nomadiformis sp. nov. urn:lsid:zoobank.org:act:905E8BD4-657C-4323-A2F4-A08B30F3484E

Figs $7 \mathrm{H}, 16$

\section{Proposed common name}

Nomadiform epeolus.

\section{Diagnosis}

Together with the morphological features that are diagnostic for the 'Trophocleptria group', the following in combination can be used to tell E. nomadiformis sp. nov. apart from all other Epeolus: the axillae are crenulate along the lateral margin, each with a large tooth near the base (Fig. 16D); the mesoscutellum has a pair of posteriorly directed teeth (Fig. 16D); the mesopleura are coarsely punctate, each with sparser punctures ventrolaterally (many $\mathrm{i} \geq 2 \mathrm{~d}$ ) than in the upper half, with interspaces smooth and shining; the fore wings are deeply infuscate apically (Fig. 16A-C); T1 has only a broad, medially narrowed or interrupted bright to pale yellow basal fascia (Fig. 16A-B); T2 has a complete bright to pale yellow apical fascia (Fig. 16A-B); and the remaining terga lack fasciae (Fig. 16A-C), although the apical impressed areas occasionally have sparse, off-white hairs. In overall appearance, this species is more nomadiform than epeoliform (sensu Michener 2007). Epeolus nomadiformis sp. nov. most closely resembles E. boliviensis and E. fulvopilosus, but in E. boliviensis T1 lacks a basal fascia, although a subapical fascia is present, which is usually narrower than the T2 apical fascia, and in E. fulvopilosus $\mathrm{T} 3$ and $\mathrm{T} 4$ are distinctly fasciate.

\section{Etymology}

The specific epithet is derived from 'Nomada', a genus of cleptoparasitic bees similar in overall appearance to this particular species of Epeolus. The Latin suffix -formis means 'having the form of'.

\section{Material examined}

\section{Primary type material}

MEXICO • +, holotype; Veracruz, S Ixhuatlán (SE Huatusco); 17-18 Jul. 1990; I. Yarom leg.; KUNHM SEMC1248290.

\section{Secondary type material}

BELIZE • 1 क , paratype; Stann Creek, Middlesex; 18 Mar. 1965; E.C. Welling leg.; CNC 754064 1 q, paratype; same collection data as for preceding; 7 Apr. 1965; E.C. Welling leg.; CNC 754063.

MEXICO • 1 9, paratype; Nuevo León, Cola de Caballo; 19 Jun. 1975; H.V. Weems Jr. leg.; FSCA - 1 ㅇ, paratype; Quintana Roo, 12 km NW of Reforma; 14 Oct. 1986; C.D. Michener leg.; KUNHM SEMC1247933 • 1 क , paratype; Veracruz, El Desengaño (El Mirador); $19.2101^{\circ} \mathrm{N}, 96.8966^{\circ} \mathrm{W}$; 26 Jul. 2006; M. Bonet leg.; BOLD sample ID: CCDB-28238 B01; BBSL 0000003960 • 1 q, paratype; Veracruz, Estación de Biología Los Tuxtlas (33 km NE of Catemaco); 1 Jul.-1 Aug. 1983; S. and J. Peck leg.; RAM. 


\section{DNA barcoded material with BIN-compliant sequences}

Unavailable.

\section{Description}

\section{Female}

MeAsurements. Length $8.5 \mathrm{~mm}$; head length $2.1 \mathrm{~mm}$; head width $2.5 \mathrm{~mm}$; fore wing length $7.5 \mathrm{~mm}$.

INTEGUMENT COLORATION. Mostly black; notable exceptions as follows: at least partially ferruginous on mandible, labrum, antenna, pronotal collar, pronotal lobe, tegula, axilla, mesoscutellum, metanotum, mesopleuron, propodeum, legs and pygidial plate. Mandible with apex darker than all but extreme base; preapical tooth lighter than mandibular apex. Antenna brown except scape, pedicel and F1 extensively orange. Pronotal collar, pronotal lobe and tegula pale ferruginous to amber. Wing membrane dusky subhyaline, slightly darker at apex. Legs with brown or black more extensive than reddish orange.

Pubescence. Face with tomentum densest around antennal socket. Clypeus, upper paraocular and frontal areas, and vertexal area mostly exposed. Pronotal collar and dorsum of metasoma with bright to pale yellow short, appressed setae. Mesoscutum without pale tomentum, except for small patch between tegula and axilla. Mesopleuron nearly bare, except along margins. Metanotum with tomentum uninterrupted, uniformly pale yellow. T1 with broad, medially interrupted pale yellow basal fascia. T2 with complete bright yellow apical fascia, broadest medially and without anterolateral extensions. Metasoma otherwise without fasciae. T5 laterally with long, erect simple setae. T5 with pseudopygidial area lunate, its apex
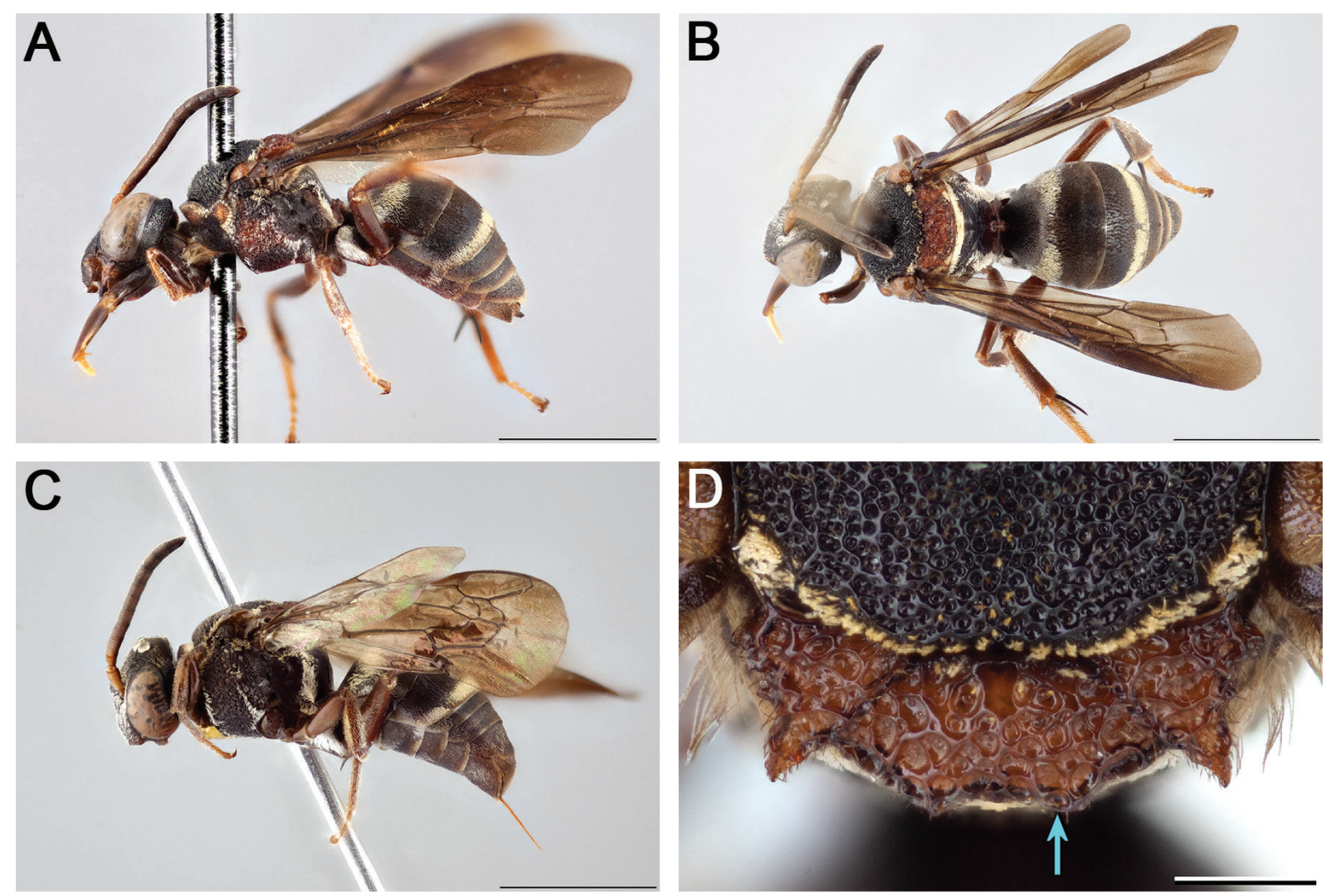

Fig. 16. Epeolus nomadiformis sp. nov., 우. A-B. Holotype, (KUNHM SEMC1248290). A. Habitus, lateral view. B. Habitus, dorsal view. C-D. Paratype, (CNC 754064). C. Habitus, lateral view. D. Axillae and mesoscutellum, dorsal view (blue arrow indicates one of two posteriorly directed tooth-like projections of mesoscutellum). Scale bars: $A-C=3 \mathrm{~mm} ; \mathrm{D}=0.5 \mathrm{~mm}$. 
twice as wide as medial length, indicated by silvery setae on impressed disc of apicomedial region elevated from rest of tergum. S5 with apical fimbria of coppery to silvery hairs extending beyond apex of sternum by $\sim 1 / 2$ MOD.

Surface sculpture. Punctures dense, but those of head and mesosoma sparser in some areas, larger, deeper and more distinct. Labrum with areas of sparser punctures ( $i>1 d)$ than clypeus $(i<1 d)$. Small impunctate matte spot lateral to lateral ocellus. Mesoscutum, mesoscutellum and axilla very coarsely and densely rugose-punctate. Tegula densely punctate anteriorly and mesally ( $i \leq 1 \mathrm{~d})$, sparsely punctate $(\mathrm{i}>2 \mathrm{~d})$ to impunctate posteriorly and along margins. Mesopleuron with denser $(i<1 \mathrm{~d})$ punctures in upper half than ventrolateral half $(\mathrm{i} \leq 2 \mathrm{~d})$, interspaces shining though with some coriarious surface miscrosculpture; mesopleuron with punctures similar in size throughout. Metasomal terga with punctures very fine, dense (i $\approx 1 \mathrm{~d}$ ), evenly distributed on disc.

Structure. Preapical tooth acute. Labral apex with pair of small denticles (separated by shallow concavity) not preceded by carinae. Frontal keel strongly raised. Frontal area with pair of discrete, sparsely punctate granulose protrusions, each located near upper mesal margin of compound eye. Head dorsally with pair of prominent protrusions, each located where upper genal area meets vertexal area. Vertexal area strongly convex in frontal view. Scape with greatest length $1.5 \times$ greatest width. F2 noticeably longer than wide $(\mathrm{L} / \mathrm{W}$ ratio $=1.4)$. Preoccipital ridge separated from hypostomal carina by no less than 1 MOD. Pronotal collar elongate (medial length $\sim 1$ MOD), expanded laterally to about $2 \times$ medial length in dorsal view and relatively straight along anterior margin. Mesoscutellum weakly bigibbous, depressed along posterior margin beneath distinct overhanging ridge produced to pair of posteriorly directed teeth. Axilla large, its lateral margin more than half as long as mesoscutellar width (AL/MSCW ratio $=0.7$ ) and tip extending as far back as apex of horizontal dorsal portion of mesoscutellum; axilla with tip conspicuously diverging from side of mesoscutellum, distinctly hooked, and axilla with free portion $2 / 5$ its medial length; axilla with lateral margin crenulate, with large tooth near base, and carinate but relatively straight. Mesopleuron with carina delineating its anterior and lateral surfaces. Fore wing with three submarginal cells. Pygidial plate apically truncate.

\section{Male \\ Unknown.}

\section{Distribution}

Central America and Mexico (Fig. 7H).

\section{Ecology}

\section{Host records}

Unknown.

\section{Floral records}

The label of one examined voucher specimen indicates a floral association with Bidens pilosa L. (Asteraceae).

\section{Remarks}

Females of Epeolus nomadiformis sp. nov. differ from those of E. fulvopilosus only in the absence of yellow tomentum along the midline of the mesoscutum and fasciae on T3 and T4. Otherwise, the two forms are virtually identical. The male of $E$. nomadiformis sp. nov. is presently unknown, and the only male of E. fulvopilosus was identified as such in part because it has pale yellow apical fasciae on T3 and T4 (Fig. 10C). Another species within the 'Trophocleptria group', Epeolus obscuripes, exhibits continuous variation in the density of hairs on the apical impressed areas of T3 and T4; at one extreme 
the hairs are as dense as those on the preceding terga, whereas at the other they are virtually absent. Moreover, sequenced representatives of the two forms (with and without fasciae on T3 and T4) share the same BIN, further justifying their treatment as a single species. By contrast, in E. fumipennis, another species within the 'Trophocleptria group', T3 and T4 (as well as T1 and T2) are always fasciate in both sexes.

Presently, no intermediates are known between E. fulvopilosus and the form that lacks fasciae on T3 and T4. DNA barcode sequences are presently not available for E. fulvopilosus, but a partial sequence $297 \mathrm{bp}$ in length is available for a female specimen of what is herein considered to be E. nomadiformis sp. nov., from Veracruz (state), Mexico, which is most similar (99.7\%) to the single BIN-compliant sequence available for E. claripennis (a visibly different bee, see Figs 8, 16), obtained from a male specimen from San José Province, Costa Rica. Given the low level of genetic divergence between these two morphologically very different forms, it is unclear whether DNA barcodes would be helpful in differentiating E. nomadiformis sp. nov. from E. fulvopilosus, to which E. nomadiformis sp. nov. is even more similar. However, a lack of barcode sequence divergence would not necessarily mean that the different forms are conspecific anyway, as it is not uncommon in bees to have merged BINs with multiple species. For example, Gibbs (2017) found that 43 out of the 110 species of the Lasioglossum Curtis, 1833 subgenus Dialictus Robertson, 1902 (Hymenoptera: Halictidae) for which barcode data were examined were not assigned separate BINs, but all are considered valid and diagnosable using morphological features. Similarly, Packer \& Ruz (2017) found no barcode sequence differentiation between two species of Chilicola Spinola, 1851 subgenus Chilioediscelis Toro \& Moldenke, 1979 despite considerable morphological differences between them in both sexes and their not being sister taxa in a morphology-based phylogeny (Willis \& Packer 2007). Hence, in the absence of intermediates and since at this time there is no genetic evidence suggesting that the distinctly yellow-banded form, known as E. fulvopilosus, and that which consistently exhibits reduced mesosomal and metasomal pubescence are the same species, I have opted to treat them as heterospecific, and herein newly describe the latter under the name E. nomadiformis sp. nov.

Epeolus obscuripes Cockerell, 1917 stat. nov.

Figs 1H, 4B, 7I, 12C, 17

Epeolus bifasciatus obscuripes Cockerell, 1917: 298 (さ).

Epeolus schmidti Friese, 1925: 32 (ㅇ, đ)), new lectotype designation, syn. nov.

\section{Proposed common name}

Dark-legged epeolus.

\section{Diagnosis}

Together with the morphological features that are diagnostic for the 'Trophocleptria group', the following in combination can be used to tell E. obscuripes apart from all other Epeolus except E. bifasciatus: the mesoscutum lacks paramedian bands; the axillae are smooth (i.e., not crenulate) along the lateral margin (Fig. 17D); the mesoscutellum does not have a pair of posteriorly directed teeth (Fig. 17D); the mesopleura are coarsely punctate, each with smaller and sparser punctures ventrolaterally (many $\mathrm{i} \geq 1 \mathrm{~d}$ ) than in the upper half, with interspaces smooth and shining; T1 has only a broad, medially narrowed or interrupted, bright to pale yellow basal fascia (Fig. 17A-C); and T2 has a complete, bright to pale yellow apical fascia (Fig. 17A-C). Whereas in E. bifasciatus the frontal area has a pair of pronounced granulose protrusions, the pseudopygidial area of the female is very wide (the apex $>2 \times$ the medial length), only $\mathrm{T} 1$ and $\mathrm{T} 2$ of the male are distinctly fasciate, and the pronotal collar, pronotal lobes, axillae and mesoscutellum are entirely ferruginous, in E. obscuripes the frontal area typically has only a pair of weak protrusions, which are virtually lacking in some specimens, the pseudopygidial area of 
the female is more elongate medially (the apex $\leq 2 \times$ the medial length), T3-T6 of the male typically have well-developed bright to pale yellow fasciae, and the pronotal collar, pronotal lobes, axillae and mesoscutellum range from entirely black to entirely ferruginous. Epeolus obscuripes is also similar to E. fumipennis in that in males of both species T1-T6 are typically fasciate. However, in E. fumipennis the mesoscutum has a pair of well-defined paramedian bands, the axillae are longer, extending as far back as or beyond the ridge overhanging the depressed posterior margin of the mesoscutellum, and T1 has a broad, medially narrowed bright to pale yellow submedial fascia. Despite the specific epithet 'obscuripes', meaning dark foot in Latin, the color of the legs does not reliably distinguish this species from $E$. bifasciatus, which may also have dark brown to black legs.

\section{Material examined}

Primary type material

COSTA RICA • Õ, E. schmidti lectotype; San José, San José; May 1922; Schmidt leg.; ZMB.

MEXICO • ^ે, E. bifasciatus obscuripes holotype; Veracruz, Medellín; “H. H. Hyde ; Baker coll. 1785”; USNM 534041.

\section{Secondary type material}

COSTA RICA • 1 q, E. schmidti lectoallotype; Alajuela, San Mateo; May 1922; Schmidt leg.; ZMB.

\section{DNA barcoded material with BIN-compliant sequences}

Available. BOLD:ACW1534. Specimens examined and sequenced:

MEXICO • 1 đ̧; Jalisco, San José del Carmen; 10 Oct. 2008; L. Packer leg.; BOLD sample ID: CCDB28238 A08; PCYU • 1 q; Oaxaca, S of San Sebastián Frontera; $18.2163^{\circ}$ N, $97.6466^{\circ}$ W; 25 Sep. 2008; L. Packer leg; BOLD sample ID: CCDB-22014 C06; PCYU • 1 q; Sonora, Rancho Fundición (30 km E of Álamos); $27.0183^{\circ} \mathrm{N}, 108.7483^{\circ} \mathrm{W} ; 3$ Oct. 2006; M.E. Irwin leg.; BOLD sample ID: CCDB28239 G08; BBSL FDP124693.

\section{Non-barcoded material}

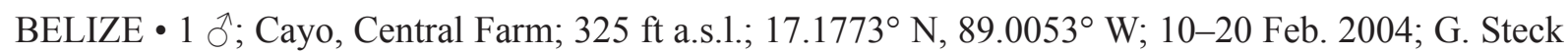

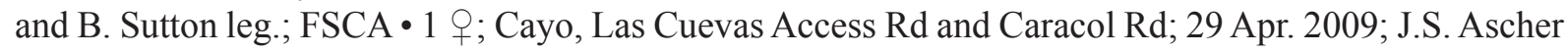
leg.; AMNH AMNH_IZC 00290833.

COSTA RICA • 1 \%; Puntarenas, Las Cruces; 25 Aug. 1977; T.P. Cogley leg.; FSCA.

EL SALVADOR • 1 đ; La Libertad, Mount San Salvador; 8 Jul. 1963; M.E. Irwin and D.Q. Cavagnaro leg.; EMEC 1135879.

GUATEMALA • 1 q; Alta Verapaz, 5 km W of Purulhá; 11 Oct. 2005; J.B. Heppner leg.; FSCA.

HONDURAS • 1 +; Cortés, Estación Experimental Café (ca. Peña Blanca rainforest); 15 Aug. 1992; C. Porter and L. Stange leg.; FSCA • 1 đ̃; Santa Bárbara, La Fé, Finca La Roca (5.3 km S of Peña Blanca); $14.9500^{\circ} \mathrm{N}, 88.0333^{\circ} \mathrm{W} ; 21$ Jun. 1994; Brooks and Ashe leg.; KUNHM SEMC1248337.

MEXICO • 1 क; ANSP • 1 \% ; Chiapas, 3 km S of Palenque (Nututun); 25 Apr. 1993; W. LaBerge leg.; KUNHM SEMC1248323 • 1 đ̊;; Chiapas, 32 mi W of San Cristóbal (Jct 190-195); 20 May 1969; H.J. Teskey leg.; CNC 754056 • 1 đ̊; Chiapas, Palenque ruins; 22 Jun. 1969; B.V. Peterson leg.; CNC (754061) • 1 क; Jalisco, Chamela; 7 Nov. 1986; J.G. and B.L. Rozen leg.; AMNH • 1 \%; Jalisco, El Tuito; 6 Nov. 1987; L. Godinez leg.; KUNHM SEMC1248317• 2 q o ; Jalisco, Estación de Biología - Chamela; 30 Sep. 1985; J.G. Rozen leg.; AMNH • 1 ô; same collection data as for preceding; 6 Oct. 
1985; J.G. Rozen leg.; AMNH • 1 q; same collection data as for preceding; 4 Nov. 1987; L. Godinez leg.; KUNHM SEMC1248316 • 1 ô; Jalisco, Guadalajara; "8.1.03"; McClendon leg.; ANSP • 1 क; Jalisco, Tuxpan; "ix.4"; McClendon leg.; ANSP • 1 今̄; Morelos, 12 mi E of Cuernavaca; 14 Aug. 1954; J.G. Chillcott leg.; CNC 754076 • 2 우우 Nuevo León, Cola de Caballo; 20 Jun. 1976; D. Weems leg.; FSCA • 1 क; Oaxaca, 3 mi S of El Camarón; 2 Oct. 1986; R. Miller and L. Stange leg.; FSCA • 1 đ; Puebla, Tepexco-Izúcar de Matamoros (Carretera Federal 160); $18.6540^{\circ}$ N, 98.6595 W; 4 Sep. 1998; T.L. Griswold leg.; BBSL BBSL334999 • 1 9; Querétaro, Jalpan de Serra (along Río Jalpan); 3 Sep. 1991; D. Yanega leg.; KUNHM SEMC1248286 • 1 \&; San Luis Potosí, 14 mi W of Xilitla; 22 Jul. 1954; J.G. Chillcott leg.; CNC 754075 • 1 q; San Luis Potosí, 9 km N of Tamazunchale (Hwy 85); 9 Jul. 1990; W. Bell leg.; KUNHM SEMC1248283・1 O; San Luis Potosí, Cascada el Salto (12 km NW of El Naranjo); KUNHM SEMC1248330 1 q; same collection data as for preceding; 20 May 1989; D. Yanega leg.; KUNHM SEMC1248284 • 1 क ; same collection data as for preceding; 4 Jul. 1990; I. Yarom leg.; KUNHM SEMC1248288 • 1 ô; San Luis Potosí, Col Salto del Agua; 20 May 1989; D. Yanega leg.; KUNHM SEMC1248285 • 1 đ ; San Luis Potosí, El Salto; 19 Jun. 1973; H.V. Weems Jr. leg.; FSCA •

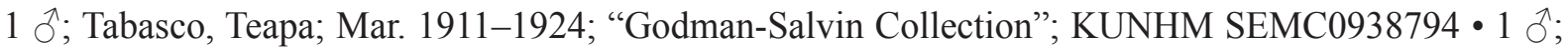
Veracruz, 8 km S of Carrizal; 5 Nov. 1991; T. Griswold leg.; KUNHM SEMC1248324 • 1 \&; Veracruz, Catemaco; 16-18 Jun. 1969; W.R.M. Mason leg.; CNC 754059 • 2 q ; Yucatán, Chichén Itzá; 24 Nov. 1981; L.A. Stange leg.; FSCA • 1 đ̇; same collection data as for preceding; 5 Jan. 1992; J.R. Vockeroth leg.; CNC 754062 • 1 ô; same collection data as for preceding; 17 Dec. 1993; L. Masner leg.; CNC 754060 .
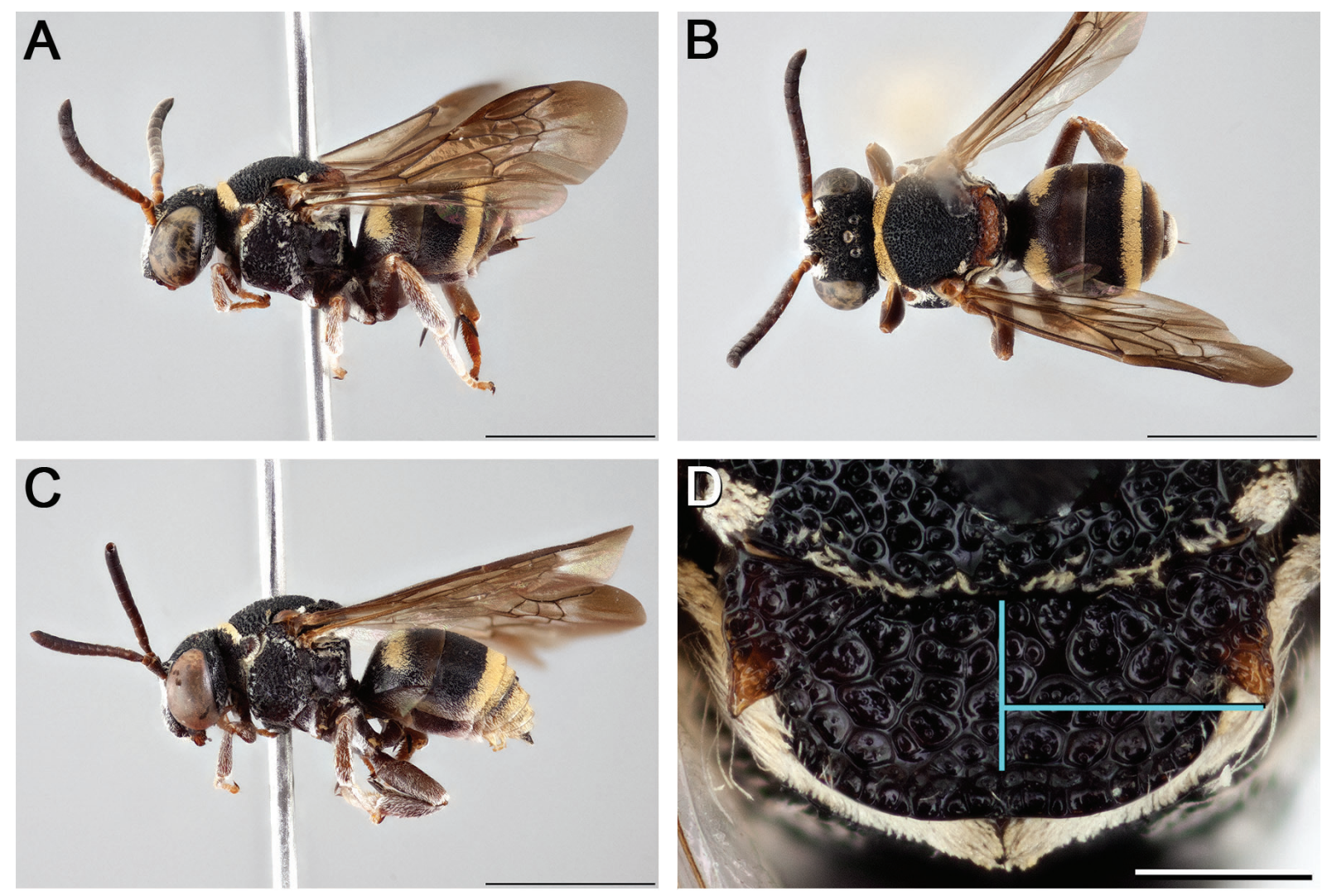

Fig. 17. Epeolus obscuripes Cockerell, 1917 stat. nov. A. Female, habitus, lateral view. B. Female, habitus, dorsal view. C. Male, habitus, lateral view. D. Female axillae and mesoscutellum, dorsal view (blue lines indicate the posterior extent of the axilla relative to the length of the horizontal dorsal portion of the mesoscutellum). Scale bars: A-C $=3 \mathrm{~mm} ; \mathrm{D}=0.5 \mathrm{~mm}$. 


\section{Redescription}

Male

Measurements. Length $6.1 \mathrm{~mm}$; head length $1.9 \mathrm{~mm}$; head width $2.3 \mathrm{~mm}$; fore wing length $5.6 \mathrm{~mm}$.

INTEGUMENT COLORATION. Mostly black; notable exceptions as follows: at least partially ferruginous on mandible, labrum, antenna, pronotal collar, pronotal lobe, tegula, axilla, mesoscutellum, metanotum and legs. Mandible with apex darker than all but basal quarter; preapical tooth lighter than mandibular apex (difficult to see in E. bifasciatus obscuripes holotype because mandibles closed; described from nontype specimens). Antenna brown except scape, pedicel and F1 extensively orange. F2 with orange spot basally. Pronotal lobe and tegula pale ferruginous to amber. Wing membrane dusky subhyaline, slightly darker at apex. Legs with brown or black more extensive than reddish orange.

Pubescence. Face with tomentum densest around antennal socket. Tomentum slightly sparser on clypeus; upper paraocular and frontal areas and vertexal area mostly exposed. Pronotal collar and dorsum of metasoma with bright yellow setae. Mesoscutum without pale tomentum, except for small patch between tegula and axilla. Mesopleuron nearly bare, except along margins. Metanotum with tomentum uninterrupted, uniformly pale yellow. $\mathrm{T} 1$ with broad, medially interrupted bright yellow basal fascia. T2 with narrower, complete, bright yellow apical fascia without anterolateral extensions. T3-T6 with tomentum sparse and partly rubbed off in E. bifasciatus obscuripes holotype, but with complete, bright yellow apical fasciae of moderately dense tomentum in E. schmidti lectotype and most non-type specimens. S3-S5 with long (>1 MOD), curved, coppery to silvery subapical hairs.

Surface SCulPture. Punctures dense, but those of head and mesosoma sparser in some areas, larger, deeper and more distinct. Labrum with larger punctures than clypeus, but punctures of both equally dense (most $\mathrm{i}<1 \mathrm{~d}$ ). Small, impunctate, shiny spot lateral to lateral ocellus. Mesoscutum, mesoscutellum and axilla very coarsely and densely rugose-punctate. Tegula densely punctate anteriorly and mesally $(i \leq 2 d)$, sparsely punctate $(i>2 d)$ to impunctate posteriorly and along margins. Mesopleuron with larger and denser $(i<1 d)$ punctures in upper half than ventrolateral half (many $i \geq 1 d$ ), interspaces shining. Metasomal terga with punctures very fine, dense $(i \approx 1 d)$, evenly distributed on disc. Pygidial plate with large deep punctures closely clustered basomedially and sparser apically and laterally, with interspaces shining.

Structure. Preapical tooth acute. Labral apex with three small denticles, each preceded by small discrete longitudinal ridge. Frontal keel strongly raised. Frontal area with pair of sparsely punctate granulose protrusions, each located near upper mesal margin of compound eye. In E. schmidti lectotype and lectoallotype and multiple non-type specimens, protrusions discrete and more densely punctate, interspaces shining. Head dorsally with pair of protrusions, each located where upper genal area meets vertexal area. Vertexal area strongly convex in frontal view. Scape with greatest length $1.7 \times$ greatest width. F2 noticeably longer than wide $(\mathrm{L} / \mathrm{W}$ ratio $=1.3)$. Preoccipital ridge separated from hypostomal carina by $\geq 2$ MOD. Pronotal collar elongate (medial length $\sim 1$ MOD), expanded laterally to about $2 \times$ medial length in dorsal view and relatively straight along anterior margin. Mesoscutellum moderately bigibbous, depressed along posterior margin beneath overhanging ridge. Axilla intermediate in size, its lateral margin nearly half as long as mesoscutellar width $(\mathrm{AL} / \mathrm{MSCW}$ ratio $=0.4-0.5)$ and tip extending well beyond midlength of mesoscutellum but not as far back as its posterior margin; axilla with tip conspicuously diverging from side of mesoscutellum, distinctly hooked, and axilla with free portion between $1 / 3$ and $2 / 5$ its medial length; axilla with lateral margin relatively straight and carinate. Metanotum with blunt median process obscured by tomentum (process more pronounced in E. schmidti lectotype and multiple non-type specimens than in E. bifasciatus obscuripes holotype). Mesopleuron with carina delineating its anterior and lateral surfaces. Fore wing with three submarginal cells. Pygidial plate apically truncate. 


\section{Female}

Description as for male except for usual secondary sexual characters and as follows: F2 even longer than wide $(\mathrm{L} / \mathrm{W}$ ratio $=1.5)$; T3-T5 usually without fasciae; T5 laterally with long, erect simple setae; T5 with pseudopygidial area lunate, its apex twice as wide as medial length, indicated by silvery setae on impressed disc of apicomedial region elevated from rest of tergum; pygidial plate with smaller, denser punctures; S4 and S5 with straight and much shorter hairs (S5 with apical fimbria of coppery to silvery hairs extending beyond apex of sternum by $\sim 1 / 3 \mathrm{MOD}$ ).

\section{Distribution}

Northwestern Mexico to Costa Rica (Fig. 7I).

\section{Ecology}

\section{Host records}

Unknown.

\section{Floral records}

The label of one examined voucher specimen indicates a floral association with Bidens pilosa.

\section{Remarks}

In Moure et al. (2007), E. bifasciatus obscuripes appears as a junior synonym of E. fulvopilosus, although it is not clear when and where this change in taxonomic status was first proposed, as no such change appears in any of the accompanying references. The holotype of E. bifasciatus obscuripes differs from that of E. fulvopilosus in many aspects, and the latter is structurally more similar to E. boliviensis, E. claripennis and E. nomadiformis sp. nov. In the holotype of $E$. bifasciatus obscuripes, the axillae are much shorter than in the holotype of E. fulvopilosus, the lateral margin of each axilla is smooth (not crenulate as in E. fulvopilosus) and the axillae extend beyond the midlength of the mesoscutellum but not as far back as its posterior margin. By contrast, in the holotype of E. fulvopilosus the axillae extend as far back as the apex of the horizontal dorsal portion of the mesoscutellum, which is produced to two posteriorly directed teeth (not straight as in E. obscuripes). Cockerell (1932) indicated that E. bifasciatus obscuripes is sufficiently distinct such that there may be justification to elevate its name to the taxonomic rank of species. In addition to the diagnostic morphological features that separate $E$. obscuripes from other similar species, its status as a separate species is supported by a separate BIN and large barcode sequence divergence (6.3\%) from its nearest neighbor, E. bifasciatus (Supplementary File 3).

Friese (1925) described E. schmidti from both sexes, represented by two syntypes (one female and one male) deposited at the ZMB. Both specimens were examined, and the male is herein designated as the lectotype, the same sex as the primary types of E. bifasciatus obscuripes (herein recognized as belonging to the same species) and E. bifasciatus, the species to which it is most similar. The female syntype at the $\mathrm{ZMB}$ is herein designated as the lectoallotype. Below what is presumed to be Heinrich Friese's original type label for the male specimen, which simply says "Type", is a label that says "LECTOTYPE" and "desig. Melo, 2016". The female bears a label that says "PARALECTOTYPE" and "desig. Melo, 2016". Since Melo's (2016) lectotype designations of Friese's Neotropical Epeolus types cannot be traced to any publication, the designation for E. schmidti is made herein instead. Ferrari (2017) cited personal communication with G. Melo regarding the addition of the latter's lectotype label to another of Friese's syntype specimens (in this case Colletes nigritulus), with 2015 given as the year of the designation, indicating that the designation (at that time) remained to be published.

The E. schmidti lectotype differs from the E. bifasciatus obscuripes holotype most notably in that the frontal protrusions are much less obvious and more densely punctate and that the frontal keel and metanotum are much more strongly protuberant. However, these differences fall within the range 
of variation observed among sequenced specimens that were assigned the same BIN. Also, in the E. schmidti lectotype T3-T6 have more pronounced bands of dense, bright yellow pubescence, which are less conspicuous and more sparsely hairy in the E. bifasciatus obscuripes holotype and multiple nontype specimens. These bands are absent altogether in most studied female specimens of E. obscuripes.

\section{Epeolus odyneroides sp. nov. \\ urn:1sid:zoobank.org:act:ACB2A692-644C-4DFC-A133-E1CA56EECAC4}

Figs 3D, 5D, 7J, 18, 27B

\section{Proposed common name}

Potter-wasp epeolus.

\section{Diagnosis}

The following morphological features in combination can be used to tell E. odyneroides sp. nov. apart from all other Epeolus: the axillae are small to intermediate in size, not extending beyond the midlength of the mesoscutellum and the free portion of each axilla is less than $1 / 3$ as long as its entire medial length, and like the mesoscutellum black (Fig. 18D); the mesoscutellum does not have a distinct ridge delineating its dorsal and posterior portions (Fig. 3D); T1 does not have any fasciae (Fig. 18B-C); and T2-T4 have complete, bright to pale yellow apical fasciae (Fig. 18A-C). Epeolus odyneroides sp. nov. most closely resembles E. luteipennis in terms of pubescence and structure. Whereas in E. luteipennis each mesopleuron is densely punctate throughout (most $\mathrm{i}<1 \mathrm{~d}$ ) and $\mathrm{T} 1$ has a complete or medially interrupted off-white to pale yellow basal fascia, in E. odyneroides sp. nov. each mesopleuron has sparser punctures ventrolaterally (many $\mathrm{i}>1 \mathrm{~d}$ ) than in the upper half (Fig. 5D) and T1 lacks fasciae altogether. Additionally, in E. odyneroides sp. nov. the frontal keel has a small tooth-like process, which is absent in E. luteipennis, and the mesoscutum and mesopleura have long, erect simple setae among the shorter branched hairs; only the latter type is present in E. luteipennis. This species is also very similar in overall appearance to Triepeolus bilineatus, Tri. cameroni and Tri. mexicanus, but both sexes of E. odyneroides sp. nov. can easily be told apart from any similar-looking Triepeolus by the presence of a preapical tooth on each mandible; in all Triepeolus spp., the mandibles are simple (Rightmyer 2004).

\section{Etymology}

The specific epithet is derived from 'Odynerus', a genus of potter wasps (Hymenoptera: Vespidae: Eumeninae). This name has become the root in the names of many genera, including Pachodynerus de Saussure, 1875 (Hymenoptera: Vespidae: Eumeninae), which is similar in overall appearance to this particular species of Epeolus. The Greek suffix -oides means 'resembling'.

\section{Material examined}

Primary type material

MEXICO • +, holotype; Tlaxcala, Volcán La Malinche (N side); $19.2900^{\circ} \mathrm{N}, 98.0453^{\circ} \mathrm{W} ; 10$ Sep. 1996; R. Brooks leg.; KUNHM SM0253729.

\section{Secondary type material}

MEXICO 1 q , paratype; Estado De México, 6 km E of Tenancingo; 30 Oct. 1991; Rodriguez leg.; KUNHM SEMC1248301 • 1 đ̊n, allotype; Tlaxcala, Volcán La Malinche; $19.2900^{\circ} \mathrm{N}, 98.0453^{\circ} \mathrm{W}$; 10 Sep. 1996; R. Brooks leg.; BOLD sample ID: CCDB-28237 E04; KUNHM SM0255860 • 1 q, paratype; same collection data as for preceding; KUNHM SM0253730. 
DNA barcoded material with BIN-compliant sequences

Available. BOLD:ACZ2542. See Type material for specimens examined and sequenced (indicated by unique CCDB-plate and well number).

\section{Description}

\section{Female}

MeAsurements. Length $8.8 \mathrm{~mm}$; head length $2.3 \mathrm{~mm}$; head width $3.1 \mathrm{~mm}$; fore wing length $8.3 \mathrm{~mm}$.

InTEGUMENT COLORATION. Almost entirely dark brown to black; notable exceptions as follows: at least partially ferruginous on mandible, antenna and T5. Mandible with apex and preapical tooth lighter than rest of mandible (preapical tooth difficult to see in holotype because mandibles closed; described from paratype). Tegula pale ferruginous to amber along lateral and posterior margins. Wing membrane subhyaline, apically dusky on anterior margin.

Pubescence. Face with tomentum densest on clypeus and around antennal socket, sparser on upper paraocular area and vertexal area. Dorsum of mesosoma and metasoma with bands of off-white and bright yellow short, appressed setae. Pronotal collar with tomentum uniformly bright yellow. Mesoscutum with faint anteromedial, V-shaped patch of bright yellow tomentum, short, appressed, bright yellow setae also present along posterior margin; mesoscutum otherwise covered in sparse and erect, simple pale hairs. Mesopleuron sparsely hairy, but tomentum moderately dense ventrally as well as between two sparsely hairy patches (one beneath base of fore wing (hypoepimeral area), a larger circular patch occupying
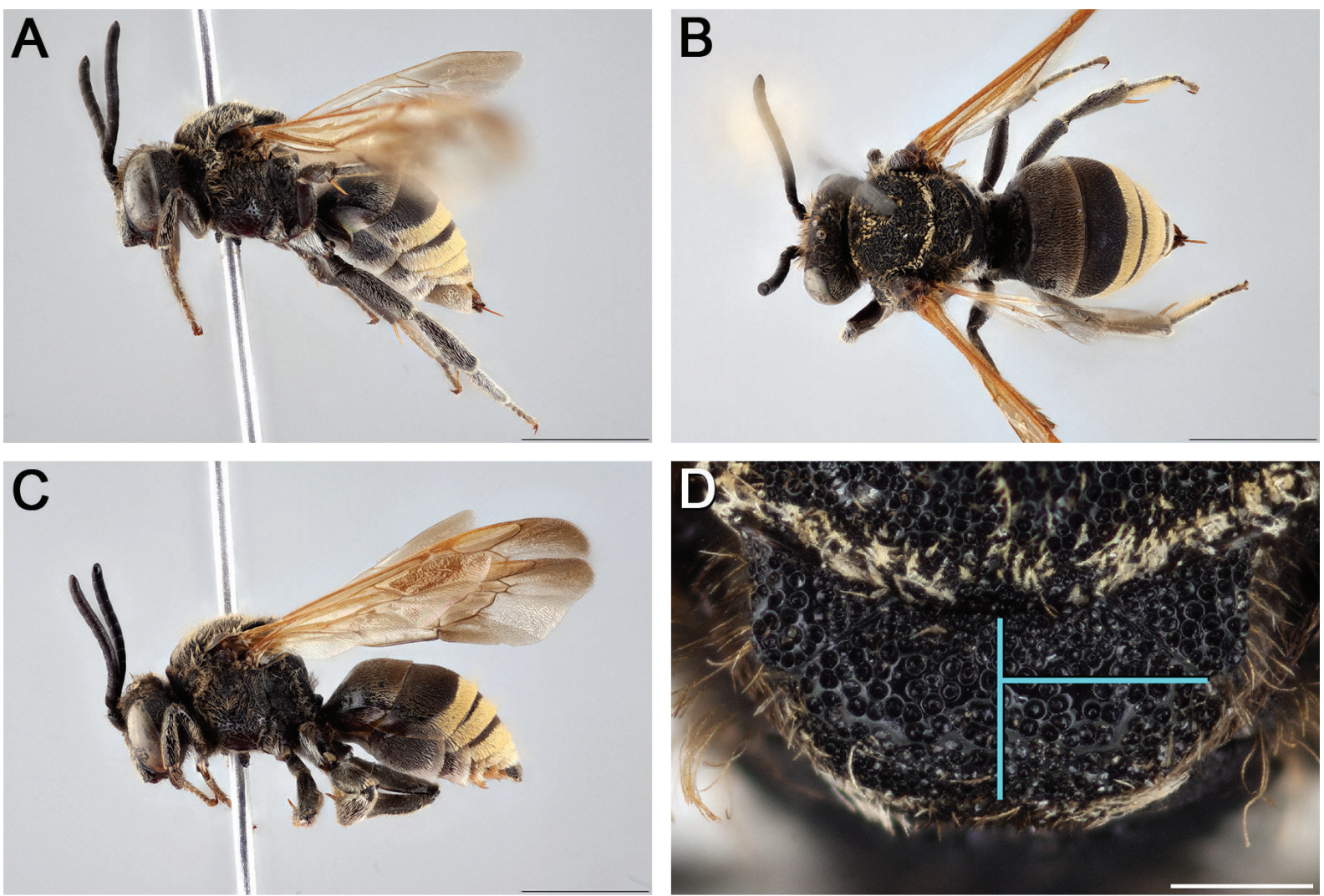

Fig. 18. Epeolus odyneroides sp. nov. A-B, D. Holotype, $q$ (KUNHM SM0253729). C. Allotype, § (KUNHM SM0255860). A. Habitus, lateral view. B. Habitus, dorsal view. C. Habitus, lateral view. D. Axillae and mesoscutellum, dorsal view (blue lines indicate the posterior extent of the axilla relative to the length of the mesoscutellum). Scale bars: $\mathrm{A}-\mathrm{C}=3 \mathrm{~mm} ; \mathrm{D}=0.5 \mathrm{~mm}$. 
much of ventrolateral half of mesopleuron). Mesopleuron with long, erect simple setae among shorter branched hairs. Metanotum with tomentum uninterrupted, pale yellow laterally and black medially. $\mathrm{T} 1$ without fasciae, basally and laterally with sparse off-white tomentum. T2-T4 each with complete bright yellow apical fascia, T2 fascia without anterolateral extensions. T5 with large patch of bright yellow tomentum bordering and separate from pseudopygidial area. 55 with pseudopygidial area lunate, its apex more than twice as wide as medial length, indicated by silvery setae on impressed disc of apicomedial region elevated from rest of tergum. S5 with apical fimbria of coppery to silvery hairs not extending beyond apex of sternum by more than $1 / 4$ MOD.

Surface sculpture. Punctures dense. Labrum with larger and sparser punctures (most $i>1 d$ ) than clypeus $(i<1 d)$. Small impunctate shiny spot lateral to lateral ocellus. Mesoscutum, mesoscutellum and axilla coarsely and densely rugose-punctate. Tegula densely punctate mesally ( $\mathrm{i}=1-2 \mathrm{~d}$ ), sparsely punctate $(i>2 d)$ to impunctate along margins. Mesopleuron with denser $(i \leq 1 \mathrm{~d})$ punctures in upper half than ventrolateral half; ventrolateral half with most interspaces large (i $>1 \mathrm{~d})$, interspaces shining; mesopleuron with punctures similar in size throughout. Metasomal terga with punctures very fine, dense (i $\approx 1 \mathrm{~d})$, evenly distributed on disc.

StRUCTURE. Preapical tooth acute. Labrum with pair of small subapical denticles not preceded by carinae. Frontal keel not strongly raised, but small tooth present. Vertexal area weakly convex in frontal view. Scape with greatest length $1.8 \times$ greatest width. F2 as long as wide $(\mathrm{L} / \mathrm{W}$ ratio $=1.2)$. Preoccipital ridge separated from hypostomal carina by about 1.5 MOD. Pronotal collar rather short (medial length $\sim 2 / 3$ MOD) and convex along anterior margin. Mesoscutellum moderately bigibbous. Axilla small to intermediate in size, its lateral margin less than half as long as mesoscutellar width (AL/MSCW ratio $=0.3$ ) and tip not extending beyond midlength of mesoscutellum; axilla with tip broadly rounded, unattached to mesoscutellum for less than $1 / 3$ medial length of axilla; axilla with lateral margin relatively straight and without carina. Fore wing with three submarginal cells. Pygidial plate mostly hidden in holotype, but apically truncate in paratype.

\section{Male}

Description as for female except for usual secondary sexual characters and as follows: F2 shorter, not noticeably longer than wide $(\mathrm{L} / \mathrm{W}$ ratio $=1.1)$; pygidial plate apically rounded; S4 and S5 with much longer (>1 MOD), curved, coppery to silvery subapical hairs.

\section{Distribution}

Presently only known from two locations in Central Mexico (Fig. 7J).

\section{Ecology}

\section{Host records}

\section{Unknown.}

\section{Floral records}

Labels of examined voucher specimens indicate floral associations with Heterotheca inuloides Cass. (Asteraceae), Salvia L. (Lamiaceae), and Simsia lagasceiformis DC. (Asteraceae).

\section{Remarks}

In addition to the diagnostic morphological features that separate E. odyneroides sp. nov. from other similar species, its status as a separate species is supported by a separate BIN and large barcode sequence divergence $(5.1 \%)$ from its nearest neighbor, E. canadensis, which is a visibly different bee (see Figs 18 , 22D). Epeolus odyneroides sp. nov. most closely resembles E. luteipennis, for which only a partial 
sequence $421 \mathrm{bp}$ in length is available. However, the distance between the two sequences (only one is presently available per species) is larger (6.3\%, Supplementary File 3$)$.

As well as resembling certain eumenines, E. odyneroides sp. nov. very closely resembles honey wasps in the genus Brachygastra Perty, 1833 (Hymenoptera: Vespidae: Polistinae).

Epeolus pulchellus Cresson, 1865

Figs 1I, 3C, 7K, 19

Epeolus pulchellus Cresson, 1865: 185 (ठ̊).

\section{Proposed common name}

Cuban epeolus.

\section{Diagnosis}

Epeolus pulchellus has unique patterns of pubescence on the dorsum of the mesosoma and metasoma, which can be used to tell it apart from all other Epeolus: the mesoscutum has three large patches of bright yellow tomentum (an anteromedial ovate patch, which is slightly separated from the anterior margin of the mesoscutum, and a pair of posterolateral patches) (Fig. 19B), T1 has a pair of submedial triangular (almost semicircular) patches of bright yellow tomentum (Fig. 19B), T2 and T3 have widely separated bright yellow apical fasciae and $\mathrm{T} 4$ has a pair of widely separated patches of bright yellow tomentum (Fig. 19B). Epeolus pulchellus does not closely resemble any other species of Epeolus and is the only species in the genus known to occur in Cuba, where it is endemic.

\section{Material examined}

\section{Primary type material}

CUBA $\bullet \curvearrowright$, holotype (studied from images); J. Gundlach leg.; IESH.

DNA barcoded material with BIN-compliant sequences Unavailable.

\section{Non-barcoded material}

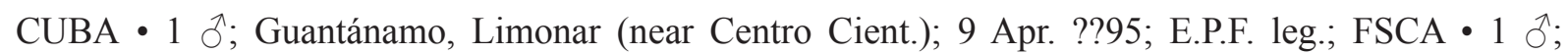
Guantánamo, mountains near Guantánamo; BBSL・1 ô; Pinar Del Río, El Mulo (Sierra del Rosario); Jun. ??87; KUNHM SEMC1248271 • 1 q; Sancti Spíritus, El Hondan - Topes de Collantes; Jul. ??93; L. Roque leg.; LACM LACM ENT 363336.

\section{Redescription}

\section{Male}

Measurements. Length 7.6-7.9 mm; head length 2.0-2.2 mm; head width 2.6-2.8 mm; fore wing length $6.9-7.5 \mathrm{~mm}$.

InTEGUMENT COLORATION. Mostly black; notable exceptions as follows: at least partially ferruginous on mandible, labrum, antenna, pronotal lobe, tegula and legs. Mandible with apex darker than all but basal quarter; preapical tooth lighter than mandibular apex. Antenna entirely orange. Pronotal lobe and tegula pale ferruginous to amber. Wing membrane dusky subhyaline, slightly darker at apex. Legs from trochanter to tarsus entirely orange, coxae brown.

PUBESCENCE. Face with tomentum very dense around antennal socket, otherwise almost entirely bare. Dorsum of mesosoma and metasoma with bands of bright yellow short, appressed setae. Pronotal collar 
with tomentum uniformly bright yellow. Mesoscutum with anteromedial ovate patch of bright yellow tomentum, slightly separated from anterior margin, and pair of separated posterolateral patches of bright yellow tomentum. Mesopleuron with upper half densely hairy, although scrobe visible; ventrolateral half densely hairy along margins, otherwise sparsely hairy. Metanotum with tomentum very narrowly interrupted medially, uniformly yellow. T1 with pair of submedial triangular verging on semicircular patches of bright yellow tomentum, medially separated from one another and from apical margin. T2 and T3 with fasciae widely interrupted medially and narrowed before becoming somewhat broader laterally, T2 fascia without anterolateral extensions. T4 and T5 each with pair of widely separated patches of bright yellow tomentum tapering laterally. S3-S5 with long (>1 MOD), curved, coppery to silvery subapical hairs.

Surface sculpture. Punctures dense, but those of head and mesosoma sparser in some areas, larger, deeper and more distinct. Labrum and clypeus with punctures equally dense (most $i \leq 1 \mathrm{~d}$ ). Small impunctate shiny spot lateral to lateral ocellus. Mesoscutum, mesoscutellum and axilla very coarsely and densely rugose-punctate. Tegula densely punctate anteriorly and mesally (i $\leq 2 \mathrm{~d})$, sparsely punctate (i $>2 \mathrm{~d}$ ) to impunctate posteriorly and along margins. Mesopleuron with denser $(\mathrm{i}<1 \mathrm{~d})$ punctures in upper half than ventrolateral half (many $i \geq 1 \mathrm{~d}$ ), interspaces shining; mesopleuron with many smaller punctures among large ones. Metasomal terga with punctures very fine, dense (i $\approx 1 \mathrm{~d})$, evenly distributed on disc. Pygidial plate with large deep punctures closely clustered throughout.
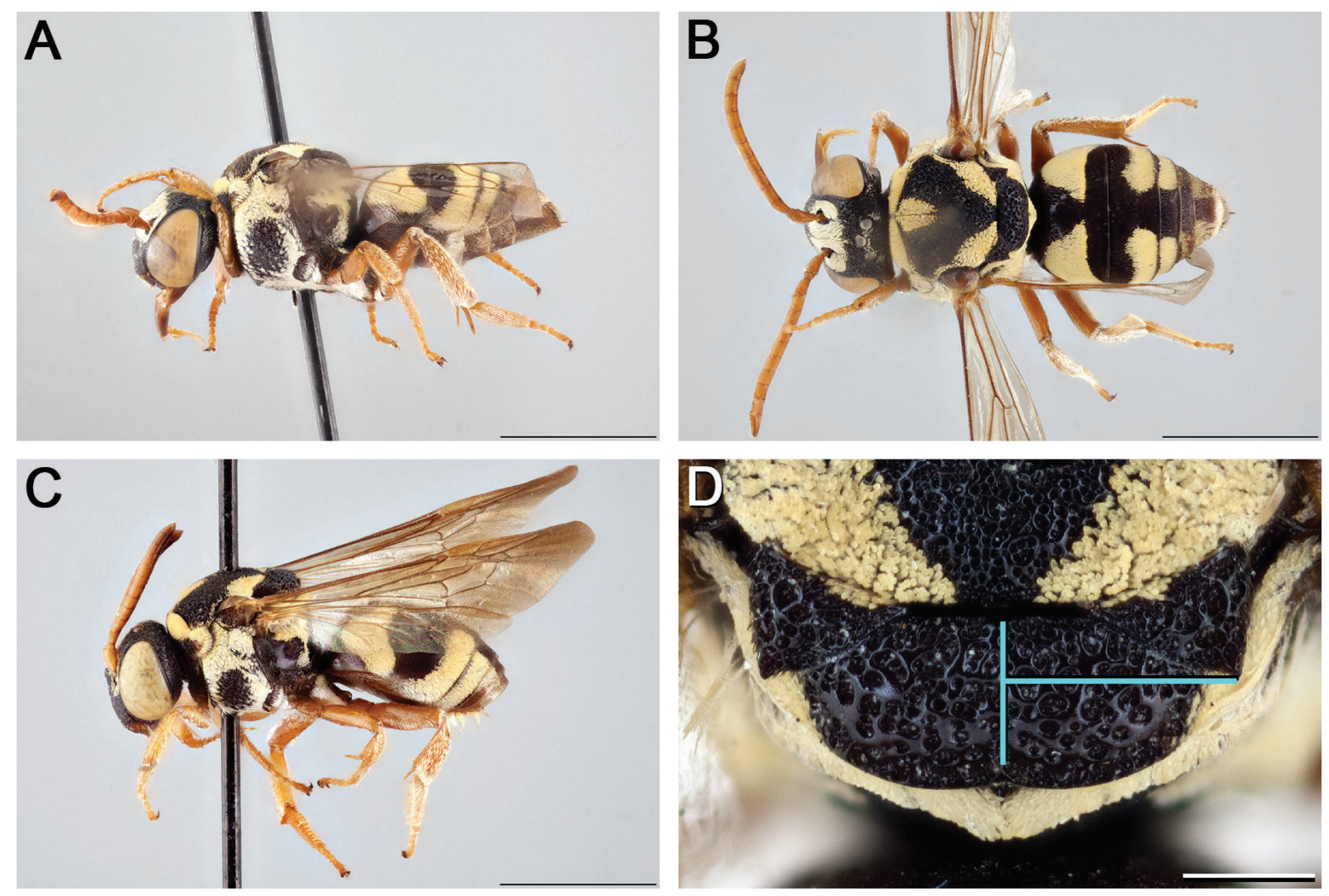

Fig. 19. Epeolus pulchellus Cresson, 1865 A. Female, habitus, lateral view. B. Female, habitus, dorsal view. C. Male, habitus, lateral view. D. Female axillae and mesoscutellum, dorsal view (blue lines indicate the posterior extent of the axilla relative to the length of the horizontal dorsal portion of the mesoscutellum). Scale bars: A-C $=3 \mathrm{~mm}$; $\mathrm{D}=0.5 \mathrm{~mm}$. 
StRUCTURE. Preapical tooth forming right-angled triangle. Labral apex with three small denticles, each preceded by small discrete longitudinal ridge. Frontal keel strongly raised. Frontal area with pair of discrete, sparsely punctate protrusions, interspaces shining; each located near upper mesal margin of compound eye. Head dorsally with pair of protrusions, each located where upper genal area meets vertexal area. Vertexal area strongly convex in frontal view. Scape with greatest length $1.7 \times$ greatest width. F2 noticeably longer than wide $(\mathrm{L} / \mathrm{W}$ ratio $=1.2)$. Preoccipital ridge separated from hypostomal carina by no less than 1 MOD. Pronotal collar somewhat elongate (medial length $\sim 4 / 5 \mathrm{MOD}$ ), expanded laterally to about $2 \times$ medial length in dorsal view, and relatively straight along anterior margin. Mesoscutellum weakly bigibbous. Axilla small to intermediate in size, its lateral margin less than half as long as mesoscutellar width $(\mathrm{AL} / \mathrm{MSCW}$ ratio $=0.4)$ and tip not extending beyond midlength of mesoscutellum; axilla with tip conspicuously diverging from side of mesoscutellum, distinctly hooked, and axilla with free portion between $1 / 3$ and $2 / 5$ its medial length; axilla with lateral margin relatively straight and without carina. Metanotum with blunt median process obscured by tomentum. Mesopleuron with weak carina delineating its anterior and lateral surfaces. Fore wing with three submarginal cells. Pygidial plate apically rounded.

\section{Female}

Description as for male except for usual secondary sexual characters and as follows: F2 even longer than wide $(\mathrm{L} / \mathrm{W}$ ratio $=1.6)$; T5 laterally with long, erect simple setae; T5 with pseudopygidial area lunate, its apex more than twice as wide as medial length, indicated by silvery setae on impressed disc of apicomedial region elevated from rest of tergum; pygidial plate with smaller, denser punctures; S4 and S5 with straight and much shorter hairs (S5 with apical fimbria of coppery to silvery hairs extending beyond apex of sternum by $\sim 2 / 3 \mathrm{MOD}$ ).

\section{Distribution}

This species is known only from Cuba and is the only species of Epeolus known to occur in the country (Fig. 7K).

\section{Ecology}

\section{Host records}

Unknown. Presumably E. pulchellus is associated with one or more of the three species of Colletes - C. granpiedrensis Genaro, 2001, C. hicaco Genaro, 2003 and C. submarginatus Cresson, 1865 (Genaro 2003) - known to occur in Cuba.

\section{Floral records}

This species has been observed visiting the flower of Tridax procumbens (L.) L. (Asteraceae) (J.A. Genaro, personal communication, 2018).

\section{Remarks}

Images of the holotype of E. pulchellus (kindly provided for study by the curatorial staff at the IESH) show the specimen to be in poor condition; both antennae are missing, the wings are badly damaged, on the specimen there are hyphae and fruiting bodies from mold, and much of the pubescence is discolored/rubbed off. However, still visible on the specimen's right side is one of the two submedial triangular verging on semicircular patches of bright yellow tomentum on $\mathrm{T} 1$, which are unique to this species among Epeolus. Since many of this species' features cannot be described from the holotype, the redescription of the male of E. pulchellus provided herein is based mainly on other material - male specimens available for detailed examination that closely match Cresson's (1865) original description. The female of E. pulchellus is described here for the first time. 
Epeolus pulchellus is herein recognized as belonging to the 'Trophocleptria group' on the basis of the following morphological features, which are diagnostic for the intrageneric group: the pronotal collar is relatively straight along its anterior margin and somewhat elongate, each mesopleuron has a weak carina delineating its anterior and lateral surfaces, and the penis lacks a pair of divergent, fleshy lateral lobes, which are unique to Epeolus among Nomadinae (Rightmyer 2004). Although the frontal area does not have any conspicuous protrusions, a small swelling (more sparsely punctate than the surrounding area) is present on each side, near the upper mesal margin of the compound eye.

\section{New species records for Central America and Mexico}

The following records are associated with specimens that were personally examined and are new for the named countries and districts/states.

Epeolus brumleyi Onuferko, 2018

MEXICO • 1 q; Chihuahua, 5 km W of Ciudad Jiménez; 21 Aug. 1991; T. Griswold leg.; KUNHM SM0307746.

Epeolus ferrarii Onuferko, 2018

GUATEMALA・ 1 đ̊; Zacapa, San Lorenzo; Nov. 1986; M. Sharkey leg.; CNC 754068.

Epeolus pusillus Cresson, 1864

BELIZE • 1 万ో; Belize, Tropical Education Center; 1 Mar. 2007; J.G. Rozen and J.S. Ascher leg.; AMNH AMNH_IZC 00290832 .

Epeolus scutellaris Say, 1824

MEXICO • 1 गे; Chihuahua, 29 mi N of La Bufa (La Bufa-Creel Rd); 28 Aug. 1950; R.F. Smith leg.; KUNHM SEMC1248344.

\section{Key to species of the genus Epeolus in the Caribbean, Central America and Mexico}

1. Axilla in dorsal view with tip extending as far back as apex of horizontal dorsal portion of mesoscutellum (Fig. 9C). Axilla and mesoscutellum entirely ferruginous (Fig. 9C). T1-T4 fasciate, apical fasciae separated into rounded lobes medially (Fig. 9B) [Hispaniola]

E. danieli (Genaro, 2014) comb. nov. (Fig. 9)

- Mesosoma and metasoma without the combination of features listed above [other regions] .......... 2

2. Pronotal collar with anterior margin relatively straight (best seen in dorsal view) (Fig. 2A-B). Mesoscutellum with distinct ridge along apex of horizontal dorsal portion overhanging depressed posterior margin (best seen in posterior view) (Fig. 3A-B), except in E. pulchellus (Fig. 3C). Penis without pair of fleshy lateral lobes (Fig. 1A-D, G-I). Frontal area commonly with pair of sparsely punctate to impunctate protrusions, each located near upper mesal margin of compound eye (Fig. 4A) 3 ('Trophocleptria group')

- Pronotal collar with anterior margin convex (best seen in dorsal view) (Fig. 2C). Mesoscutellum without distinct ridge delineating dorsal and posterior portions (Fig. 3D). Penis with pair of divergent, fleshy lateral lobes (Fig. 1E-F). Frontal area never with protrusions (Fig. 4C-F) 11 (all other Epeolus spp.)

3. Metasomal terga with tomentum entirely black (Figs 8A-C, 15A-C). Fore wing dusky throughout or deeply infuscate basally, clear and hyaline apically (Figs $8 \mathrm{~A}-\mathrm{B}, 15 \mathrm{~B})$

- At least T2 with yellow apical fascia (Figs 6A-C, 10A-C, 11A-C, 16A-C, 17A-C, 19A-C). Fore wing dusky throughout or most deeply infuscate on apical margin (Figs 6A-B, 10B, 11A-B, 16AC, 17A-C, 19C) 
4. Mesoscutellum with pair of posteriorly directed teeth (Fig. 8D). Mesopleuron coarsely punctate, with punctures in ventrolateral half sparse (many $i \geq 2 d$ ) (Fig. 5A)

.E. claripennis Friese, 1908 (Fig. 8)

- Mesoscutellum without pair of posteriorly directed teeth (Fig. 15D). Mesopleuron finely punctate, with punctures in ventrolateral half dense (few $\mathrm{i} \geq 2 \mathrm{~d}$ ) (Fig. 5B)

5. Axilla with lateral margin crenulate, with large tooth near base. Mesoscutellum with pair of posteriorly directed teeth (Figs 6D, 10D, 16D)

- Axilla with lateral margin smooth or if crenulate, then without large tooth near base. Mesoscutellum without pair of posteriorly directed teeth (Figs 11D, 17D, 19D)

6. T1 with only (bright to pale yellow) subapical fascia, which is usually narrower (its breadth sometimes equaling just a few hairs) than the (bright to pale yellow) apical fascia of T2 (Fig. 6B)

E. boliviensis Friese, 1908 (Fig. 6)

- T1 with medially narrowed or interrupted (bright to pale yellow) basal fascia, which is as broad as or broader than the (bright to pale yellow) apical fascia of T2 (Figs 10B, 16B)

7. T3 and $\mathrm{T} 4$ with complete, bright yellow fasciae (Fig. 10A-C)

E. fulvopilosus Cameron, 1902 (Fig. 10)

- T3 and T4 without fasciae, although apical impressed areas occasionally with sparse, off-white hairs (Fig. 16A-C)

E. nomadiformis sp. nov. (Fig. 16)

8. Mesoscutum with well-defined paramedian band (Figs 2B, 11B). Axilla in dorsal view with tip extending as far back as or beyond apex of horizontal dorsal portion of mesoscutellum (Fig. 11D)

E. fumipennis Say, 1837 (Fig. 11)

- Mesoscutum without paramedian band (Figs 17B, 19B). Axilla in dorsal view with tip not extending as far back as apex of horizontal dorsal portion of mesoscutellum (Figs 17D, 19D)

9. Mesoscutum with anteromedial ovate patch of bright yellow tomentum as well as a pair of large posterolateral patches (Fig. 19B) [Cuba] E. pulchellus Cresson, 1865 (Fig. 19)

- Mesoscutum with pale tomentum limited to pair of small patches, each between tegula and axilla, and posterior margin narrowly (Fig. 17B, D) [Central America and Mexico]

10. Frontal area always with pair of pronounced granulose protrusions, each located near upper mesal margin of compound eye (Fig. 4A). Pseudopygidial area of female shorter medially, such that its apex is more than twice as wide as medial length (Fig. 12B). T3-T6 of male without fasciae; apical impressed areas occasionally with sparse, off-white hairs, but these do not form distinct bands. Pronotal collar, pronotal lobe, axilla and mesoscutellum entirely ferruginous (Fig. 20A) E. bifasciatus Cresson, 1864 (Onuferko 2018a: fig. 26)

- Frontal area with pair of protrusions usually not strongly pronounced, in some cases almost lacking entirely (Fig. 4B). Pseudopygidial area of female longer medially, such that its apex is at most twice as wide as medial length (Fig. 12C). T3-T6 of male typically with well-developed bright to pale yellow fasciae (Fig. 17C). Pronotal collar, pronotal lobe, axilla and mesoscutellum entirely dark brown or black to entirely ferruginous (Fig. 17)

E. obscuripes Cockerell, 1917 stat. nov. (Fig. 17)

11. Axilla in dorsal view with tip extending to or beyond $2 / 3$ the length of mesoscutellum (Fig. 21A-C)

- Axilla in dorsal view with tip extending to less than $2 / 3$ the length of mesoscutellum (Figs 13D, 14D, $18 \mathrm{D}, 21 \mathrm{D}-\mathrm{F})$ 
12. Axilla with free portion $\sim 2 / 5$ of its entire medial length or longer and usually distinctly hooked (i.e., concave, not relatively straight along medial margin) (Fig. 21A). Axilla with lateral margin convex (Fig. 21A) or relatively straight (Fig. 22A)

- Axilla with free portion clearly less than $2 / 5$ of its entire medial length (Fig. 21B-C) or if borderline $(0.35<x<0.4)$ then relatively straight (i.e., not concave) along medial margin. Axilla with lateral margin convex (Fig. 21B-C)

13. Metanotum with distinct posteromedial depression (Fig. 3E). T1-T4 with apical fasciae interrupted medially (Fig. 22A)

E. axillaris Onuferko, 2018 (Onuferko 2018a: fig. 18)

- Metanotum without depression (Fig. 3F). T1-T4 with apical fasciae complete (Fig. 22B)
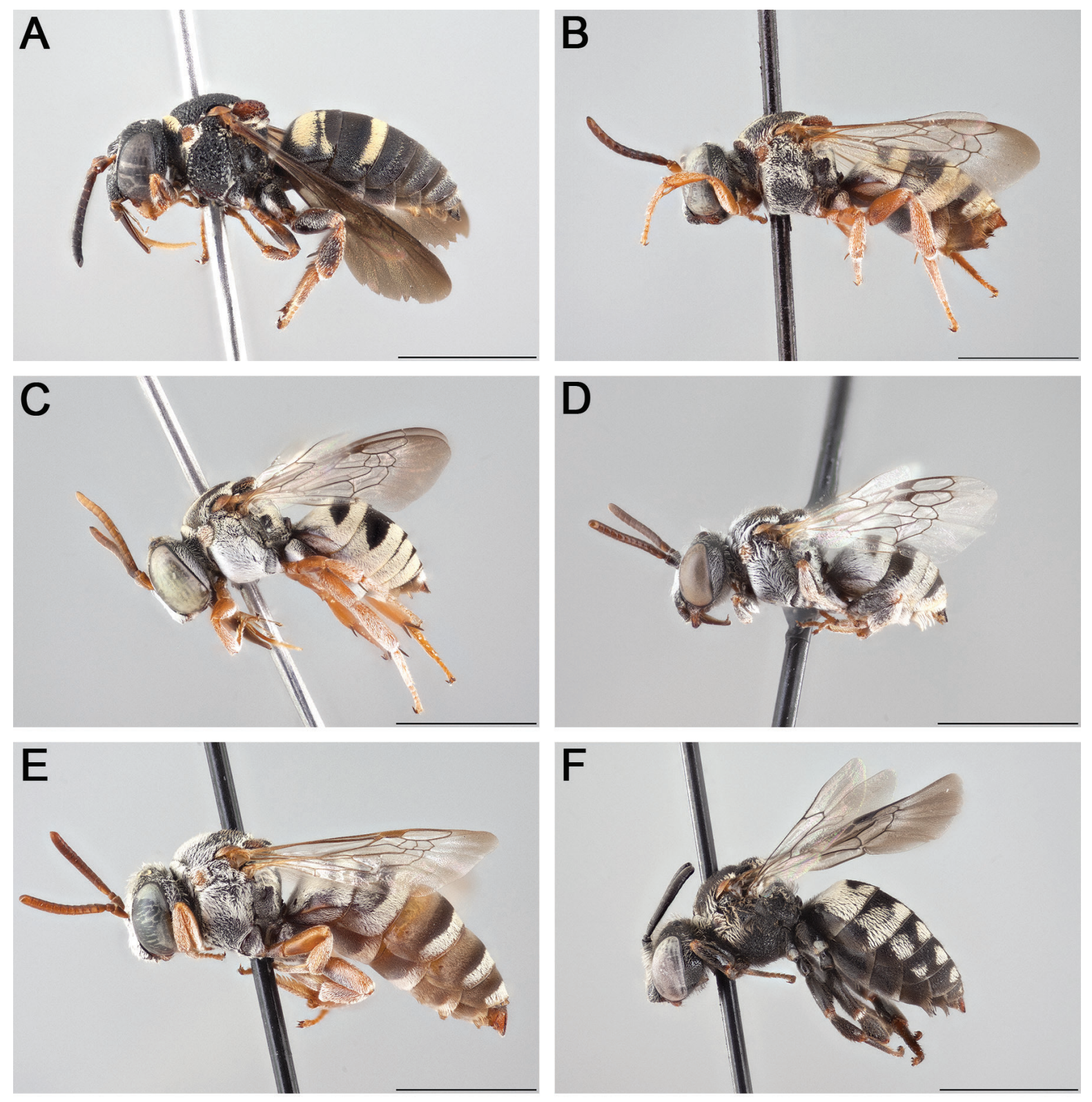

Fig. 20. Epeolus spp., habitus of male, lateral view. A. E. bifasciatus Cresson, 1864. B. E. scutellaris Say, 1824. C. E. basili Onuferko, 2018, paratype. D. E. mesillae (Cockerell, 1895). E. E. australis Mitchell, 1962. F. E. asperatus Cockerell, 1910. Scale bars $=3 \mathrm{~mm}$. 
14. Preoccipital ridge joining hypostomal carina (approximately at $2 / 5$ length of proboscidial fossa) (Fig. 23A). Mandible simple (Fig. 24A) .......... E. ainsliei Crawford, 1932 (Onuferko 2018a: fig. 4)

- Preoccipital ridge not joining hypostomal carina (Fig. 23B). Mandible with small, obtuse preapical (almost submedial) tooth (Fig. 24B) ..............E. rufulus Cockerell, 1941 (Onuferko 2018a: fig. 81)

15. Head dorsally with pair of small protrusions, each located where upper genal area meets vertexal area (Fig. 4C). Mesopleuron of male obscured by white tomentum only in upper half (although hypoepimeral area usually with sparser tomentum), with large, sparsely hairy circular area occupying
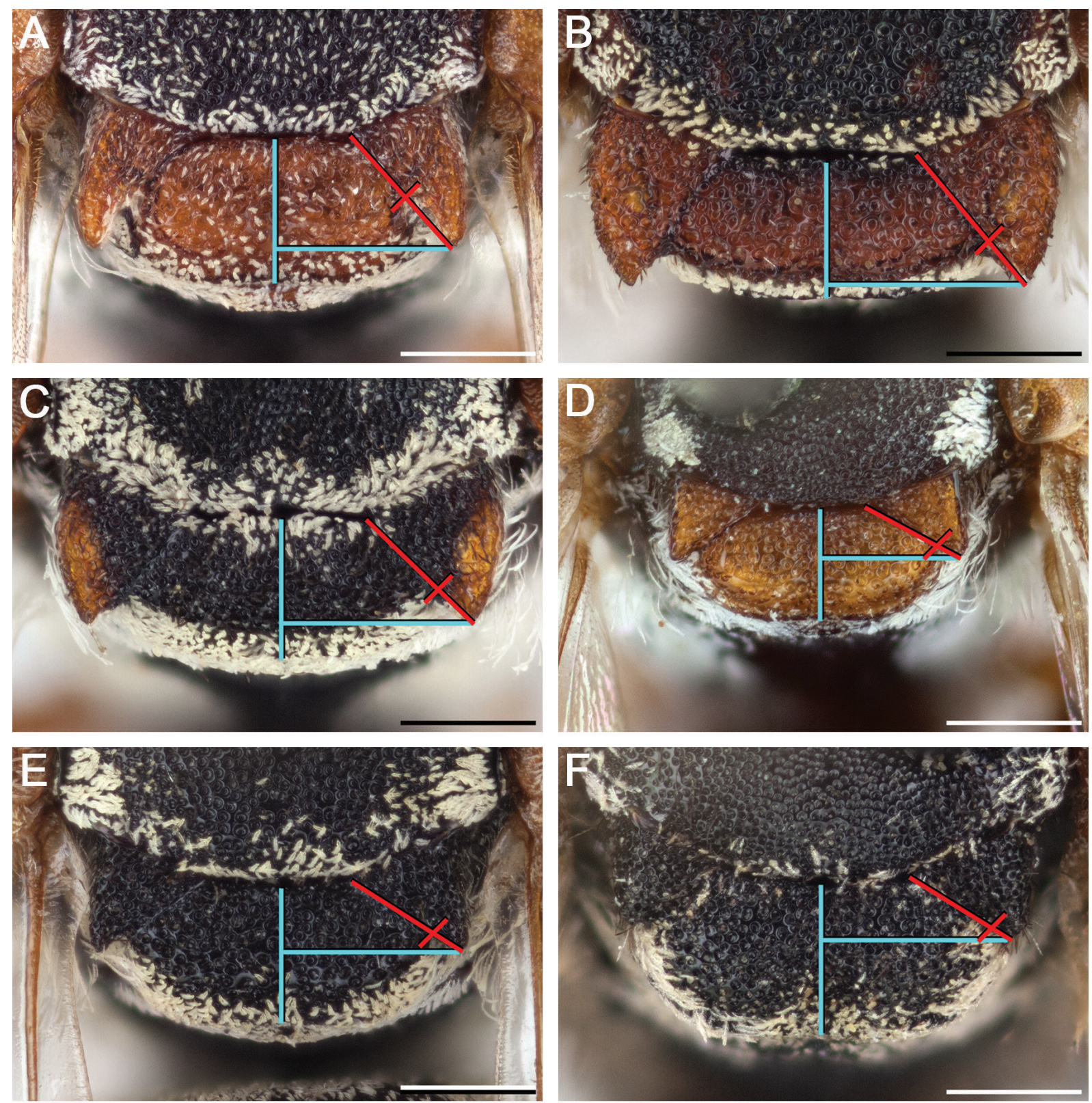

Fig. 21. Axillae and mesoscutellum of female, dorsal view. A. E. ainsliei Crawford, 1932. B. E. scutellaris Say, 1824. C. E. basili Onuferko, 2018, paratype. D. E. tessieris Onuferko, 2018, holotype. E. E. minimus (Robertson, 1902). F. E. asperatus Cockerell, 1910. Blue lines indicate the posterior extent of the axilla relative to the length of the mesoscutellum; red lines indicate the extent of the free portion of the axilla relative to its entire medial length. Scale bars $=0.5 \mathrm{~mm}$. 
much of ventrolateral half (Fig. 20B). Axilla in dorsal view with tip extending to or beyond band of pale tomentum along posterior margin of mesoscutellum (Fig. 21B)

E. scutellaris Say, 1824 (Onuferko 2018a: fig. 83)

- Head dorsally without pair of protrusions (Fig. 4D). Mesopleuron of male (excluding hypoepimeral area) entirely obscured by white tomentum (Fig. 20C). Axilla in dorsal view with tip at most extending to band of pale tomentum along posterior margin of mesoscutellum (Fig. 21C)
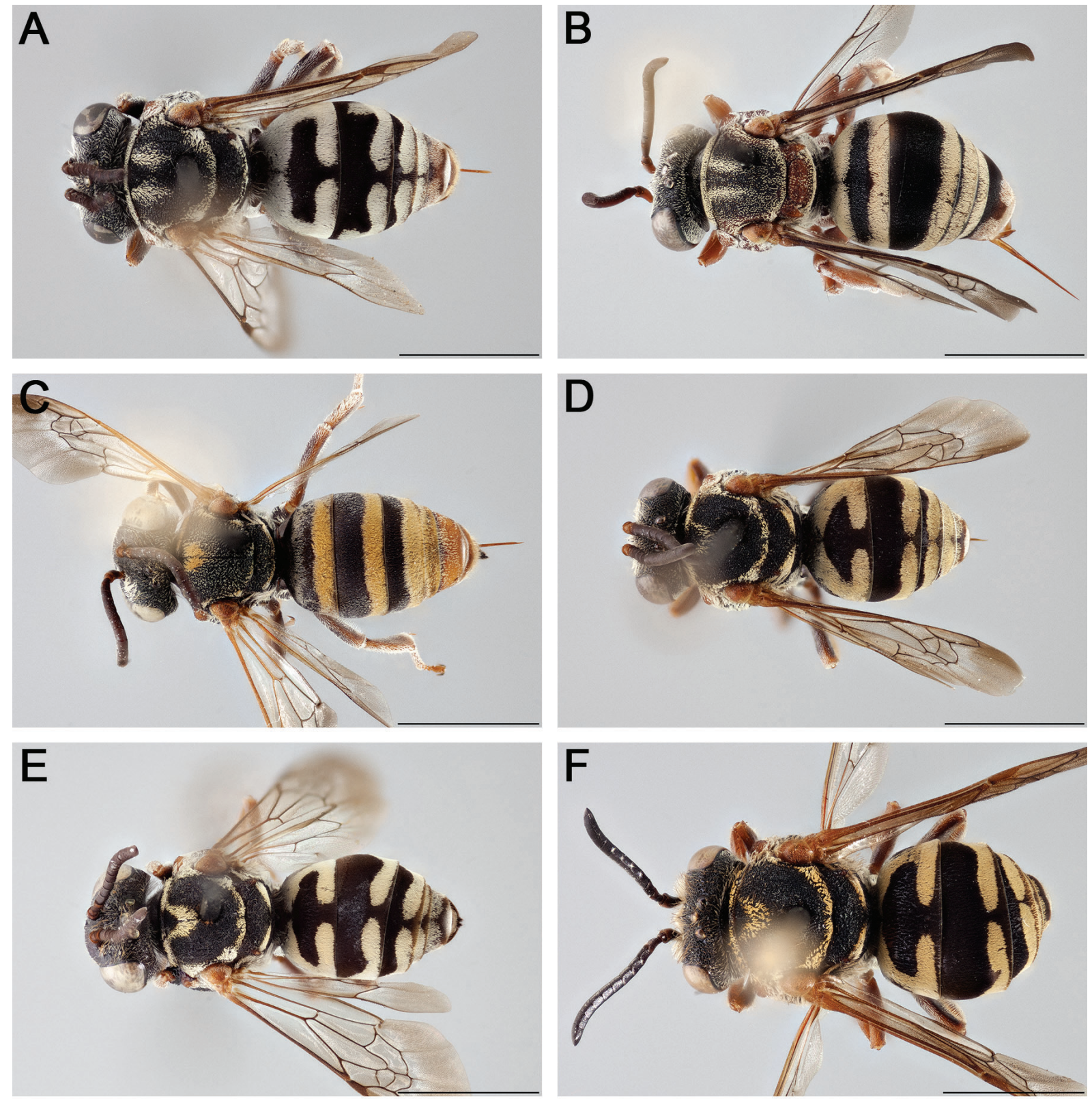

Fig. 22A-F (continued on next page). Epeolus spp. habitus of female, dorsal view. A. E. axillaris Onuferko, 2018, paratype. B. E. ainsliei Crawford, 1932. C. E. splendidus Onuferko, 2018, paratype. D. E. canadensis Mitchell, 1962. E. E. compactus Cresson, 1878. F. E. ferrarii Onuferko, 2018, paratype. Scale bars $=3 \mathrm{~mm}$. 
16. T2-T4 each with fascia on or only very slightly separated from apical margin of tergum, more or less evenly broad. T1 with longitudinal extent of discal patch variable, but commonly less than breadth of apical fascia (Fig. 25A)

E. novomexicanus Cockerell, 1912 (Onuferko 2018a: fig. 73)

- T2 and T3 (for female) or T2-T4 (for male) each with fascia clearly separated from apical margin of tergum medially, commonly narrowed or narrowly interrupted medially. T1 with longitudinal extent of discal patch no less (and usually greater) than breadth of apical fascia (Fig. 25B)

17. Flagellum with ventral surface and usually also metasomal sterna same reddish brown or reddish orange color as legs (Fig. 26A)

E. basili Onuferko, 2018 (Onuferko 2018a: fig. 24)
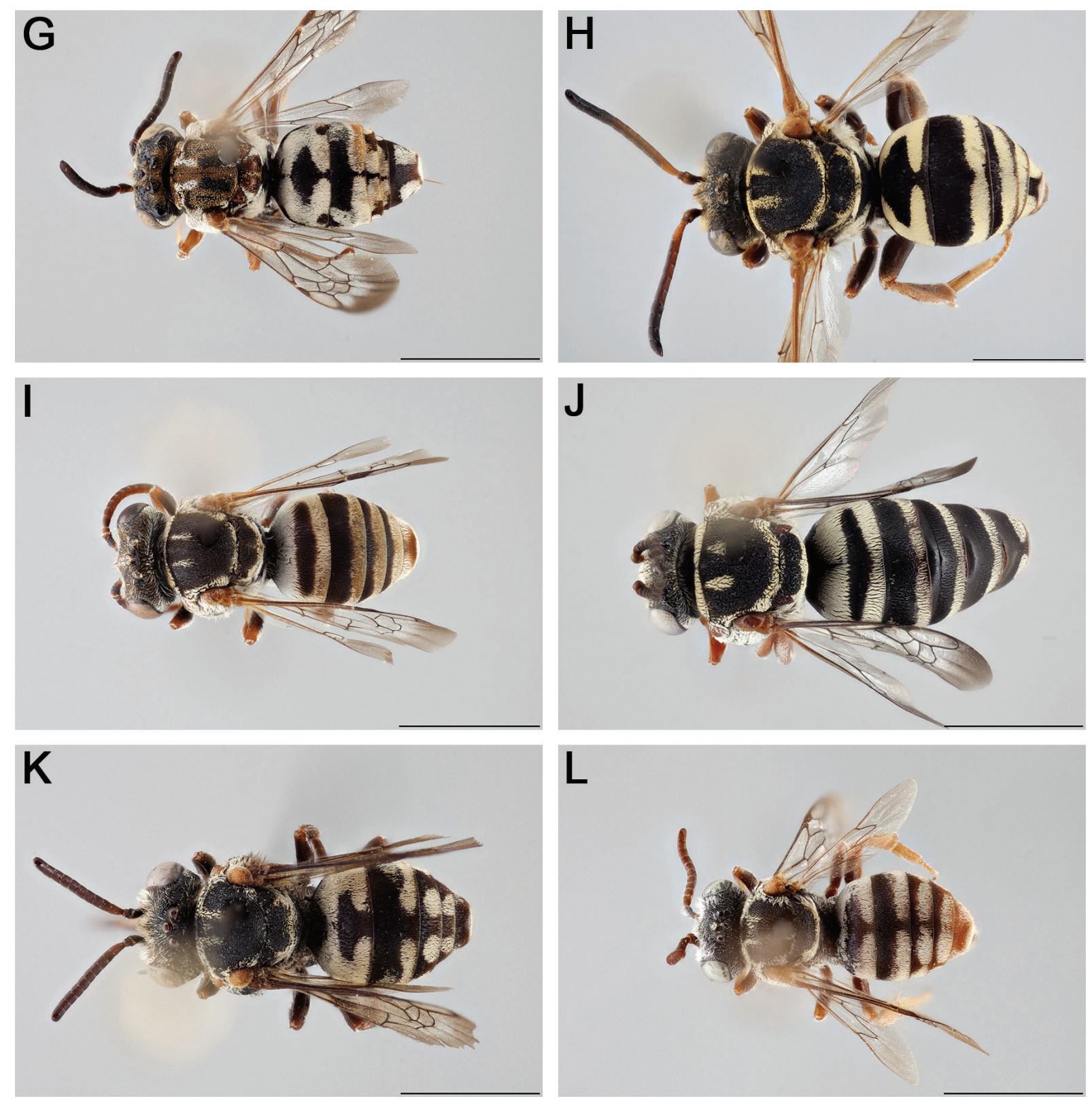

Fig. 22G-L (continued). Epeolus spp., habitus of female, dorsal view. G. E. chamaesarachae Onuferko, 2018, paratype. H. E. flavofasciatus Smith, 1879. I. E. mesillae (Cockerell, 1895). J. E. brumleyi Onuferko, 2018, paratype. K. E. asperatus Cockerell, 1910. L. E. barberiellus Cockerell, 1907. Scale bars $=3 \mathrm{~mm}$. 
- Entire flagellum, except sometimes F1, and metasomal sterna (excluding apical margins) dark brown or black, clearly not the same reddish-orange color as legs from tibiae to tarsi (Fig. 26B)

E. pusillus Cresson, 1864 (Onuferko 2018a: fig. 79)

18. T1 without apical fascia (Figs 14B, 18B)

- T1 with apical fascia (Figs 13B, 22C-L)

19. Frontal keel without tooth-like process (Fig. 27A). Mesopleuron with punctures in ventrolateral half dense (most i<1d) (Fig. 5C). T1 with complete or medially interrupted off-white to pale yellow basal fascia (Fig. 14B). Antenna, pronotal lobe and legs reddish orange in part (Fig. 14A-C)

E. luteipennis Friese, 1916 (Fig. 14)

- Frontal keel with small tooth-like process (Fig. 27B). Mesopleuron with punctures in ventrolateral half sparse (most i>1d) (Fig. 5D). T1 without fasciae (Fig. 18B). Antenna, pronotal lobe and legs entirely dark brown to black (Fig. 18A-C) E. odyneroides sp. nov. (Fig. 18)

20. Mesoscutum with anteromedial patch of bright or pale yellow tomentum (Fig. 22C-F)

- Mesoscutum with gray or bright to pale yellow paramedian band (usually parallel and not joined except sometimes posteriorly) or largely obscured by pale tomentum (Fig. 22G-L); if joined posteriorly (i.e., U- or V-shaped), then not distinctly narrowed anterolaterally

21. Dorsum of mesosoma and metasoma with bright yellow short, appressed setae. T1-T4 with apical fasciae complete. T1 with little if any space between off-white basal fascia and bright yellow apical fascia (Fig. 22C)

E. splendidus Onuferko, 2018 (Onuferko 2018a: fig. 85)

- Dorsum of mesosoma and metasoma with pale yellow short, appressed setae. At least apical fascia of T1 medially interrupted. T1 with elongate discal patch (medially as long as or longer than breadth of apical fascia) between off-white to pale yellow basal and apical fasciae (Fig. 22D-F)
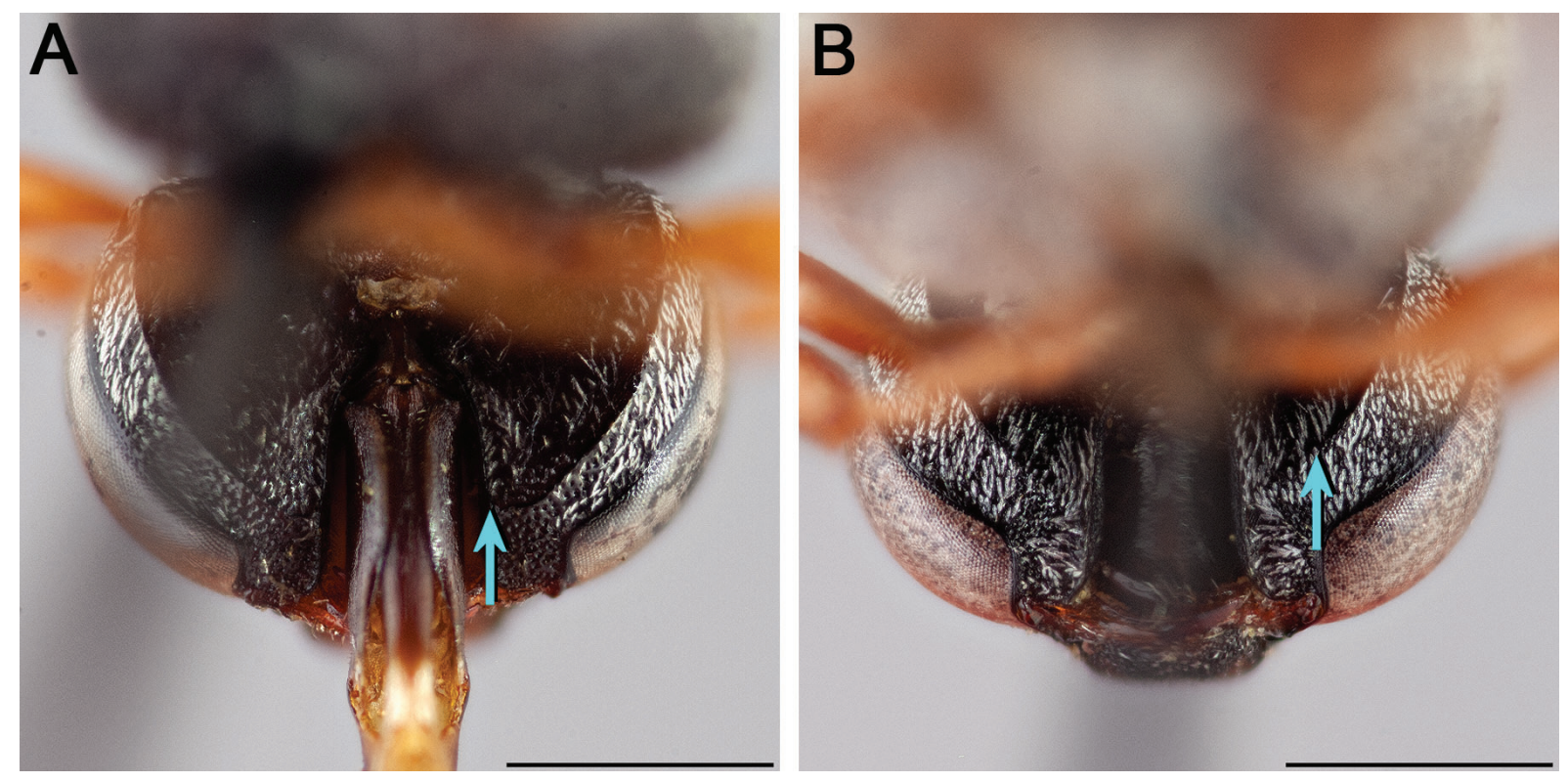

Fig. 23. Head of male, posterior view. A. E. ainsliei Crawford, 1932, in which the preoccipital ridge joins the hypostomal carina (blue arrow). B. E. rufulus Cockerell, 1941, in which the preoccipital ridge does not join the hypostomal carina (blue arrow). Scale bars $=1 \mathrm{~mm}$. 
22. T1 in dorsal view with apical fascia straight, basal fascia arched and indistinguishable from longitudinal band, such that discal patch is semicircular or triangular (Fig. 22D)

E. canadensis Mitchell, 1962 (Onuferko 2018a: fig. 30)

- T1 in dorsal view with basal and apical fasciae subparallel, at angles from longitudinal band, such that discal patch is quadrangular, trapezoidal or (if fasciae thickened laterally) diamond-shaped (Fig. 22E-F)
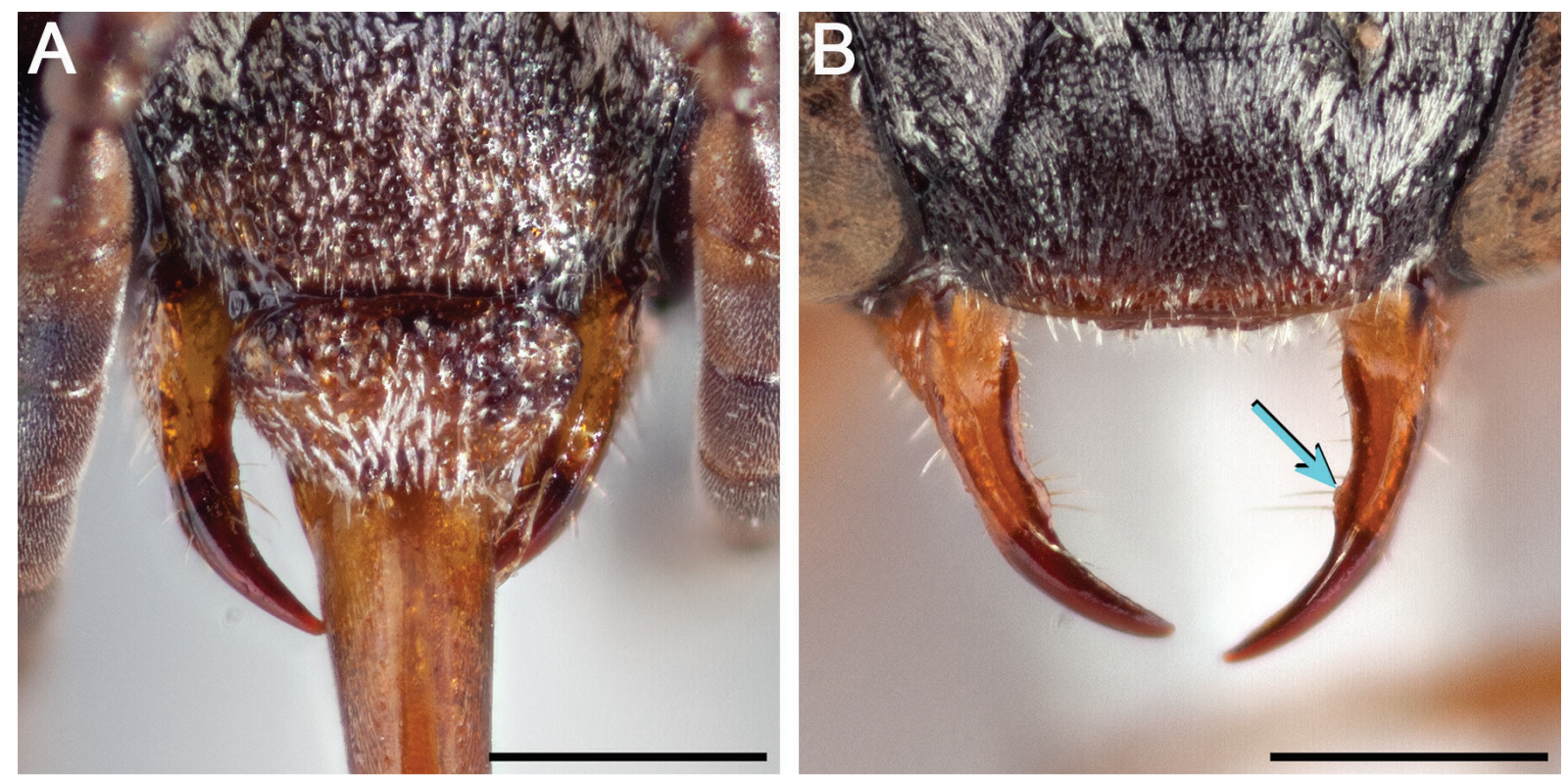

Fig. 24. Mandibles of female A. E. ainsliei Crawford, 1932, each of which lacks a preapical tooth. B. E. rufulus Cockerell, 1941, each of which has a blunt, obtuse preapical (almost submedial) tooth (blue arrow). Scale bars $=0.5 \mathrm{~mm}$.
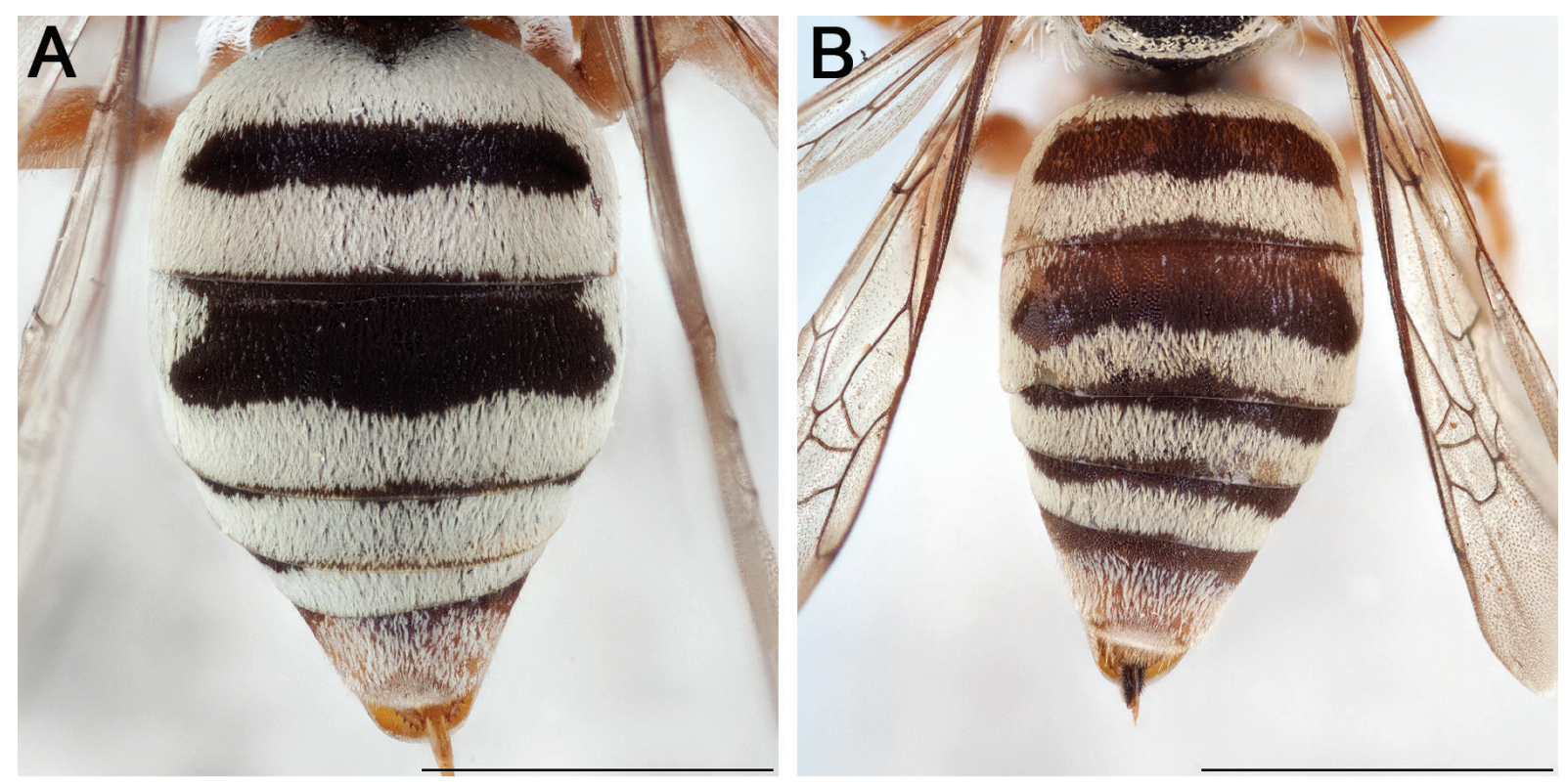

Fig. 25. Metasoma of female, dorsal view. A. E. novomexicanus Cockerell, 1912. B. E. basili Onuferko, 2018, paratype. Scale bars $=2 \mathrm{~mm}$. 
23. T1-T4 with apical fasciae broadened submedially and either narrowed or separated into rounded lobes medially (Fig. 22E)

E. compactus Cresson, 1878 (Onuferko 2018a: fig. 36)

- T1-T4 with apical fasciae not broadened submedially; fasciae more or less evenly broad and uninterrupted medially or tapering and thus narrowed or separated medially (Fig. 22F)

E. ferrarii Onuferko, 2018 (Onuferko 2018a: fig. 45)

24. Vertexal area with two pairs of shiny (usually impunctate) protrusions (Fig. 4E). T1 apical fascia with pair of small posterolateral patches of black tomentum (Fig. 22G)

- Vertexal area without two pairs of protrusions, at most with single pair of closely punctate dorsal protrusions, each located where upper genal area meets vertexal area (Fig. 4F). T1 apical fascia without pair of small posterolateral patches of black tomentum (Fig. 22H-L)

25. Mesopleuron with punctures in ventrolateral half sparse (few $i \leq 1 \mathrm{~d}$ ) (Fig. 5E)

E. chamaesarachae Onuferko, 2018 (Onuferko 2018a: fig. 34)

- Mesopleuron with punctures in ventrolateral half dense (many $\mathrm{i} \leq 1 \mathrm{~d}$ ) (Fig. 5F)

E. diadematus Onuferko, 2018 (Onuferko 2018a: fig. 41)

26. Metanotum with blunt median process (Fig. 13D). T1 in dorsal view with discal patch in shape of rounded triangle with anterolateral sides concave (Fig. 13B)

- Metanotum without process (Fig. 21D-F). T1 with discal patch variable, but if triangular in dorsal view then with anterolateral sides straight or convex (Fig. 22H)

27. Mesopleuron either with most interspaces between punctures small ( $i \leq 1 \mathrm{~d})$ throughout or rugose, with punctures ill-defined (Fig. 5G)

E. hanusiae sp. nov. (Fig. 13)

- Mesopleuron with punctures in ventrolateral half well separated ( $\mathrm{i}>1 \mathrm{~d}$ ), upper half more densely punctate than ventrolateral half (Fig. 5H)

E. interruptus Robertson, 1900 (Onuferko 2018a: fig. 61)

28. T1 in dorsal view with apical fascia straight, basal fascia arched, though in some cases widely interrupted medially, and indistinguishable from longitudinal band, such that discal patch is semicircular or triangular (Fig. 22H)

E. flavofasciatus Smith, 1879 (Onuferko 2018a: fig. 47)
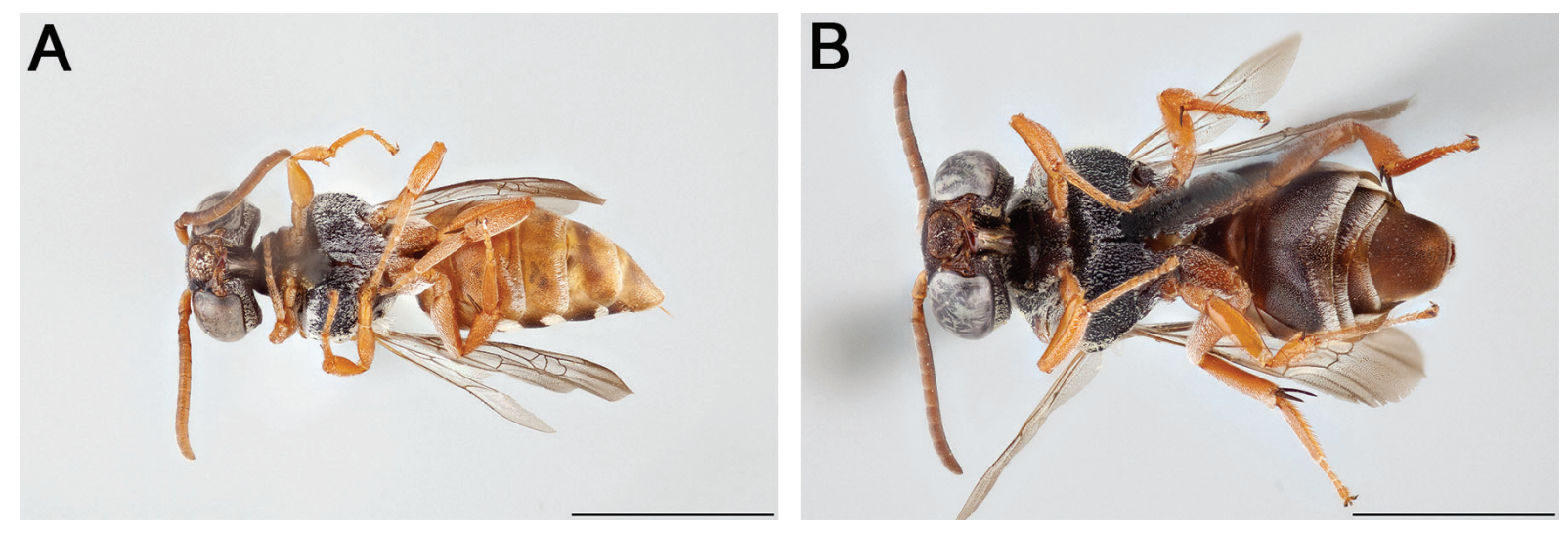

Fig. 26. Epeolus spp., habitus of female, ventral view. A. E. basili Onuferko, 2018, paratype showing antennae, legs, and metasomal sterna with similar reddish-orange coloration. B. E. pusillus Cresson, 1864 showing color contrast between reddish-orange legs and dark brown antennae and metasomal sterna. Scale bars $=3 \mathrm{~mm}$. 
- T1 in dorsal view with basal and apical fasciae subparallel, usually at angles from longitudinal band, such that discal patch is quadrangular, trapezoidal, or elliptical, but sometimes thickened laterally such that discal patch is diamond-shaped or in the shape of a pointed oval (Fig. 22I-L)

29. T2-T4 with apical fasciae complete, more or less evenly broad (Fig. 22I-J)

- T1 and T2 with apical fasciae broken or at least greatly narrowed medially, those of T3 and T4 broken or complete (Fig. 22K-L)
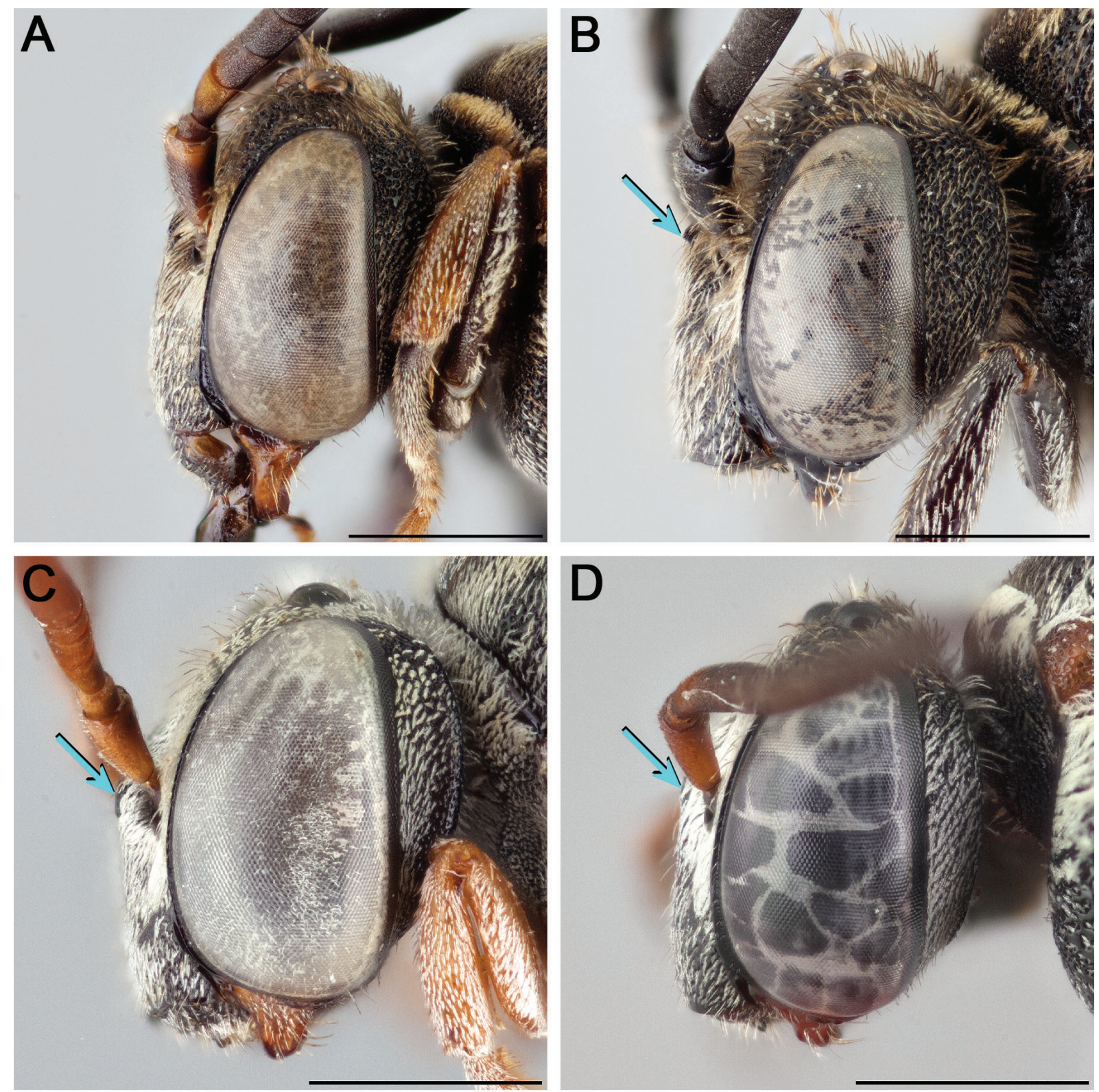

Fig. 27. Head of female, lateral view. A. E. luteipennis Friese, 1916, in which the frontal keel lacks a tooth-like process. B. E. odyneroides sp. nov., holotype (KUNHM SM0253729), in which the frontal keel has a small tooth-like process (blue arrow). C. E. australis Mitchell, 1962, in which the frontal keel (blue arrow) is strongly raised. D. E. brumleyi Onuferko, 2018, paratype, in which the frontal keel (blue arrow) is weakly protuberant by comparison. Scale bars $=1 \mathrm{~mm}$. 
30. Fore wing with two submarginal cells, apically dusky in female, hyaline throughout in male (Fig. 20D). Mesopleuron almost entirely obscured by tomentum, at least in male (Fig. 20D). Axilla and mesoscutellum black (Fig. 22I) ...........E. mesillae (Cockerell, 1895) (Onuferko 2018a: fig. 67)

- Fore wing with three submarginal cells, subhyaline, apically dusky in both sexes (Fig. 20E). Mesopleuron obscured by tomentum only in upper half, with a large, sparsely hairy circle occupying much of ventrolateral half (Fig. 20E). At least axilla ferruginous in part (Fig. 22J) 31

31. Frontal keel strongly raised (Fig. 27C). Pygidial plate of male narrow (medial length $\sim 1.5 \times$ basal width) (Fig. 28A)

E. australis Mitchell, 1962 (Onuferko 2018a: fig. 14)

- Frontal keel weakly protuberant (Fig. 27D). Pygidial plate of male broad (medial length $\approx$ basal width) (Fig. 28B) ………………………....E. brumleyi Onuferko, 2018 (Onuferko 2018a: fig. 28)

32. Axilla and mesoscutellum entirely ferruginous (Fig. 21D). Mesopleuron with punctures in ventrolateral half sparse (most i $>1$ d) (Fig. 5I)

E. tessieris Onuferko, 2018 (Onuferko 2018a: fig. 87)

- Axilla (except sometimes tip) and mesoscutellum black (Fig. 21E-F). Mesopleuron with punctures in ventrolateral half dense (most $i \leq 1 \mathrm{~d})$ (Fig. 20F)

33. F2 of female at least $1.2 \times$ as long as wide (Fig. 29A). Axilla of both sexes with free portion more than $1 / 4$ as long as its entire medial length, its tip distinctly pointed (Fig. 21E)

E. minimus (Robertson, 1902) (Onuferko 2018a: fig. 69)

- F2 of female at most $1.1 \times$ as long as wide (Fig. 29B). Axilla of both sexes with free portion at most $1 / 4$ as long as its entire medial length, its tip broadly rounded (Fig. 21F) 34

34. T3 and T4 each with pair of ovate patches of pale tomentum. Legs mostly to entirely dark brown or black (Fig. 22K)

E. asperatus Cockerell, 1910 (Onuferko 2018a: fig. 10)

- T3 and T4 each with complete or medially and/or laterally interrupted fascia. Legs mostly to entirely reddish orange (Fig. 22L)

E. barberiellus Cockerell, 1907 (Onuferko 2018a: fig. 22)
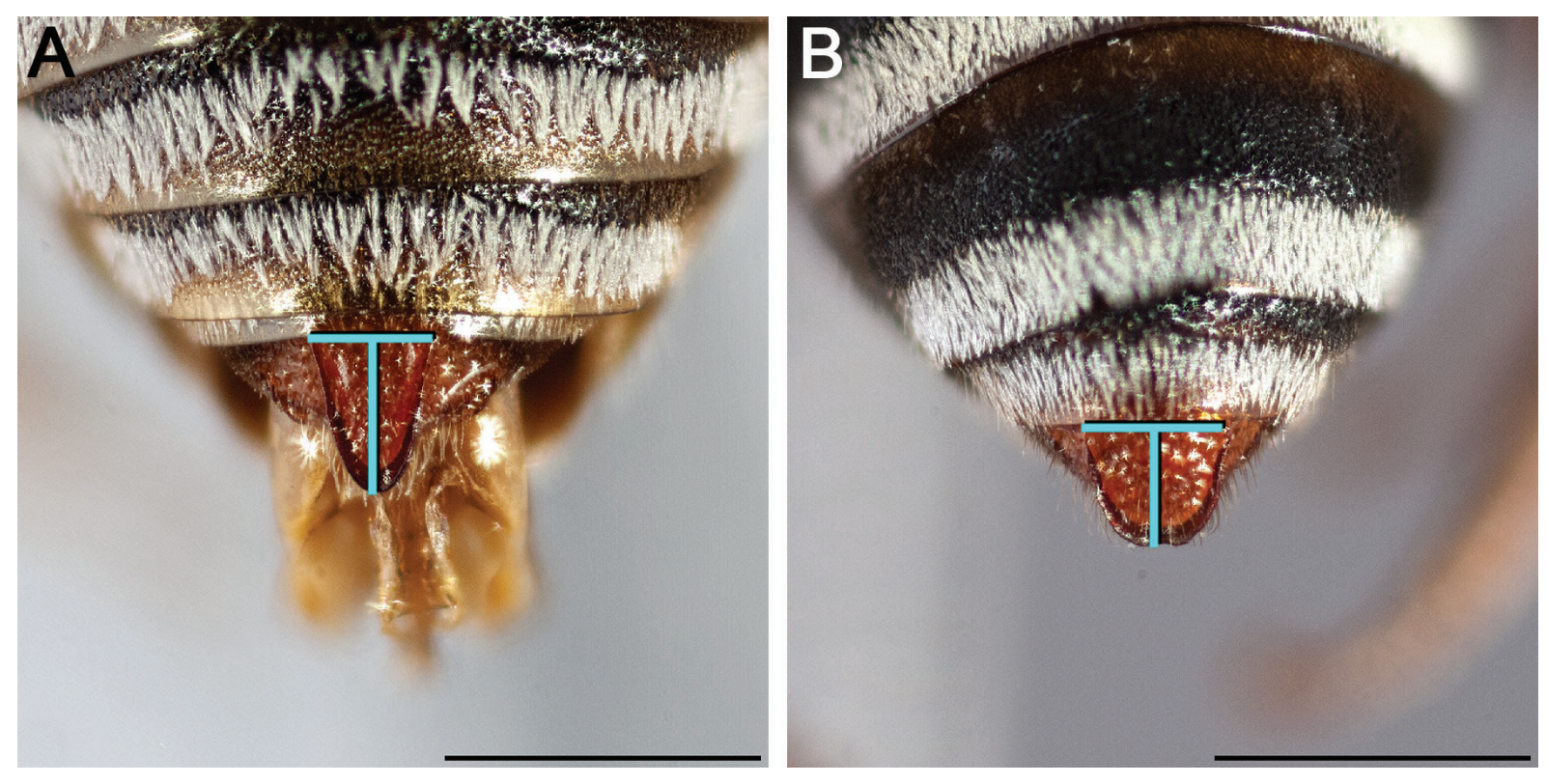

Fig. 28. Pygidial plate of male, dorsal view. A. E. australis Mitchell, 1962 (longer than wide and apically narrowed). B. E. brumleyi Onuferko, 2018, allotype (about as long as wide and broadly rounded apically). Scale bars $=1 \mathrm{~mm}$. 


\section{Discussion}

Epeolini is most diverse in terms of generic richness in the Neotropics, where all eight of its constituent genera are found. Epeolus and Triepeolus are the only genera in the tribe to exhibit their greatest species richness elsewhere (in the Nearctic region) (Rightmyer 2008; Onuferko 2018a). In Latin America, Mexico has a greater richness of Epeolus than any other country, but its species have never before been revised or reviewed. A better taxonomic understanding of this genus is warranted, especially given the potential of cleptoparasitic bees to serve as indicators of bee community health (Sheffield et al. 2013). Although less diverse in the Caribbean, Central America and South America, Epeolus is represented in each of these areas by several endemics, whose taxonomy before the present study has been poorly understood. In contrast, the other Neotropical epeoline genera have been well-studied. Roig-Alsina (1989) revised Doeringiella Holmberg, 1886 for all known species, and later (2003) Pseudepeolus Holmberg, 1886 (as a subgenus of Doeringiella). Roig-Alsina (1996) revised Rhogepeolus Moure, 1955 and provided a key to the known species. Rightmyer (2008) revised Triepeolus for all species except those in the Tri. simplex Robertson, 1903 and Tri. verbesinae (Cockerell, 1897) species groups. The species of Odyneropsis were reviewed by Moure (1955), and Rightmyer (2004) listed those likely to be included in the subgenus Parammobates Friese, 1906. The remaining genera, Rhinepeolus Moure, 1955 and Thalestria, are monotypic.

Herein, the presumably monophyletic 'Trophocleptria group' is considered to include 12 species (those marked by an asterisk are endemic to South America and not treated herein): ${ }^{*} E$. asperrimus, E. bifasciatus, E. boliviensis, *E. carioca, E. claripennis, E. fulvopilosus, E. fumipennis, E. niger, E. nomadiformis sp. nov., E. obscuripes, E. pulchellus and *E. variolosus. Epeolus luteipennis is the only species outside of the 'Trophocleptria group' recorded from South America (Ecuador by Cockerell 1917 (as E. xanthurus) and herein newly reported from Venezuela). Given the comparatively low diversity of Epeolus in South America (even within the 'Trophocleptria group' Central America exhibits a greater diversity of forms) and the fact that in South America more species of Colletes have been associated with isepeoline (Hymenoptera: Apidae: Nomadinae) cleptoparasites (Isepeolus Cockerell, 1907 and Melectoides Taschenberg, 1883) than Epeolus (Roig-Alsina 1991; Ferrari 2017), it seems likely that Epeolus dispersed to South America from the North American continent. In the Caribbean, Epeolus is represented by a single and very distinctive species in Cuba, E. pulchellus, which was not previously recognized as belonging to the 'Trophocleptria group', another species, E. danieli, in Hispaniola, where Epeolus was not previously known to occur, and a more widely distributed species, E. boliviensis, which is newly reported from Trinidad.
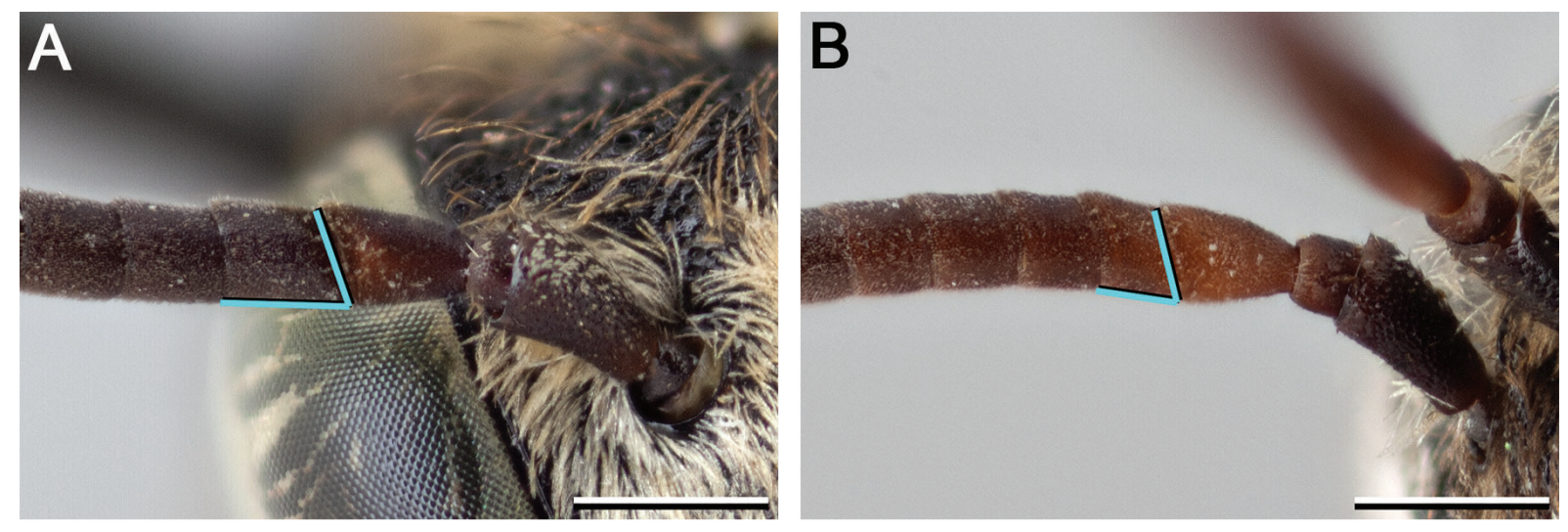

Fig. 29. Antenna (basal portion) of female. A. E. minimus (Robertson, 1902), in which F2 is noticeably longer than wide. B. E. asperatus Cockerell, 1910, in which F2 is not noticeably longer than wide. Scale bars $=0.5 \mathrm{~mm}$. 
With regard to DNA barcoding, all samples assigned a separate BIN were treated as heterospecific because there was also morphological evidence that suggests separate species status. Therefore, the typological species concept was used consistently to delineate species in the present study. Although the taxonomy of the genus is now much better understood than it was before, attempts should be made to obtain additional barcode sequence data to see if the diagnostic features for the different species correspond to distinct genetic clusters. BIN-compliant sequences are presently only available for four of the 12 treated species, although partial sequences are available for another three. Two species newly described herein were solely identified as such on the basis of consistent but marginally distinct morphological features that separate them from their most similar congeners. Although the use of DNA barcodes alone may prove useful in delineating similar species within complexes of closely related species, in cases where barcodes fail, further tests of species identity should be carried out using additional loci (Gibbs 2017).

Despite the improved taxonomic understanding of this group, very little is known about the ecology of Neotropical species of Epeolus. Future research should aim to uncover the habitat preferences, phenology, and bee and floral host associations of the species present in the region.

\section{Acknowledgements}

Most of this study was carried out while I was a PhD candidate at York University (Toronto, Canada) working under the supervision of Professor Laurence Packer, whom I thank for making available to me specimens for study and materials needed to carry out this project. The key was tested by Rafael Ferrari, Spencer Monckton and Laurence Packer, all of whom provided me with constructive feedback, which I very much appreciate. I am especially grateful to Dr. Julio A. Genaro and Daniela Hernández Cuadra for helping me translate the Abstract and key into Spanish. I am also extremely thankful to Julio for sharing information about the Caribbean species with me. I appreciate Dr. John Ascher's input on the proposed common names. I am grateful to aculeate wasp expert Dr. Matthias Buck (RAM) for bringing to my attention the striking similarity of some of the species of Epeolus treated herein to certain kinds of Neotropical wasps. I thank the institutions and associated contacts listed in the Material and methods for providing me with material for research. Most specimens were imaged at the PCYU using a camera system purchased under the auspices of Canadensys with funds from the Canadian Foundation for Innovation and Ontario Research Fund. Images of the holotype of Tri. danieli, some of which are published herein, were kindly provided for study by the curatorial staff at the MNHNSD. I thank Gustavo Blanco (IESH) for taking and sharing detailed photos of the holotype of E. pulchellus, to which I referred in redescribing that species. While working on this project during my $\mathrm{PhD}$, I was supported financially by the Susan Mann Dissertation Scholarship (issued to me by the Faculty of Graduate Studies at York University), which I am very grateful to have received. I have since been in receipt of the Beaty Postdoctoral Fellowship for Species Discovery and sincerely thank the Ross Beaty Family and the Canadian Museum of Nature for the financial and logistical support I received while carrying this project to completion. Robert and Cecily Bradshaw generously provided the PCYU with funds for DNA barcoding, which was carried out at the Biodiversity Institute of Ontario, University of Guelph by a dedicated team that processed the submitted tissue samples. This study was made possible with funds from Laurence Packer's discovery grant awarded by the Natural Sciences and Engineering Research Council of Canada. I greatly appreciate the time and consideration given to the submitted paper by an anonymous reviewer, who gave excellent feedback, and European Journal of Taxonomy topical editor Dr. Gavin Broad. Lastly, I thank the many collectors (past and present) whose vouchers and associated data were used in the present study; they have made an invaluable contribution to furthering the knowledge of Neotropical Epeolus. 


\section{References}

Ascher J.S. \& Pickering J. 2019. Discover Life bee species guide and world checklist (Hymenoptera: Apoidea: Anthophila).

Available from http://www.discoverlife.org/mp/20q?guide=Apoidea_species [accessed 4 Mar. 2019].

Becker R.A. \& Wilks A.R. 2018. R version by Brownrigg R., enhancements by Minka T.P. \& Deckmyn A. 2018. maps: Draw Geographical Maps. R package version 3.3.0.

https://CRAN.R-project.org/package=maps

Bivand R. \& Lewin-Koh N. 2018. maptools: Tools for Handling Spatial Objects. R package version 0.94. https://CRAN.R-project.org/package=maptools

Brumley R.L. 1965. A Revision of the Bee Genus Epeolus Latreille of Western America North of Mexico. M.Sc. thesis, Utah State University, Logan.

Cameron P. 1902. Descriptions of new genera and species of American Hymenoptera. Transactions of the American Entomological Society 28: 369-377.

Cockerell T.D.A. 1917. XXXIII.-Descriptions and records of bees.-LXXVII. Annals and Magazine of Natural History 20: 298-304. https://doi.org/10.1080/00222931709487008

Cockerell T.D.A. 1932. Bees (Hymenoptera, Apoidea) collected at Chichen Itzá, Yucatan, by the Harvard expeditions of 1929-1930. Bulletin of the Brooklyn Entomological Society 27 (1): 9-17.

Cockerell T.D.A. 1933. Some wasp-like bees from Guatemala. Psyche 40 (2): 60-61.

https://doi.org/10.1155/1933/43643

Cockerell T.D.A. 1949. Bees from Central America, principally Honduras. Proceedings of the United States National Museum 98: 429-490.

Cresson E.T. 1865. On the Hymenoptera of Cuba. Proceedings of the Entomological Society of Philadelphia 4: 1-200.

Ferrari R.R. 2017. Taxonomic revision of the species of Colletes Latreille, 1802 (Hymenoptera: Colletidae: Colletinae) found in Chile. Zootaxa 4364 (1): 1-137.

https://doi.org/10.11646/zootaxa.4364.1.1

Friese H. 1908. Die Apidae (Blumenwespen) von Argentina nach den Reisenergebnissen der Herren A.C. Jensen-Haarup und P. Jörgensen in den Jahren 1904-1907. Flora og Fauna 10: 1-94. https://doi.org/10.5962/bhl.title.14257

Friese H. 1916. Zur Bienenfauna von Costa Rica (Hym.). Stettiner Entomologische Zeitung 77: 287-348.

Friese H. 1925. Neue neotropische Bienenarten, zugleich II. Nachtrag zur Bienenfauna von Costa Rica (Hym). Stettiner Entomologische Zeitung 86: 1-41.

Genaro J.A. 2003. El género Colletes en Cuba (Hymenoptera: Apiformes: Colletidae). Solenodon 3: 53-56.

Genaro J.A. 2014. El género Triepeolus Robertson, 1901 en la Hispaniola, con la descripción de una especie nueva (Hymenoptera: Anthophila: Apidae). Novitates Caribaea 7: 22-27.

https://doi.org/10.33800/nc.v0i7.55

Gibbs J. 2009. New species in the Lasioglossum petrellum species group identified through an integrative taxonomic approach. The Canadian Entomologist 141 (4): 371-396.

https://doi.org/10.4039/n09-020

Gibbs J. 2010. Revision of the metallic species of Lasioglossum (Dialictus) in Canada (Hymenoptera, Halictidae, Halictini). Zootaxa 2591: 1-382. https://doi.org/10.11646/zootaxa.2591.1.1 
Gibbs J. 2011. Revision of the metallic Lasioglossum (Dialictus) of eastern North America (Hymenoptera: Halictidae: Halictini). Zootaxa 3073: 1-216. https://doi.org/10.11646/zootaxa.3073.1.1

Gibbs J. 2017. DNA barcoding a nightmare taxon: assessing barcode index numbers and barcode gaps for sweat bees. Genome 61 (1): 21-31. https://doi.org/10.1139/gen-2017-0096

Hebert P.D.N., Cywinska A., Ball S.L. \& deWaard J.R. 2003a. Biological identifications through DNA barcodes. Proceedings of the Royal Society of London Series B, Biological Sciences 270: 313-321. https://doi.org/10.1098/rspb.2002.2218

Hebert P.D.N., Ratnasingham S. \& deWaard J.R. 2003b. Barcoding animal life: cytochrome c oxidase subunit 1 divergences among closely related species. Proceedings of the Royal Society of London Series B, Biological Sciences 270: S96-S99. https://doi.org/10.1098/rsb1.2003.0025

Kimura M. 1980. A simple method for estimating evolutionary rates of base substitutions through comparative studies of nucleotide sequences. Journal of Molecular Evolution 16 (2): 111-120. https://doi.org/10.1007/BF01731581

LeConte J.L. (ed.) 1859. The complete writings of Thomas Say on the entomology of North America. Vol. I. Baillière Brothers, New York. https://doi.org/10.5962/bhl.title.13257

Mawdsley J.R. 1993. The entomological collection of Thomas Say. Psyche 100: 163-171.

https://doi.org/10.1155/1993/59616

Michener C.D. 1954. Bees of Panamá. Bulletin of the American Museum of Natural History 104: 1-175.

Michener C.D. 1974. Further notes on nests of Ancyloscelis (Hymenoptera: Anthophoridae). Journal of the Kansas Entomological Society 47: 19-22.

Michener C.D. 2000. The Bees of the World. The Johns Hopkins University Press, Baltimore.

Michener C.D. 2007. The Bees of the World, Second ed. The Johns Hopkins University Press, Baltimore.

Mitchell T.B. 1962. Bees of the eastern United States. Volume II. North Carolina Agricultural Experiment Station Technical Bulletin 152: 1-557.

Moure J.S. 1955. Notas sôbre Epeolini sulamericanos (Hymenopt.-Apoidea). Dusenia 6: 115-138.

Moure J.S., Urban D. \& Melo G.A.R. 2007. Catalogue of Bees (Hymenoptera, Apoidea) in the Neotropical Region. Sociedade Brasileira de Entomologia, Curitiba.

Onuferko T.M. 2017. Cleptoparasitic bees of the genus Epeolus Latreille (Hymenoptera: Apidae) in Canada. Canadian Journal of Arthropod Identification 30: 1-62. https://doi.org/10.3752/cjai.2017.30

Onuferko T.M. 2018a. A revision of the cleptoparasitic bee genus Epeolus Latreille for Nearctic species, north of Mexico (Hymenoptera, Apidae). ZooKeys 755: 1-185.

https://doi.org/10.3897/zookeys.755.23939

Onuferko T.M. 2018b. A record of bilateral gynandromorphism in Epeolus (Hymenoptera: Apidae: Nomadinae). Journal of Melittology 76: 1-6. https://doi.org/10.17161/jom.v0i76.7056

Packer L. \& Ruz L. 2017. DNA barcoding the bees (Hymenoptera: Apoidea) of Chile: species discovery in a reasonably well known bee fauna with the description of a new species of Lonchopria (Colletidae). Genome 60 (5): 414-430. https://doi.org/doi:10.1139/gen-2016-0071

Packer L., Ali E., Dumesh S. \& Walker K. 2016. The identification of pollinators: where are we and where should we go? In: Gemmill-Herren B. (ed.) Pollination Services to Agriculture: Sustaining and Enhancing a Key Ecosystem Service: 57-73. Routledge Taylor \& Francis Group, London. 
Pauly A., Devalez J., Sonet G., Nagy Z.T. \& Boevé J.L. 2014. DNA barcoding and male genital morphology reveal five new cryptic species in the West Palearctic bee Seladonia smaragdula (Vachal, 1895) (Hymenoptera: Apoidea: Halictidae). Zootaxa 403: 257-290. https://doi.org/10.11646/zootaxa.4034.2.2

R Core Team 2018. R: A language and environment for statistical computing. R Foundation for Statistical Computing, Vienna, Austria. https://www.R-project.org/

Ratnasingham S. \& Hebert P.D.N. 2007. BOLD: The Barcode of Life Data System (www.barcodinglife. org). Molecular Ecology Notes 7 (3): 355-364. https://doi.org/10.1111/j.1471-8286.2007.01678.x

Ratnasingham S. \& Hebert P.D.N. 2013. A DNA-based registry for all animal species: the Barcode Index Number (BIN) system. PloS ONE 8 (8): e66213. https://doi.org/10.1371/journal.pone.0066213

Reemer M. 2013. Taxonomic exploration of Neotropical Microdontinae (Diptera: Syrphidae) mimicking stingless bees. Zootaxa 3697: 1-88. http://dx.doi.org/10.11646/zootaxa.3697.1.1

Rightmyer M.G. 2004. Phylogeny and classification of the parasitic bee tribe Epeolini (Hymenoptera: Apidae, Nomadinae). Scientific Papers, Natural History Museum, University of Kansas 33: 1-51. https://doi.org/10.5962/bhl.title.8479

Rightmyer M.G. 2008. A review of the cleptoparasitic bee genus Triepeolus (Hymenoptera: Apidae). Part I. Zootaxa 1710: 1-170. https://doi.org/10.11646/zootaxa.1710.1.1

Rocha-Filho L.C. \& Packer L. 2015. Revision of the Neotropical subgenera Coelioxys (Platycoelioxys) Mitchell and C. (Rhinocoelioxys) Mitchell (Hymenoptera; Megachilidae) with the description of one new species. Zootaxa 3941: 151-203. https://doi.org/10.11646/zootaxa.3941.2.1

Roig-Alsina A. 1989. A revision of the bee genus Doeringiella (Hymenoptera, Anthophoridae, Nomadinae). The University of Kansas Science Bulletin 53: 576-621.

Roig-Alsina A. 1991. Revision of the cleptoparasitic bee tribe Isepeolini (Hymenoptera: Anthophoridae). The University of Kansas Science Bulletin 54: 257-288.

Roig-Alsina A. 1996. Las especies del género Rhogepeolus Moure (Hymenoptera: Apidae: Epeolini). Neotrópica 42: 55-59.

Roig-Alsina A. 2003. The bee genus Doeringiella Holmberg (Hymenoptera: Apidae): a revision of the subgenus Pseudepeolus Holmberg. Journal of Hymenoptera Research 12 (1): 136-147.

Say T. 1837. Descriptions of new species of North American Hymenoptera, and observations on some already described. Boston Journal of Natural History 1: 361-416.

Schrottky C. 1910. Two New Nomadidae (Hymenoptera) from South America. Journal of the New York Entomological Society 18: 208-210.

Sheffield C.S., Pindar A., Packer L. \& Kevan P.G. 2013. The potential of cleptoparasitic bees as indicator taxa for assessing bee communities. Apidologie 44 (5): 501-510.

https://doi.org/10.1007/s13592-013-0200-2

Simpson G.G. 1951. The species concept. Evolution 5 (4): 285-298. https://doi.org/10.1111/j.1558-5646.1951.tb02788.x

Smith-Pardo A.H. 2005. Systematics and mimicry of the genus Neocorynura: an example of two species from Central America (Hymenoptera: Halictidae). Acta Zoologica Cracoviensia 48B (1-2): 11-21. https://doi.org/10.3409/173491505783995572

US Census Bureau. 2018. States, 2014 (cartographic boundary file, cb_2014_us_state_500k). https://www.census.gov/geo/maps-data/data/cbf/cbf_state.html 
Walter D.E. \& Winterton S. 2007. Keys and the crisis in taxonomy: extinction or reinvention? Annual Reviews of Entomology 52: 193-208. https://doi.org/10.1146/annurev.ento.51.110104.151054

Willis E. \& Packer L. 2007. Revision and phylogenetic analysis of Chilioediscelis (Hymenoptera: Colletidae) with descriptions of three new species. Zootaxa 1762: 29-52.

https://doi.org/10.11646/zootaxa.1762.1.2

Manuscript received: 12 April 2019

Manuscript accepted: 15 July 2018

Published on: 7 October 2019

Topic editor: Gavin Broad

Desk editor: Radka Rosenbaumová

Printed versions of all papers are also deposited in the libraries of the institutes that are members of the EJT consortium: Muséum national d'Histoire naturelle, Paris, France; Meise Botanic Garden, Belgium; Royal Museum for Central Africa, Tervuren, Belgium; Royal Belgian Institute of Natural Sciences, Brussels, Belgium; Natural History Museum of Denmark, Copenhagen, Denmark; Naturalis Biodiversity Center, Leiden, the Netherlands; Museo Nacional de Ciencias Naturales-CSIC, Madrid, Spain; Real Jardín Botánico de Madrid CSIC, Spain; Zoological Research Museum Alexander Koenig, Bonn, Germany; National Museum, Prague, Czech Republic. 


\section{Electronic supplementary material}

Supplementary File 1

A database of Epeolus records in the Americas south of the United States, including those of the exclusively South American species E. variolosus (Holmberg, 1886) (not treated herein) and species revised in Onuferko (2018a). Included are all GPS coordinates used in the construction of species distribution maps.

Supplementary File 2

Abstract, definition of acronyms, proposed common names for the treated species, and key (in Spanish). Resumen, definición de acrónimos, nombres comunes propuestos para las especies tratadas y clave (en español).

Supplementary File 3

A neighbor-joining tree of COI sequences $>200$ bp in length of Epeolus spp. known or presumed to occur in the Americas south of the United States, generated in BOLDSYSTEMS (http://www.boldsystems.org/) and based on Kimura's two parameter distance model. For species also occurring in Canada and the United States, sequences were published separately in the 'Epeolus of North America' project and deposited in GenBank (https://www.ncbi.nlm.nih.gov/genbank/) as part of the study by Onuferko (2018a). 